\title{
BIOGEOGRAFIA E BIONOMIA DOS CRUSTÁCEOS DO LITORAL EQUATORIAL BRASILEIRO *
}

\author{
PETROONIO ALVES COELHO ** \\ MARILENA RAMOS PORTO *** \\ MARIA LUISE KOENING ***
}

\section{SINOPSE}

O presente trabalho expõe a distribuicăo de um grupo de seres bênticos, os crustáceios decápodos, isópodos e estomatópodos encontrados em um setor do litoral brasileiro escolhido de tal forma que permitisse estabelecer com pecisão os limites entre as Províncias Brasileira e Guianense. As conclusões que se extraem do presente estudo estão ligadas, de um lado, à composiçāo faunística do grupo em foco, e de outro lado, às combinacóes das espécies em unidades de povoamento, em função da natureza do substrato e de outros fatores. Antes de inventariar os rsultados obtidos no domínio da biogeografia e da bionomia bênticas será apresentado um resumo dos caracteres abióticos gerais da área estudada.

O litoral equatorial brasileiro possui condiçōes hidrológicas peculiares, resultantes do jego de vários fatores. Entre eles, torna-se necessário salientar o papel das correntes oceânicas de superficie, que contribuem com água de salinidade elevada, ao lado da influência dos grandes rios que diluem, até uma determinada distância, a água trazida pelas correntes. Ao lado disto, existe uma diminuicão da temperatura da água junto ao fundo nas proximidades do bordo externo da plataforma continental. Este conflito de influências, oceânica de um lado, fluvial-terrígena de outro, está refletido na distribuição dos diversos tipos de fundo encontrados na plataforma continental. Torna-se possivel delimitar duas regiōes naturais, uma com fundos arenosos e organogênicos banhados por água de temperatura e salidade elevadas e mais ou menos estáveis, e outra em que os fundos organogênicos estão mal representados, enquanto a temperatura e a salinidade são variáveis.

\footnotetext{
** Professor Adjunto da Universidade Federal de Pernambuco

*** Pesquisador Assistente do Conselho Nacional de Pesquisas e Auxiliar de Ensino Superior da Universidade Federal Rural de Pernambuco

* Trabalho Realizado no LACIMAR
} 
A distribuicăo destes crustáceos, que reflete este jogo de fatores abióticos, foi considerada dos pontos de vista biogeográfico e ecológico.

A análise da distribuicão das espécies, àgrupadas em conjuntos faunísticos, de acordo com as semelhancas encontradas em suas áreas de ocorrência, permitiu delimitar, com margem de erro de 60 a 120 milhas, os territórios das províncias blogeográficas que entram em contacto: guianense e brasileira. Mais ainda, as duas províncias correspondem com notável aproximação às duas regiões naturais encontradas na área estudada. Esta constatacăo conduz à seguinte definição de provincla blogeográfica: elas são zonas onde as condições hidrográficas e sedimentológicas são uniformes ou variam entre niveis críticos, marcando seus limites.

Se a biogeografia reflete as condicōes ecológicas reinantes, procurou-se verificar se o inverso era igualmente verdadeiro. Foram delimitadas cinco unidades principais de povoamento, cada qual compreendendo, geralmente, 2 fácies distintas: uma comparacão entre os mapas das distribuicóes geográfica e ecológica mostra série de coincidências, os limites entre as unidades ecológicas e biogeográficas tendo muito em comum. Deve-se lembrar, no entanto, que a comunidade encontrada nos fundos organogênicos $\theta$ arenosos profundos é comum às duas províncias.

Com relação aos tipos de distribuicão estudados, convém recordar aqui que o dado considerado mais importante foi a presenca da espécie ou do grupo, os dados hidrológlcos e sedimentológicos sendo usados então como explicacaão das distribulgöes encontradas.

\section{INTRODUÇÃO}

O litoral equatorial brasileiro, situado entre o estuário do Rio Oiapoque e o delta do Rio Parnaíba, constitui uma área peculiar caracterizada por elementos oceanográficos, climáticos e morfológicos particulares, o que tem sido reconhecido por vários autores, como SILVEIRA (1964) e MABESOONE \& COUTINHO (1972). O presente trabalho, uma contribuição para o maior conhecimento biológico desta área, estuda a distribuicão dos crustáceos recolhidos na plataforma continental ou em água costeiras durante as expedições realizadas pelo N. Oc. "Almirante Saldanha" entre 1967 e 1971, e é uma continuacão e aprofundamento de trabalhos anteriores (COELHO, 1971a, 1971b; COELHO \& RAMOS, 1973a; COELHO \& KOENING, 1973). Nele, o dado de maior importância é a área geográfica ocupada por cada espécie; informações sobre temperatura, salinidade, correntes, profundidades e tipos de fundo são exploradas numa tentativa de explicar as distribuicões 
encontradas. O estabelecimento preciso dos limites entre as unidades biogeográficas e uma compreensão mais efetiva das barreiras existentes atualmente são as conclusões a ser obtidas desta pesquisa. Estes objetivos, segundo HEDGPETH (1957), não podem ser atingidos apenas pela análise estatística dos dados sobre ocorrência das espécies, não obstante VALENTINE (1966), p. ex., ter realizado uma tentativa bem sucedida neste sentido.

Um dos primeiros autores que, estudando a biogeografia marinha do Brasil, reconheceram no litoral equatorial a existência de duas unidades biogeográficas, foi certamente LABOREL (1967). Ele colocava o limite entre as regiões guianense e brasileira nas proximidades de São Luis. Um aspecto importante do seu trabalho é a constatação da simetria existente nas costas do Atlântico Tropical Ocidental em relação à região guianense (obs.: caso particular de uma simetria mais geral existente nos biótopos bênticos do mundo inteiro; cf. HEDGPETH, 1957; BEKLENISHEV \& Col., 1972). Ao norte e ao sul, com efeito, Laborel colocou inicialmente duas regiões tropicais de fauna mais rica e depois duas regiōes de empobrecimento contendo espécies análogas ou idênticas, que ele considerava possivel que no futuro fossem encontradas em profundidade, na parte externa das regiões tropicais; a ascensão destas espécies à pequena profundidade, nos limites de sua distribuição, seria uma consequência do esfriamento das águas. As pesquisas posteriores realizadas com vários grupos de animais têm aprofundado as conclusões de LABOREL. Assim, com referência aos decápodos reptantes, COELHO (1971 a, b) reconheceu uma vasta área de transição entre as duas unidades biogeográficas, compreendendo o setor entre Salinópolis e Tutóia ou o Piauí. Posteriormente COELHO \& RAMOS (1973a) afirmaram que a linha de divisão entre as duas províncias corresponde ao limite da área de influência dos grandes rios equatoriais, também caracterizada pelo predomínio dos fundos de lama e areia. KEMPF (1970) também procurou estabelecer quais fatores possuem influência nesta delimitacão.

Em consequência do que foi dito acima, o presente trabalho fica naturalmente dividido em três partes de extensão desigual. Inicialmente, é apresentado um resumo dos conhecimentos existentes sobre a biogeografia do Atlântico Sul Ocidental, desde 
os primórdios desta Ciência até os resultados mais recentes. A seguir, os fatores abióticos considerados mais importantes para a distribuição dos seres bênticos, especialmente dos crustáceos, são objeto de análise sumária, procurando delimitar áreas naturais, em que as condições ecológicas sejam semelhantes. Finalmente a fauna é descrita e sua distribuicão analizada verificando sempre se há coincidências entre as distribuiçōes das espécies e dos fatores abióticos.

\section{HISTORIA DA BIOGEOGRAFIA DO ATLÂNTICO SUL OCIDENTAL}

A biogeografia marinha nasceu, como ciência autônoma, nos meados do século passado. Este ramo da biologia, devotado ao estudo da distribuicāo dos seres marinhos, apresenta dois aspectos particulares. Por um lado, há o estudo da distribuição das espécies, agrupadas segundo sua classificacão zoológica ou botânica, e de outro o estudo da distribuição das unidades ecológicas (comunidades ou biocenoses). Um dos pioneiros nestes estudos, DANA, propôs em 1853 uma divisão biogeográfica dos mares do mundo, baseada na distribuição dos crustáceos. Ele dividiu os mares em "reinos", estes em "sub-reinos", cada um compreendendo várias "províncias", que são as unidades de menor ordem. O litoral atlântico das Américas constituiria a "Seção Oriental» do "Reino Ocidental» e estaria subdividido em três subreinos: tórrido, temperado norte e temperado sul. Pondo à parte o sub-reino temperado norte, localizado inteiramente no Atlântico Norte, os dois outros sub-reinos abrangeriam a América do Sul em seu litoral atlântico. As três províncias: da Flórida, Caraíba e Brasileira, formariam o sub-reino tórrido. Por sua vez, o sub-reino temperado sul, incluiria quatro províncias: Paulista, Uruguaia, Platense e Norte-Patagônica. A Província da Flórida se estenderia desde o sul da Flórida até a latitude de $27^{\circ} 30^{\prime} \mathrm{N}$. A Província Caraíba incluiria as Antilhas e o lucatã e se estenderia para o sul até algum ponto no litoral da Bahia. Mais ao sul, a Província Brasileira compreenderia o litoral desde a Bahia até um pouco ao sul do Rio de Janeiro, quando comecaria a Província Paulista. As demais províncias do Atlântico Sul (Uruguaia, Platense e Norte-Patagônica) se achariam ao sul do litoral 
brasileiro, embora a Província Uruguaia incluísse uma parte do litoral do Rio Grande do Sul.

Sisternas menos complicados foram apresentados por outros autores. Assim, COOKE (1895), para os moluscos, indicava as seguintes sub-regiōes na América do Sul: Magalhânica (desde o

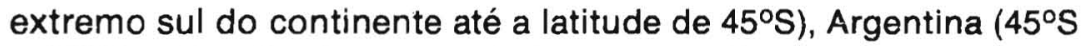
- 28 ${ }^{\circ}$ ) e Caraíba (ao norte da latitude $28^{\circ} \mathrm{S}$ ). Mais ou menos na mesma época, outros autores, como HENDERSON (1888) preferiam esquemas ainda mais simples. Para este carcinólogo, o litoral do Atlântico da América do Sul compreendia apenas a Província das Indias Ocidentais (desde as Carolinas até o Rio da Prata) e a Região Antártica (ao sul da latitutde $40^{\circ} \mathrm{S}$, porém com algumas espécies se estendendo até o Rio da Prata).

De ampla aceitacão, em se tratando da distribuição geográfica de crustáceos, foi o sistema de ECKMANN $(1935,1953)$; tal como apresentado por BALSS (1957b), não é muito diferente do de Henderson, no que diz respeito à América do Sul, e pode ser considerado como um resumo geral do que se conhecia até meados da década de 1950:

fauna tropical - até as proximidades do Rio da Prata fauna antiboreal sul-americana - desde o Rio da Prata até a extremidade sul do continente.

Com o progresso dos estudos oceanográficos, surgiram nestes últimos anos vários esquemas biogeográficos. Um dos mais conhecidos é o de BALECH (1951). Este biólogo foi aparentemente o primeiro a reconhecer o «Distrito das Guianas" como subdivisão da Província Antilhana, porém colocando seu limite sul no litoral do Rio Grande do Norte. A Província Antilhana de Balech, aceita com pequenas modificacōes por TOMMASI (1965), inclui também o "Distrito Bahiano", se estendendo do Rio Grande do Norte para o sul até $23-24^{\circ} \mathrm{S}$. A partir desta latitude era individualizada a Província Sul-Brasileira compreendendo o litoral até $30-32^{\circ} \mathrm{S}$, vindo a seguir a Província Argentina, até 41 - 44̊ S, e a Província Magalhânica, continuando até a extremidade sul do continente. KNOX (1960) não se afasta muito das ideias de Balech, porém seu 
trabalho não abrange a Província Antilhana. Estes esquemas incluem na Província Argentina a totalidade das Províncias Platense e Uruguaia de Dana, assim como parte da Província Norte-Patagônica. Igualmente a Província Sul-Brasileira abrange a Província Paulista e parte da Província Brasileira de Dana.

Outros pesquisadores, como HEDGPETH (1957) e PÉRÈS (1961) não individualizaram a área guianense e dividiram o litoral atlântico da América do Sul em 3 setores; 1) antiboreal ou subantártico, 2) temperado quente e 3) tropical. HEDGPETH porém confessa que a fauna da América do Sul estava ainda incompletamente conhecida.

Baseado em material recente recolhido pelo "Calypso", porém todo ele obtido ao sul do Recife, FOREST \& DE SAINT LAURENT (1967) fazem uma revisão da biogeografia dos crustáceos da América do Sul. Eles afirmam que a fauna do Distrito Guianense estava ainda pouco conhecida, não sendo possivel no momento delimitar suas fronteiras com precisão; apenas uma exploracão metódica da região entre o Recife e as Guianas seria capaz de fornecer dados faunísticos suficientes para um estudo zoogeográfico. Para o sul, os limites são ligeiramente diferentes dos de Balech; com efeito, Forest distingue que, entre os paguros, a fuana de origem tropical ou subtropical atinge pelo menos a latitude de $38^{\circ} \mathrm{S}$, enquanto a fauna patagônica sobe até $35^{\circ} \mathrm{S}$. O território habitado por fauna tropical ou subtropical compreenderia três setores biogeográficos: um setor temperado quente (limite norte perto de $28^{\circ} \mathrm{S}$ ) um setor subtropical desde a latitude de $28^{\circ} \mathrm{S}$ até $22-24^{\circ}$ S) e um setor tropical, certamente susceptível de subdivisão.

A partir de 1965 foram realizadas várias expedicões oceanográficas entre o Recife e as Guianas, percorrendo a área pouco explorada assinalada por Forest \& De Saint-Laurent, e foi baseado em seus primeiros resultados que LABOREL (1967) conseguiu recuar os limites entre as províncias Guianense e Brasileira até as vizinhanças de São Luís. Outros autores, como COELHO (1971a, b), KEMPF (1970), COELHO \& KOENING (1973) e COELHO \& 
RAMOS (1973a), aprofundaram o estudo da delimitação das províncias biogeográficas e dos fatores que possuem sua influência.

Há uma relativa concordância nos limites entre as províncias ao sul do paralelo $5^{\circ} \mathrm{S}$, embora tanto LABOREL como COELHO \& RAMOS tenham preferido o termo Província Paulista em vez de Província Sul-Brasileira. COELHO \& RAMOS mostraram que, ao longo da costa leste da América do Sul há vários conjuntos faunísticos, cujas áreas de ocorrência definem as várias províncias biogeográficas. Espécies tropicais ocorrem até o Norte da Argentina, espécies subtropicais entre o Rio de Janeiro e o Rio da Prata, espécies temperadas entre 0 Rio de Janeiro e o sul do continente e espécies subpolares do Rio da Prata para o sul. A fauna, no entanto, é predominantemente tropical de Santa Catarina para o Norte.

Apenas autores que tiveram oportunidade de estudar material do N.Oc. "Almirante Saldanha" colocaram o limite da Província Guianense nas vizinhanças da fronteira escolhida por Laborel. Isto se deve ao fato de que geralmente a distribuicão dos seres marinhos é associada apenas à temperatura da água, nenhuma consideraçāo merecendo a salinidade e a natureza do substrato. Além disto, a existência de um grande número de espécies tropicais encontradas ao norte e ao sul da Província Guianense parece diminuir a importância desta unidade biogeográfica. Com efeito, apenas o estudo minucioso da distribuicão de cada espécie permite reconhecer que, muitas espécies tropicais apresentam um hiato em sua área de ocorrência (correspondendo exatamente à Província Guianense, com sua curiosa fauna vasícola endêmica).

Ė preciso não confundir os termos tropical, subtropical, temperado, etc., que possuem vários significados. Aplicado a uma espécie, o termo tropical, por exemplo, significa que ela é adaptada à vida em águas de temperatura elevada, com variações sazonais reduzidas. Com relação ao regime de temperatura da água, estes termos foram definidos de maneira clara por PÉRĖS (1961). Muitos autores usam igualmente estas palavras para 
denominar unidades biogeográficas, trazendo apenas confusão, como salienta HAZEL (1970). Por este motivo os nomes das unidades biogeográficas devem ser sempre derivados de nomes de lugares, como fez DANA.

A divisão biogeográfica dos crustáceos da América do Sul, baseada em COELHO \& RAMOS (1973a) e em COELHO, KOENING \& RAMOS (no prelo) é apresentada na Figura 1; nela é possivel observar como há uma coincidência entre certos limites biogeográficos e condições de temperatura e salinidade da água. As duas partes subsequentes do presente trabalho aprofundam então o estudo das interrelações entre a biogeografia e as condições do ambiente.

\section{FATORES ABIOTICOS DO AMBIENTE BÉNTICO}

\subsection{HIDROLOGIA GERAL}

Introdução. - Estudando a distribuição dos crustáceos pertencentes a várias ordens (Isopodos, Decápodos e Estomatópodos), COELHO, KOENING \& RAMOS (no prelo) constataram que a salinidade, a temperatura, as correntes, a profundidade e o tipo de fundo são os principais fatores abióticos responsáveis pela divisão biogeográfica do litoral leste da América do Sul. Neste capítulo é apresentada uma resenha do que se conhece sobre a hidrologia geral (correntes, temperatura e salinidade), deixando as informacones sobre a natureza e a distribuição dos substratos para um capítulo posterior.

Correntes. - Como lembra NEUMANN (1965), a distribuição da temperatura, da salinidade, do oxigênio dissolvido e de outros fatores que controlam a produtividade do mar estão estreitamente ligados ao sistema de circulação oceânica.

A circulacão e a estratificação das camadas superiores do Atlântico Equatorial estão dominadas por cinco correntes: NorteEquatorial, Sul-Equatorial, das Guianas, Contra-Corrente Equatorial e Corrente sub-superficial Equatorial. $O$ "Atlas de Cartas Piloto", publicado pela DHN, mostra a direção e a velocidade das 


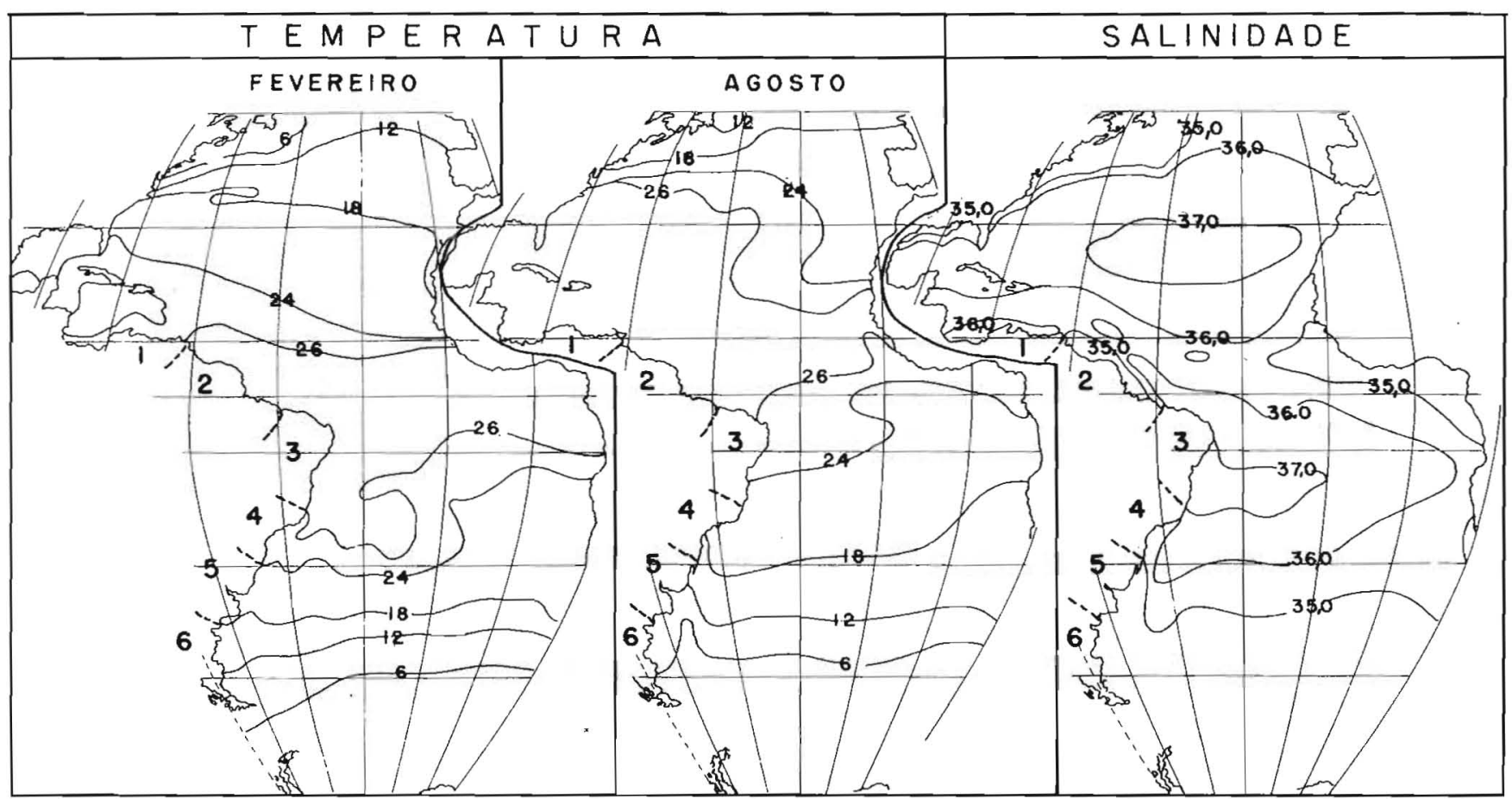

1-Prov. Antilhana. 2-Prov. Guianense. 3 - Prov. Brasileira. 4-Prov. Paulista. 5-Prov. Argentina. 6-Prov. Patagônica.

Fig. 1 - Divisão biogeográfica da América do Sul Atlântica, de acordo com COELHO \& RAMOS (1973) e COELHO, KOENING \& RAMOS (no prelo) em confrontacão com a temperatura e a salinidade da água de superficie, segundo Defant, 1961, modificada. 
correntes superficiais, de mês em mês, e como o seu fluxo é em parte mantido pelos ventos dominantes (ver também NEUMANN, 1965, 1969a; PERLROTH, 1969; DIEGUES, 1972).

METCALF (1968) assinala que, de acordo com o quadro convencional da circulacão das águas do Atlântico Ocidental, a Corrente das Guianas transporta a água central do Atlântico Sul ao longo das costas do Brasil e das Guianas até as Antilhas. Porém, como resultado de estudos recentes sobre a Corrente sub-superficial Equatorial, METCALF \& STALCUP (1967) mostraram que o fluxo de água não é contínuo através da coluna d'água. Em vez disto, nas vizinhancas da foz do Rio Amazonas, perto do meridiano $50^{\circ} \mathrm{W}$, a maior parte dos 150 ou 200 metros superiores da coluna d'água se curva sobre si mesma para a direita e quase para tráz para formar a Corrente sub-superficial Equatorial, ou de Lomonosov dos autores soviéticos, que corre para o leste. A existência desta descontinuidade, associada à variaçóes na direção dos ventos, na vazão dos rios e na localizacão da própria descontinuidade, possui efeitos importantes sobre a distribuição da temperatura e da salinidade sobre a plataforma continental.

Temperatura. - Os valores médios da temperatura da superfície da água são conhecidos atravéz de vários trabalhos, como o de DEFANT (1961), de DIEGUES (1972), das "Monthly Temperature Charts of the South Atlantic Ocean», do «Atlas de Cartas Pilotone do "Oceanographic Atlas of the North Atlantic Ocean. II. Physical properties", para citar apenas algumas das obras consultadas.

Em função da posição geográfica junto ao Equador, as temperaturas são elevadas, superiores a $26^{\circ} \mathrm{C}$ o ano inteiro, podendo atingir valores superiores a $28^{\circ} \mathrm{C}$. Há uma uniformidade na temperatura da água sobre a plataforma continental, como mostram, p. ex., os dados das expedicōes "Norte-Nordeste I" e "Norte-Nordeste $\|$ ", realizadas pelo N. Oc. "Almirante Saldanha" (cf. Fig. 2 e 3), exceto no Amapá, onde valores mais baixos, até de $15^{\circ} \mathrm{C}$, podem ser encontrados junto ao fundo nas proximidades do bordo externo da plataforma continental. Esta diminuição da temperatura é consequência de uma ressurgência que eleva até 

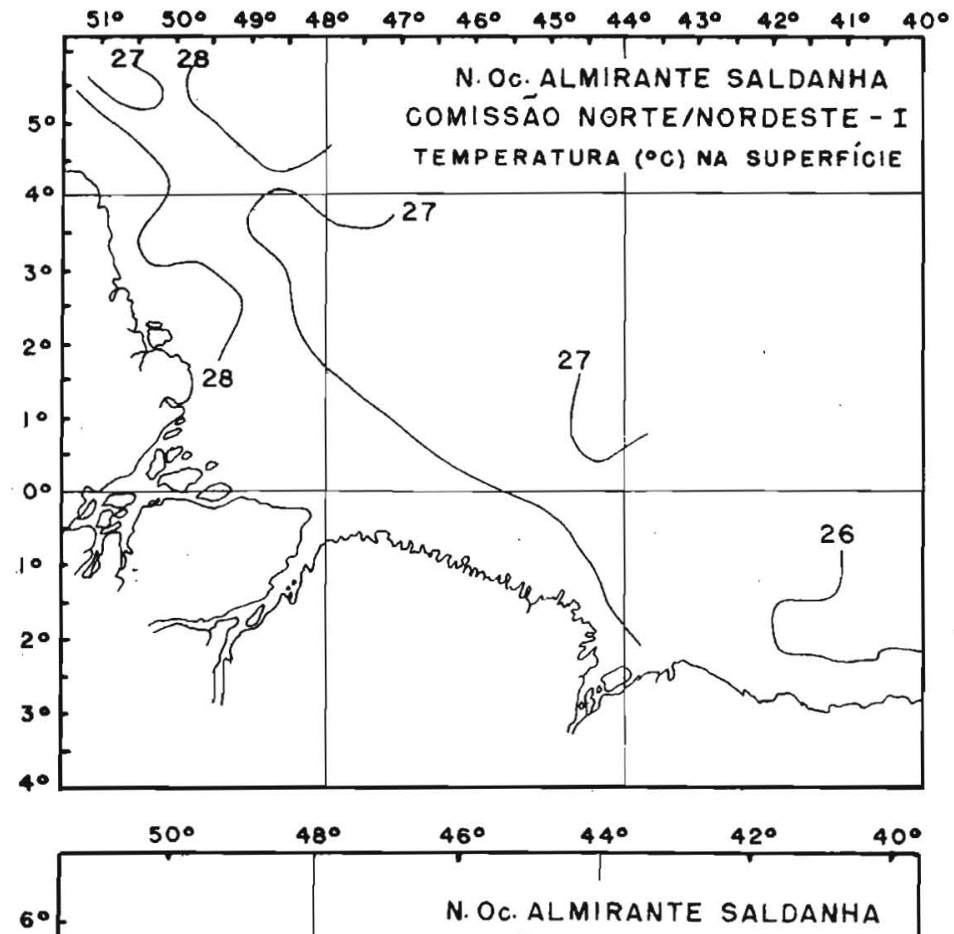
COMISSÃO NORTE/NORDESTE - II TEMPERATURA $\left(^{\circ} \mathrm{C}\right)$ NA SUPERFÍCIE

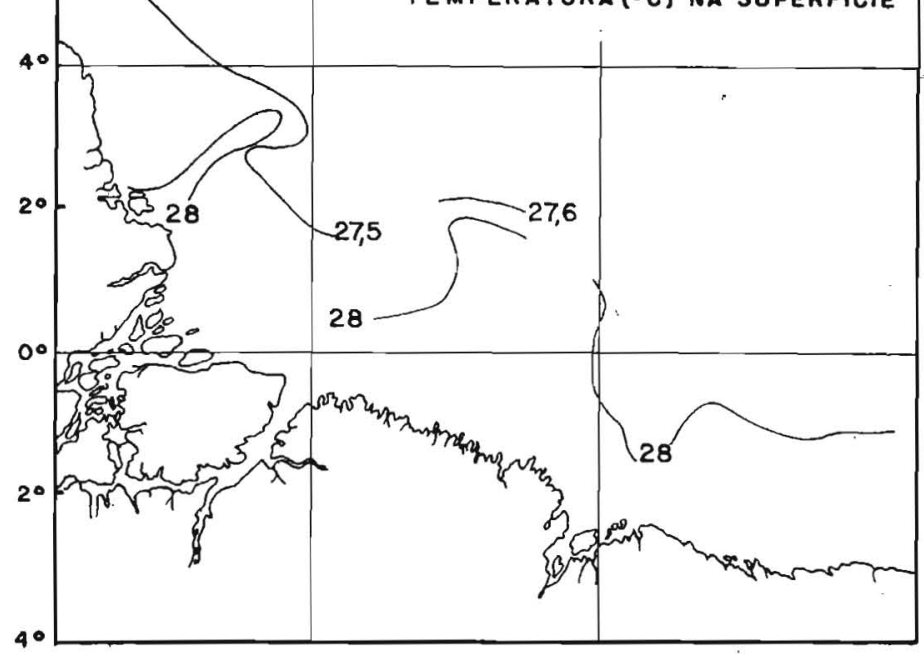

Fig. 2 - Temperatura da água de superfície no litoral Norte do Brasil durante as Comissões Oceanográficas Norte-Nordeste I e II realizadas pelo N. OC. "Almirante Saldanha". 

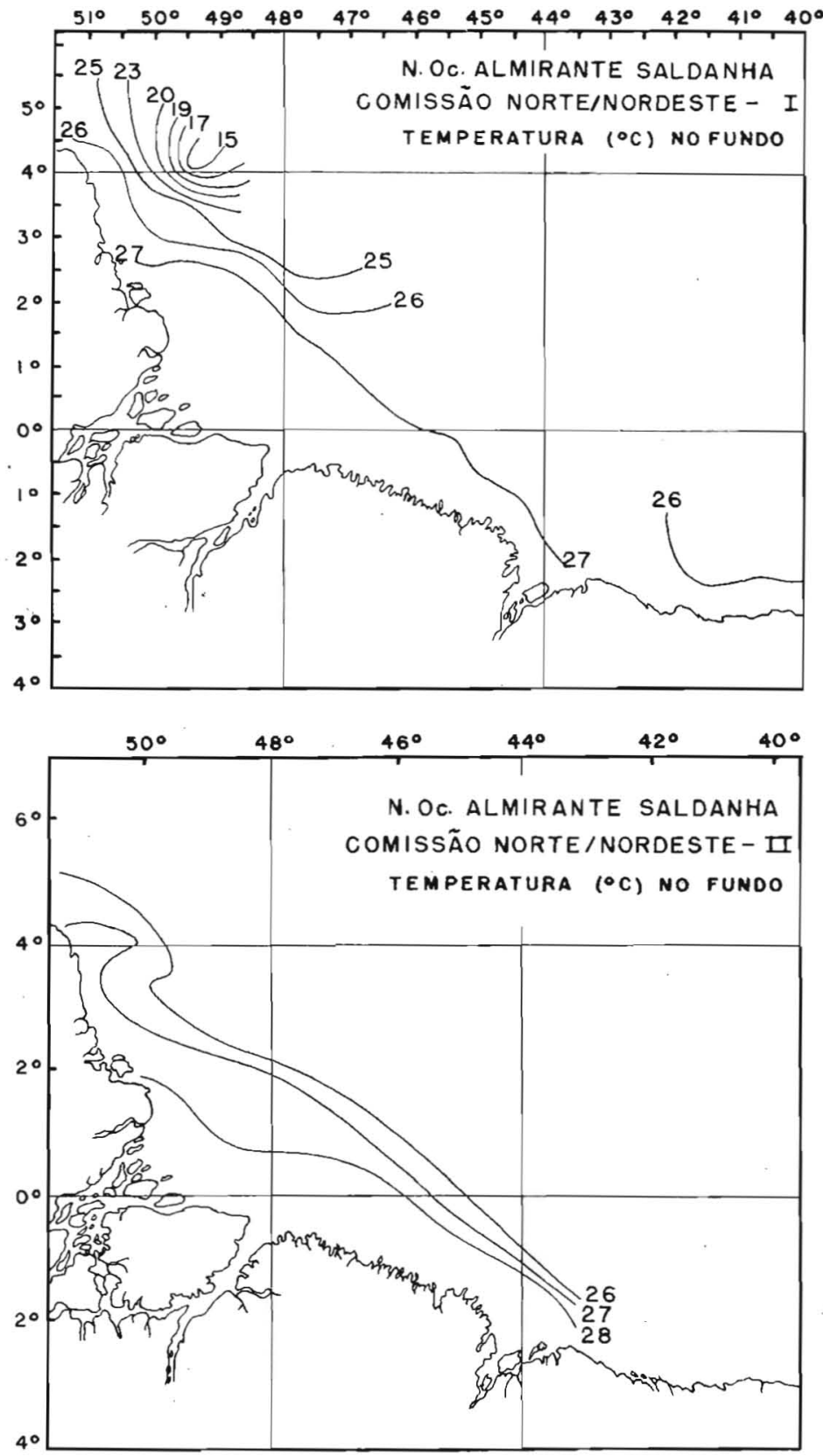

Fig. 3 - Temperatura da água junto ao fundo no litoral Norte do Brasil durante as Comissōes Oceanográficas Norte-Nordeste I e II realizadas pelo N. Oc. "Almirante Saldanha". 
a zona eufótica uma água rica em nutrientes (RYTHER, MENZEL \& CORWIN, 1967; PERLROTH, 1969; HULBURT \& CORWIN, 1969).

A temperatura da água junto ao fundo constitui assim um fator ecológico cujos valores devem ser levados em conta no estudo da distribuição dos seres bênticos. É escolhida a isoterma de $25^{\circ} \mathrm{C}$ de temperatura no fundo durante a expedição "Norte-Nordeste l" para delimitar aproximadamente a área de ressurgência ao largo do Amapá e do Pará. As condiçōes térmicas aí reinantes são comparáveis às existentes nas águas superficiais costeiras de Santa Catarina ou do Rio Grande do Sul.

Salinidade. - Os valores médios da salinidade da água superficial são conhecidos através de vários trabalhos recentes, como o de NEUMANN (1969b), o de DIEGUES (1972) ou o "Oceanographic Atlas of the North Atlantic Ocean. II. Physical Properties», para citar apneas algumas das obras mais importantes.

A vazão do Rio Amazonas e de outros rios da área exercem sua influência sobre a salinidade. Com efeito, o litoral estudado corresponde a uma bacia hidrográfica de cerca de $7.600 .000 \mathrm{~km}^{2}$, sobre a qual cai uma formidável precipitacão pluviométrica, quase sempre superior a $1.500 \mathrm{~mm}$ anuais. Assim, segundo GIBBS (1970), a vazão média do Amazonas é de $175.000 \mathrm{~m}^{3} / \mathrm{seg}$. porém durante as baixas-águas cai a $83.500 \mathrm{~m}^{3} / \mathrm{seg}$, e durante as altaságuas se eleva a $267.400 \mathrm{~m}^{3} / \mathrm{seg}$. Como lembra GUILCHER (1965), esta enorme vazão fluvial, associada a dos demais rios que desembocam no litoral estudado, permanece muito inferior à das correntes marinhas, que são da ordem dos milhões ou das dezenas de

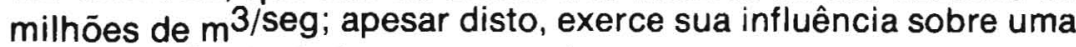
vasta porção do Atlântico, como é mostrado à seguir.

A área influenciada pela vazão dos rios pode ser considerada como aquela em que a salinidade superficial é inferior a $36 \%$. Este critério se baseia no fato de que as água oceânicas superficiais no Atlântico tropical e subtropical possuem normalmente salinidade de valor igual a este ou mais elevado.

A posição da isoalina de $36 \%$ varia durante o ano, ocupando posições extremas em novembro-dezembro e em abril. A época de 
menor influência fluvial corresponde a novembro-dezembro, quando apenas a porção interna da plataforma continental situada a oeste da foz do Tocantins está banhada por águas de salinidade baixa. A área de salinidade reduzida aumenta gradativamente até abril, quando compreende a totalidade do litoral em estudo. A partir de junho-julho, há um recuo gradual para a situação de novembro-dezembro. Levando em conta os valores médios anuais (DEFANT, 1961, pl. 5 - cf. Fig. 1), toda a plataforma desde as proximidades de São Luís até as vizinhanças de Trinidad está banhada por águas de salinidade inferior a $36 \%$; mais ainda, o setor costeiro entre a foz do Rio Tocantins e a Guiana Francesa é banhada por águas francamente mixoalinas.

A Fig. 6, baseada em dados de NEUMANN (1969b), mostra a variação anual da salinidade em áreas escolhidas formando um perfil perpendicular à foz do Rio Tocantins. Estas variações da salinidade interessam principalmente as águas superficiais, até uma profundidade de, no máximo, 60 metros (Fig. 4 e 5). As expedicões do N. Oc. "Almirante Saldanha" mostraram que, sobre o fundo, as condiçōes são bem diferentes. À leste do meridiano $43^{\circ} \mathrm{W}$, a salinidade é elevada o ano inteiro; a oeste, águas de salinidade elevada são encontradas constantemente junto ao bordo externo, mas não no restante da plataforma continental.

Torna-se necessário levar em conta os valores da salinidade da água junto ao fundo quando se estuda a distribuição dos seres bênticos. As mudanças da salinidade numa área estão associadas a variacōes no oxigênio dissolvido, no $\mathrm{pH}$, e na quantidade de nutrientes. A baixa salinidade constitui fator ecológico por si mesma, assim como reflete o aumento da influência fluvial, ou melhor, terrígena. No presente estudo, as posições da isoalina de $36 \%$ junto ao fundo durante a expedição "Norte-Nordeste I" foram escolhidas para indicar a área que está constantemente sob influência fluvial (Fig. 5).

Conclusões. - Esta Primeira Parte expõe resumidamente os conhecimentos atuais sobre a hidrologia geral do litoral norte do Brasil. Por sua influência sobre os povoamentos bênticos, três aspectos devem ser salientados: 


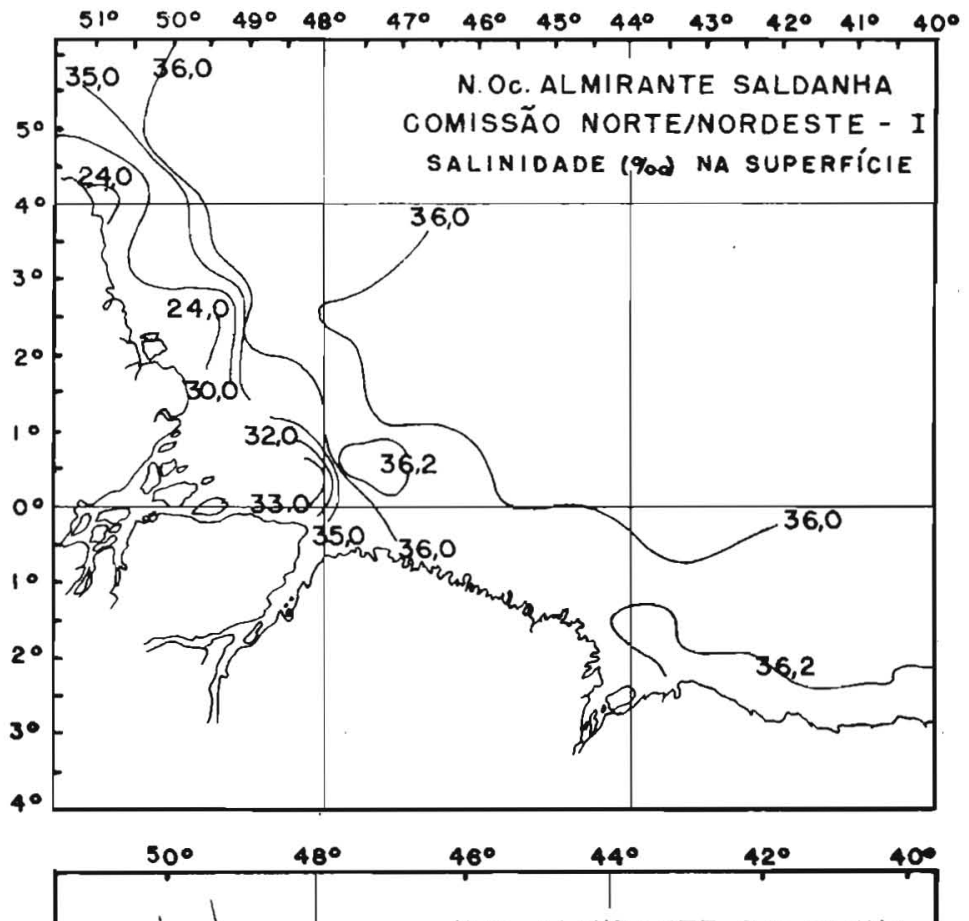

N.Oc. ALMIRANTE SALDANHA COMISSÃO NORTE/NORDESTE - I

SALINIDADE (\%) NA SUPERFICIE

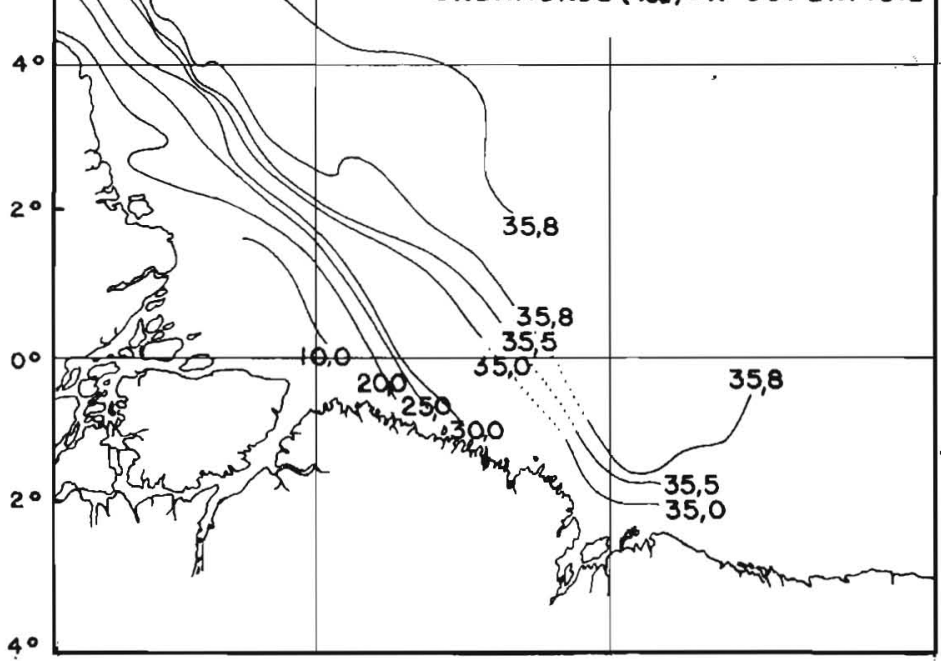

Fig. 4 - Salinidade da água de superfície no litoral Norte do Brasil durante as Comissões Oceanográficas Norte-Nordeste I e II realizadas pelo N. Oc. "Almirante Saldanha". 

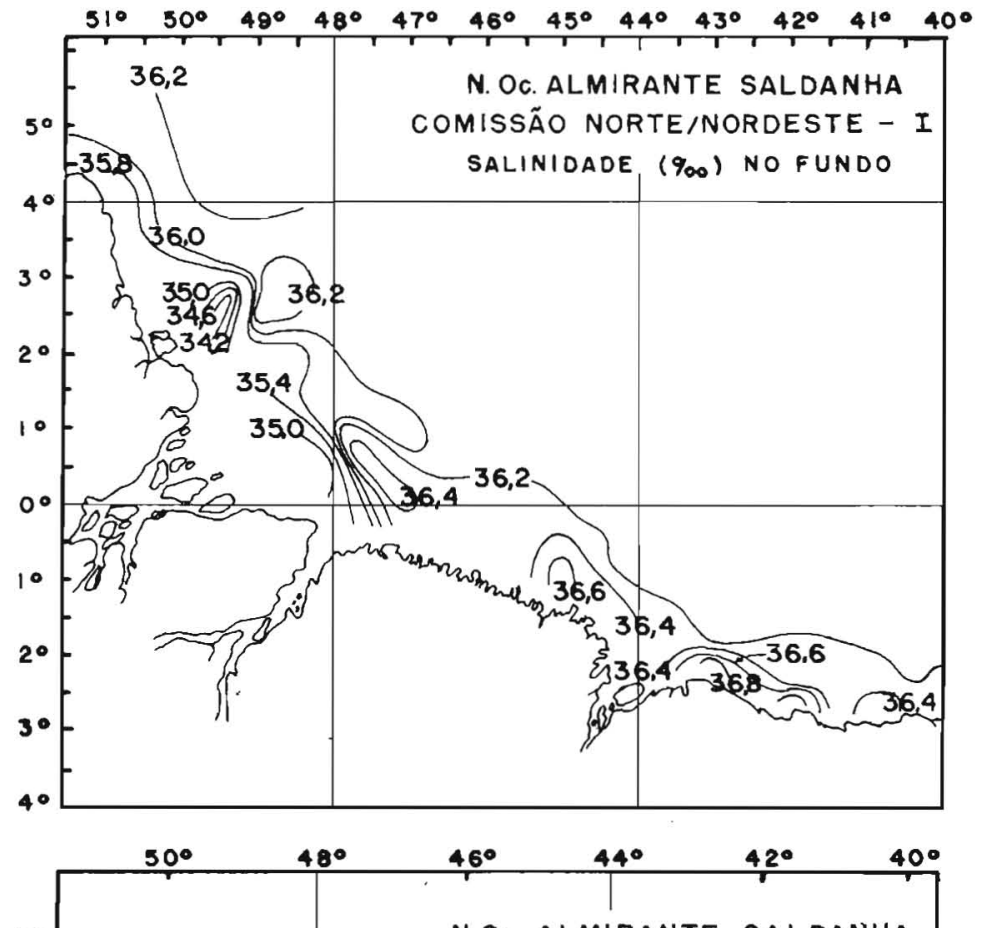

N. Oc. ALMIRANTE SALDANHA

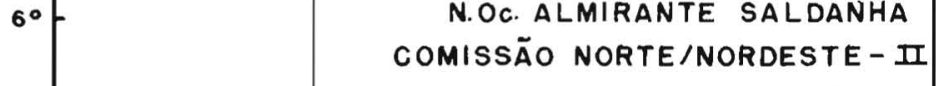

SALINIDADE (\%०o) NO FUNDO

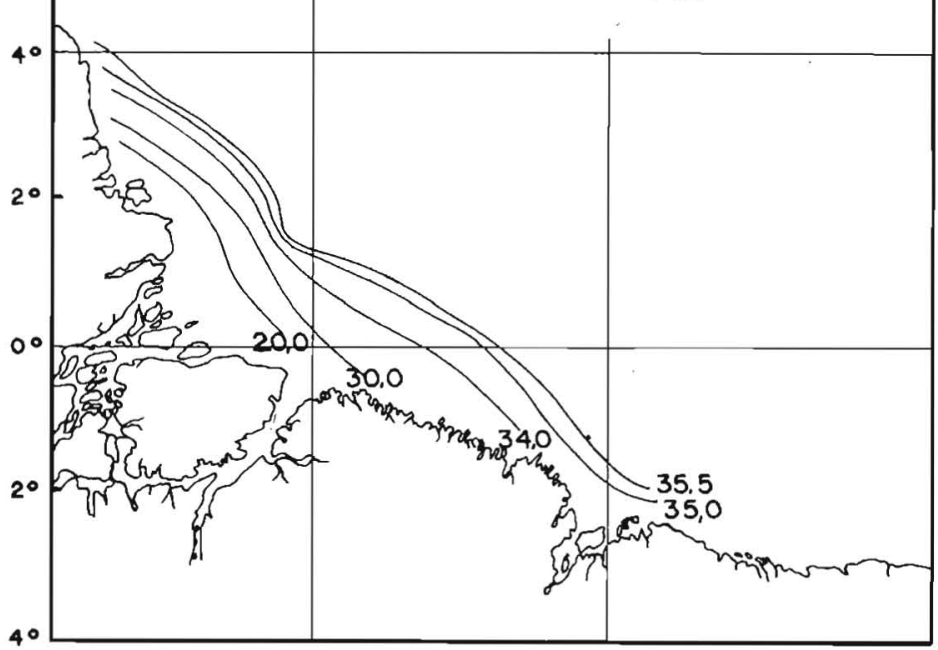

Fig. 5 - Salinidade da água junto ao fundo no litoral Norte do Brasil durante as Comissões Oceanográficas Norte-Nordeste I e II realizadas pelo N. Oc. "Almirante Saldanha". 
- o papel das correntes marinhas de superficie, trazendo água de salinidade elevada.

- a descarga dos rios, principalmente do Rio Amazonas, e suas consequências sobre a distribuição das isoalinas de superfície e de fundo.

- a diminuição da temperatura do fundo junto ao bordo externo da plataforma continental, decorrência de uma ressurgência.

Têm sido cỏnstatadas variaçōes sazonais nos valores da salinidade e da temperatura, e os valores mais baixos de ambos estão muito aquém do que seria de esperar junto à linha equatorial. Certos valores foram escolhidos que delimitam áreas sobre o fundo:

- área 1, de temperatura constantemente elevada e salinidade baixa durante parte do ano, ou constantemente elevada.

- área 2, de temperatura constantemente elevada e salinidade constantemente baixa.

- área 3, sujeita a um resfriamento (provavelmente sazonal) e de salinidade constantemente elevada.

As áreas assim definidas são mostradas na Fig. 7.

\subsection{TIPOS DE FUNDO}

Introdução. - É essencial o conhecimento da natureza do substrato para interpretar a distribuição dos seres que vivem no domínio bêntico, analizar suas exigências ecológicas ou descrever os povoamentos que eles constituem. Duros ou móveis, antigos ou atuais, é preciso expor de maneira bastante detalhada os resultados obtidos por geólogos e sedimentólogos. Isto será efetuado seguindo o plano adotado por MABESSONE \& COUTINHO (1972), porém levando em conta trabalhos realizados posteriormente, e dando uma interpretação pessoal.

Topografia da plataforma continental. - O conhecimento da topografia da plataforma continental deriva principalmente das cartas 
Salinidade superficial

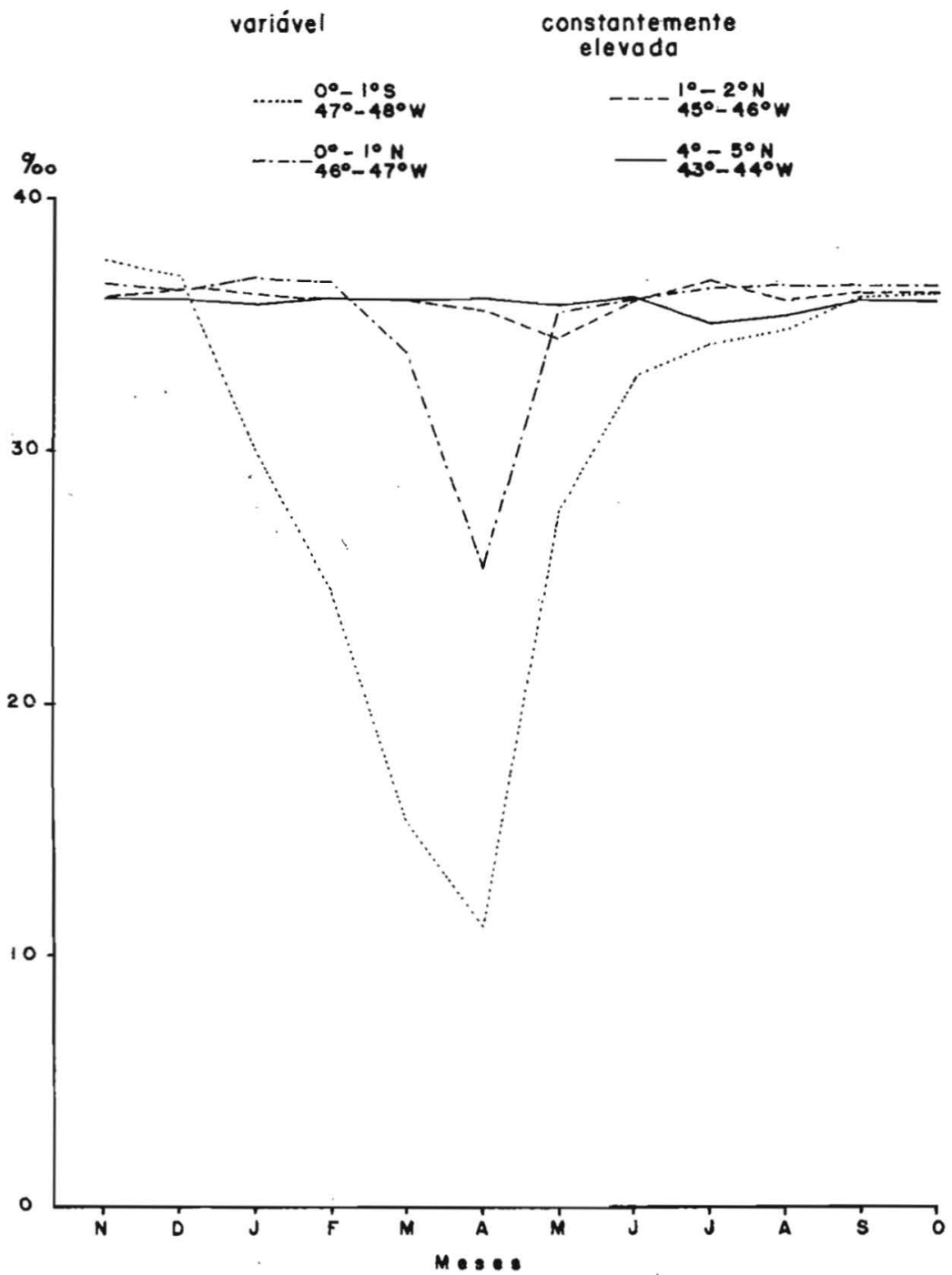

Fig. 6 - Variacão sazonal da salinidade de superfície em áreas escolhidas formando uma linha perpendicular à costa, diante de Salinópolis, Estado do Pará. Dados de Neumann (1969B). 


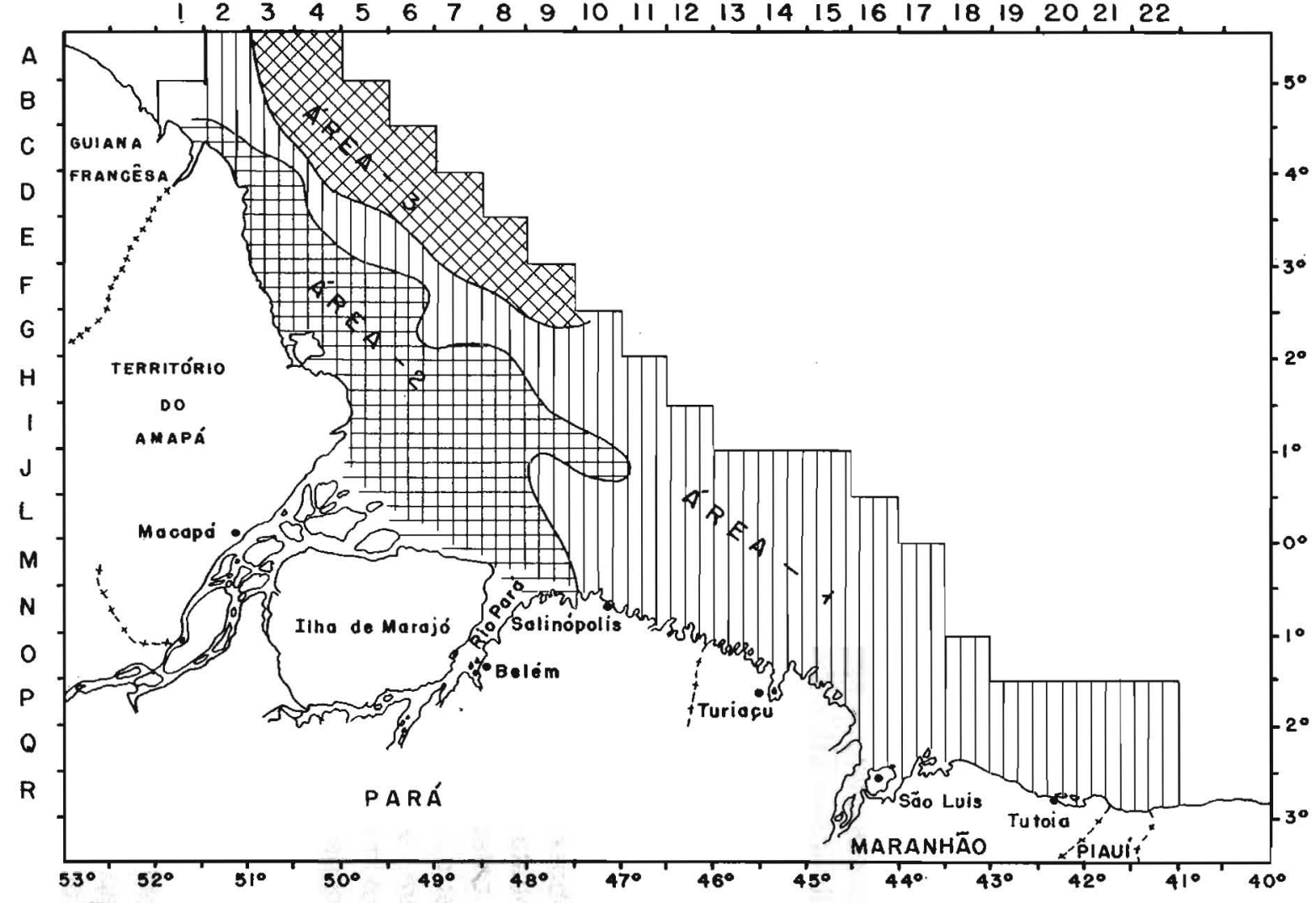

Fig. 7 - Climas hidrográficos junto ao fundo no litoral Norte do Brasil. Ver explicacão no texto 
náuticas editadas pela Diretoria de Hidrografia e Navegacão e dos registros ecobatimétricos obtidos pelo N. Oc. "Almirante Saldanha» durante várias expedicões. A partir destes elementos, é possível obter uma visão geral dos principais aspectos morfológicos, a saber: bordo da plataforma (posição, profundidade) e relevo da plataforma.

O limite externo da plataforma é constituído pela "borda», ou seja, o local em que há uma ruptura do relevo. Na região estudada, a posição em relação à costa e a profundidade da borda variam consideravelmente, permitindo distinguir duas áreas. A primeira delas é constituída pelo trecho entre o Piauí e o Pará na altura de Salinópolis, em que a borda está a uma profundidade de 75-80 metros e a uma distância que aumenta regularmente de leste para oeste desde $100 \mathrm{~km}$ até $200 \mathrm{~km}$. A outra área se estende desde Salinópolis até o Cabo Orange, onde a profundidade da borda varia, atingindo $150 \mathrm{~m}$ ao largo da llha de Maracá, e a distância da costa passa de $200 \mathrm{~km}$ em Salinópolis para $360 \mathrm{~km}$ ao largo da foz do Amazonas, diminuindo depois até o Cabo Orange, onde sua largura é de apenas $150 \mathrm{~km}$.

Há igualmente uma variacão no próprio relevo da plataforma. Sobre este aspecto, é interessante comparar a posicão relativa das isóbatas de 30 , de 50 e de 80 metros. No Piauí e no Maranhão, as isóbatas de 50 e de 80 metros estão próximas, e distantes da de 30 metros. Após uma faixa de transição correspondente ao leste do Pará, acontece que as isóbatas de 30 e de 50 metros estão próximas, e distantes da de 80 metros no oeste do Pará e no Amapá.

Classificação dos sedimentos. - Vários autores estudaram a natureza dos sedimentos que recobrem a plataforma. OTTMANN (1959) publicou algumas informações sobre a área próxima à desembocadura do Amazonas. BOTELHO (1966) tentou um mapeamento com os dados existentes até aquela época. Estudos sobre as amostras coletadas pelo N. Oc. "Almirante Saldanha" a partir de 1967 foram publicados por COUTINHO \& MORAIS (1969), KEMPF, COUTINHO \& MORAIS (1968, 1970), KEMPF (1970), 
MABESOONE \& COUTINHO (1972), ZEMBRUSKI \& Outros (1971), MARTINS \& Outros (1972) e MABESOONE, KEMPF \& COUTINHO (1973), para citar apenas algumas das contribuicões mais expressivas. ZAKHAROV (1974) apresentou o resultado das coletas soviéticas.

Da análise destes trabalhos resulta uma confusão de nomenclatura: cada autor aplicou nomenclatura diferente, havendo assim uma copiosa sinonimia para cada tipo de fundo. Em parte, isto é consequência das dificuldades existentes no estudo da área: os dados resultantes do peneiramento úmido das amostras, os teores de carbonato de cálcio e de insolúveis e a constatacão da presença ou ausência de melobésias vivas devem ser levados em conta para uma definição e delimitação perfeitas dos tipos de fundo. $O$ esquema adotado é basicamente uma combinacão dos de PÉRÈS (1968), de KEMPF, COUTINHO \& MORAIS $(1968,1970)$ e de ZEMBRUSKI \& Outros (1971). Os tipos de fundo admitidos são mostrados a seguir.

\section{A - Fundos terrígenos}

Fundos lamosos (símbolo L): são considerados fundos lamosos aqueles em que a fracão lama (constituída pelas partículas com diâmetro inferior a $0,053 \mathrm{~mm}$ ) representa $80 \%$ ou mais do sedimento.

Fundos areno-lamosos (símbolo $\mathrm{A} / \mathrm{L}$ ): nestes fundos as fracōes lama e areia (esta última constituída pelas partículas entre $2 \mathrm{~mm}$ e $0,053 \mathrm{~mm}$ ) ocorrem ambas numa porcentagem entre $20 \%$ e $80 \%$. A fração de areia é de natureza quartzosa.

Fundos arenosos (símbolo A): trata-se de uma areia quartzosa, geralmente acompanhada por grãos coloridos por óxido de ferro, minerais opacos e fragmentos de concha.

\section{$B$ - Fundos organogênicos e de transição}

Fundos biogênicos (símbolo $\mathrm{Ac}$ ): estes fundos organogênicos são constituídos por algas calcárias (RHODOPHYCEAE Corallinaceae do grupo das Melobesiae), associadas a uma grande variedade de organismos bênticos sésseis. Os fundos biogênicos 
são "vivos", isto é, as algas que os constituem estão vivas. Vários fatores são necessários à sua vitalidade, entre os quais seria possível mencionar a iluminação, as correntes e a profundidade. Existe sempre uma fracão arenosa, em proporção variável, proveniente da desagregação dos organismos, e uma pequena porcentagem de lama; ao contrário das fracões similares quanto à granulometria dos fundos terrígenos, a areia e a lama dos fundos organogênicos em geral, e dos fundos biogênicos em particular, são de natureza calcária.

Fundos biogênicos-arenosos (símbolo $\mathrm{A} / \mathrm{AC}$ ): estes fundos diferem dos anteriores pela presença de areia quartzosa, geralmente representando cerca de $50 \%$ do sedimento.

Fundos biodetríticos (símbolo D): muito semelhantes aos fundos biogênicos, porém diferindo pela ausência de algas calcárias vivas e pelo aumento da porcentagem de lama. Há uma grande quantidade de fragmentos de organismos bênticos: restos de conchas, de esqueletos, de carapacas...

Fundos biogênico-detríticos (símbolo $A C / D$ ): trata-se de um tipo de fundo intermediário entre os fundos biodetríticos e os biogênicos: neles há uma pequena proporcão de algas calcárias vivas, porém com o predomínio do material morto.

Fundos biodetrítico-arenosos (símbolo $A / D$ ): estes fundos diferenciam-se dos fundos biodetríticos pela presenca de areia quartzosa, e dos fundos biogênicos-arenosos pela ausência de algas calcárias vivas.

Distribuição dos tipos de fundo. - Com base nas características mencionadas, foi organizado uma mapa da distribuicão dos tipos de fundo (anexo l).

Fundos lamosos: estes fundos predominam nas partes da plataforma continental mais próximas da costa no Amapá e no Pará, à leste do meridiano $47^{\circ} \mathrm{W}$. Eles geralmente estão confinados às profundidades inferiores a 50 metros, ocasionalmente ultrapassando as de 60 metros.

Fundos areno-lamosos: fundos deste tipo foram localizados em certas áreas de transicão entre os fundos lamosos e os fundos arenosos; bem como formando um "canal» defronte da fóz principal do Rio Amazonas. 
Fundos arenosos: à leste do meridiano de $47^{\circ} \mathrm{W}$, em profundidade que raramente ultrapassa os 60 metros, está localizada uma importante faixa de fundos arenosos. À oeste do meridiano de $50^{\circ} \mathrm{W}$, os fundos de areia correspondem à metade mais profunda da plataforma continental. Entre $47^{\circ} \mathrm{W}$ e $50^{\circ} \mathrm{W}$, no entanto, se distribuem de maneira bastante irregular, com tendência a formar um corredor entre as duas áreas.

Fundos organogênicos: os diversos tipos de fundos organogênicos são encontrados a oeste do meridiano de $50^{\circ} \mathrm{W}$, em profundidades superiores às dos fundos de areia e de lama. Há uma sequência típica, partindo das partes mais rasas para as mais profundas: $A / A C-A C-A C / D-D$. Como pode ser observado no mapa, as coletas revelaram que nem sempre a sequência ideal está presente, bem como aparece o fundo A,D em certas áreas de contacto entre os fundos arenosos e biodetríticos. Em consequência o mapa oferece, até certo ponto, o aspecto de mosaico.

Os fundos organogênicos do Norte do Brasil estão em continuidade com os do Nordeste, porém há um hiato entre eles e os fundos similares das Antilhas: o "Oceanographic Atlas of the North Atlantic Ocean. V. Marine Geology" mostra que, entre os $50^{\circ} \mathrm{W}$ e os $60^{\circ} \mathrm{W}$ estes estão ausentes. Realmente, há um intervalo de $1.600 \mathrm{~km}$ entre os fundos organogênicos brasileiros e antilhanos.

Correlação entre as variações da salinidade e dos tipos de fundo. - Foi realizada uma confrontação entre os dados de salinidade e a natureza dos fundos. Foi assim constatado haver uma coincidência notável entre o grau de variação da salinidade e a natureza do substrato. $\mathrm{Na}$ área dotada de fundos organogênicos, a salinidade da água da superfície durante as coletas variou entre 36,509 e $35,668 \%$ oo, ao passo que junto ao fundo oscilou entre $36,537 \mathrm{e}$ $35,843 \%$ oo. A salinidade da água sobre os fundos arenosos variou entre 36,788 e 17,883\% \%o na superfície e entre 36,842 e 30,458\% junto ao fundo. Finalmente, a região dos fundos lamosos é banhada por água cuja salinidade, na superfície, oscilou entre 36,393 e 9,0930/oo e junto ao fundo entre 36,484 e 21,318\% oo. Assim, apenas os fundos organogênicos eștão constantemente 
banhados por águas cuja salinidade pouco varia, em torno dos $36 \%$ os fundos arenosos e, principalmente os fundos lamosos, estão sujeitos à oscilações nas características das massas d'água que os banham.

É de se esperar que os efeitos das variações da temperatura e da salinidade da água se somem ao da variada natureza dos fundos como fatores, permitindo explicar a distribuição da fauna bêntica.

\subsection{CONCLU USÃO GERAL DA PARTE 4}

Tudo o que foi dito precedentemente na parte 4 permite reconhecer uma subdivisão natural da área estudada, baseada no que se conhece sobre a hidrologia geral e a distribuição dos tipos de fundo. Com efeito, o meridiano de $48^{\circ} \mathrm{W}$ marca, com notável aproximacão, o limite entre duas regiōes naturais. À leste deste meridiano, predominam fundos arenosos e organogênicos, banhados por água de temperatura e salinidade relativamente pouco variáveis. À oeste, ao contrário, os fundos organogênicos estão mal representados, predominam fundos lamosos e arenosos, enquanto a temperatura e a salinidade apresentam consideráveis variaçōes. (vide Fig. 8)

Esta diversidade de condições ecológicas deve sempre ser lembrada para a compreensão dos limites das áreas ocupadas pelas espécies.

\section{DISTRIBUIÇÃO E ESTRUTURA DOS POVOAMENTOS}

\section{I. METODOLOGIA}

Introduçāo. - O presente estudo segue uma metodologia que aproveita da experiência de vários autores. Foi para nós da maior utilidade a leitura dos trabalhos de PICARD (1965), LAUBIER (1966), CABIOCH (1968), GUILLE (1970) e SOYER (1970), e deles foi extraído o essencial do sistema de análise e de interpretacão que é descrito a seguir. 
Regiões naturais do Litoral Norte do Brasil.

A - Região Oriental, com predominân-? cia de fundos arenosos e organo $=30$ gênicos banhados por água de tem² peratura e salinidade relativamente pouco varióveis.

B - Região Ocidental, com predominância de fundos lamosos e arenosos banhados por água de temperatura e salinidade apresentando consideráveis variaçöes.

Fig. 8 - Regiões naturais do litoral Norte do Brasil. O meridiano $48^{\circ} \mathrm{W}$ corresponde aproximadamente ao limite entre duas regiōes naturais caracterizadas por condiçōes de temperatura ou de salinidade da água junto ao fundo e pela natureza do próprio fundo.

isoterma de $25^{\circ} \mathrm{C}$

junto ao fundo, N-NEI posiçäo aproximada da isobata de 80 metros 
Modo de representação das distribuições. - O território que serve de base para a análise das distribuiçōes é limitado à leste e à oeste rspectivamente pelos meridianos de $41^{\circ} \mathrm{W}$ e $52^{\circ} \mathrm{W}$. A profundidade ao largo atingiu até 224 metros, porém poucas vezes ultrapassou 120 metros, em função das dificuldades encontradas na coleta de amostras de fundo. Seria possível empregar dois métodos na cartografia das áreas de ocorrência das espécies nesta vasta área. A primeira seria tracar, para cada espécie, uma carta com os pontos exatos de coleta. Como resultado seria obtida uma representacão geográfica muito precisa, que se prestaria bem ao estudo de uma área limitada onde pequeno número de estações fosse distribuído com uma certa regularidade. Quando as estacões se tornam muito abundantes e distribuídas irregularmente sobre uma área muito extensa, o método perde a vantagem da precisão desejada. O segundo método, correntemente empregado em estudos biogeográficos e ecológicos, principalmente no ambiente maŕinho, consiste em dividir a área estudada em blocos retangulares de tamanho arbitrário, escolhido de acordo com as conveniências de cada caso, e considerar como uma só todas as estações localizadas numa mesma superfície elementar. A totalidade das informacões sobre a composicão faunística de cada retângulo é reunida numa lista de espécies. A localizacão geográfica das espécies, atribuída ao centro de cada retângulo, é menos precisa que no caso anterior, porém o estudo das relaçóes entre as áreas se mostra grandemente simplificado. No presente estudo, foram adotados quadriláteros com 30 minutos de latitude e 30 minutos de longitude o que dá a eles, em virtude da baixa latitude, uma forma praticamente quadrada. Suas dimensões permitem a compreensão das distribuicões gerais, e impedem que se tenha uma falsa idéia de precisão, desproporcionada à densidade média das estações. Na elaboração dos mapas de distribuicão, foi traçada uma linha em torno dos retângulos periféricos da área de ocorrência conhecida de cada espécie ou grupo de espécies.

Apesar das dimensões dos retângulos, alguns possuem um número de estacões mais elevado que outros (Fig. 9). Realmente, não seria necessário que todas as áreas tivessem sido exploradas com a mesma intensidade para que aparecessem os caracteres 
gerais da distribuição das espécies. Como a densidade das espécies estudadas quase sempre é reduzida, convém sempre. levar em conta os dados da Fig. 9, principalmente para corrigir a impressão dada pela distribuição de espécies pouco conhecidas ou pouco comuns.

Definição e estrutura dos povoamentos. - No estudo da distribuição das espécies, foi necessário agrupá-las inicialmente em função de suas afinidades zoogeográficas, e depois de suas preferências ecológicas (vide "Lista das espécies", no anexo II).

A base da classificação geográfica das espécies repousa no conceito de "conjunto faunístico", tal como usado por COELHO \& RAMOS (1973a). São consideradas como pertencentes a um mesmo "conjunto faunístico" todas as espécies que se assemeIham do ponto de vista da. distribuição geográfica. Esta classificação biogeográfica foi realizada em funcão dos dados disponíveis sobre a área de ocorrência de cada espécie, levando em conta todas as informacões existentes, inclusive as da literatura. $\mathrm{Na}$ área em estudo, ocorrem espécies pertencentes aos seguintes conjuntos:

1 - espécies guianenses, muito comuns nas Guianas, no Amapá, e no Pará, com área de repartição se estendendo para o leste, no máximo, até o Maranhão, podendo ao norte abranger as Antilhas, o Norte da América do Sul, a América Central, o Golfo do México ou o Leste dos Estados Unidos (símbolo $G$ na lista das espécies).

2 - espécies tropicais contínuas, apresentando uma distribuição geográfica ininterrupta desde o setor caraíba (isto é, Antilhas, América Central, Norte da América do Sul) até o Nordeste do Brasil (isto é, o litoral brasileiro entre o Maranhão e o Espírito Santo). Várias delas ocorrem também no Leste dos Estados Unidos, no Golfo do México, na Flórida e no Sudeste do Brasil, assim como no Pacífico Oriental, no Atlântico Oriental e no Indopacífico. (símbolo TC na lista das espécies). 
3 - espécies tropicais disjuntas ou descontínuas, apresentando uma área de ocorrência semelhante à das tropicais continuas, porém com um hiato correspondente ao setor guianense. As espécies tropicais contínuas e disjuntas podem ser reunidas sob 0 nome de espécies anfitropicais (símbolo TD na lista das espécies).

4 - espécies brasileiras, cuja área de abundância coincide com o Nordeste do Brasil, podendo, no entanto, apresentar área de ocorrência mais ampla, abrangendo para o norte o setor guianense, e para o sul o Sudeste do Brasil ou o Sul, raramente o Uruguai ou o Norte da Argentina. As espécies guianenses, anfitropicais e brasileiras podem ser reunidas sob o nome de tropicais (símbolo B na lista das espécies).

5 - espécies anfisubtropicais, ocorrendo no Sudeste do Brasil, assim como no Leste dos Estados Unidos, Golfo do México ou no Norte do setor caraíba. No setor intermediário devem ocorrer apenas no talude continental, ou em áreas de ressurgência (símbolo Bat na lista das espécies).

Esta divisão da fauna em conjuntos faunísticos pode ser efetuada com animais pertencentes a grupos zoológicos muito diferentes. A análise dos dados de distribuicão dos octocorálios (TIXIER-DURIVAULT, 1970), por exemplo, permite reconhecer entre estes celenterados praticamente os mesmos conjuntos que entre os crustáceos decápodos. KEMPF (1970) também apresenta dados indicando claramente o mesmo fato, com relaçáo a várlos grupos zoológicos.

Algumas espécies, muito pouco conhecidas, não foram incluídas nos conjuntos faunísticos.

As duas províncias biogeográficas, cujo limite o presente estudo pretende estabelecer com precisão, seriam assim caracterizadas:

1 - Província Guianense: habitada por espécies guianenses e tropicais contínuas, ao lado de um número reduzido de espécies brasileiras. 
2 - Província Brasileira: habitada por espécies brasileiras, tropicais disjuntas e tropicais contínuas.

Por este motivo, é da maior importância a delimitacão das áreas ocupadas respectivamente pelas espécies guianenses e tropicais disjuntas para o estabelecimento do limite entre as duas províncias.

A classificação ecológica das espécies foi realizada exclusivamente a partir dos dados de coleta de cada uma delas na área estudada. Dois critérios se mostraram mais importantes, a batimetria e a natureza dos sedimentos, o que conduziu a uma dupla classificação.

O exame da distribuicão batimétrica da fauna (Fig. 10) mostrou que é possivel dividi-la em dois grupos principais, um costeiro, $\bigcirc$ outro de água profunda (símbolos $\mathrm{C}$ e $\mathrm{P}$, respectivamente, na lista das espécies). $O$ limite batimétrico entre os dois grupos se situa nas proximidades da isóbata de 80 metros. A estes dois grupos é preciso ajuntar um terceiro, o das espécies euribatas (símbolo $E$ na lista das espécies). Uma certa renovacão da fauna entre 35-45 metros permite dividir as espécies costeiras em infralitorais e circalitorais.

De acordo com a ocorrência das espécies nos diversos tipos de fundo, foi possivel distinguir:

- espécies vasícolas: encontradas de preferência em fundos lamosos, ou associadas à fracão fina noutros tipos de fundo (símbolo $\mathrm{Va}$ ).

- espécies arenícolas: encontradas de preferência em fundos arenosos, ou associadas à fração de areia noutros tipos de fundo (símbolo Ar).

- espécies cascalhícolas: encontradas de preferência em fundos organogênicos, ou em costas rochosas (símbolo $\mathrm{Ca}$ ).

Desta forma, nos fundos lamosos são encontradas apenas espécies vasícolas, porém nos fundos arenosos existem espécies arenícolas e vasícolas, enquanto nos fundos organogênicos se reunem espécies cascalhicolas, arenicolas e vasícolas. Foram reconhecidas cinco comunidades faunísticas: uma constituída 
Classificasão das espécies em funçāo da distribuiçāo batimétrica

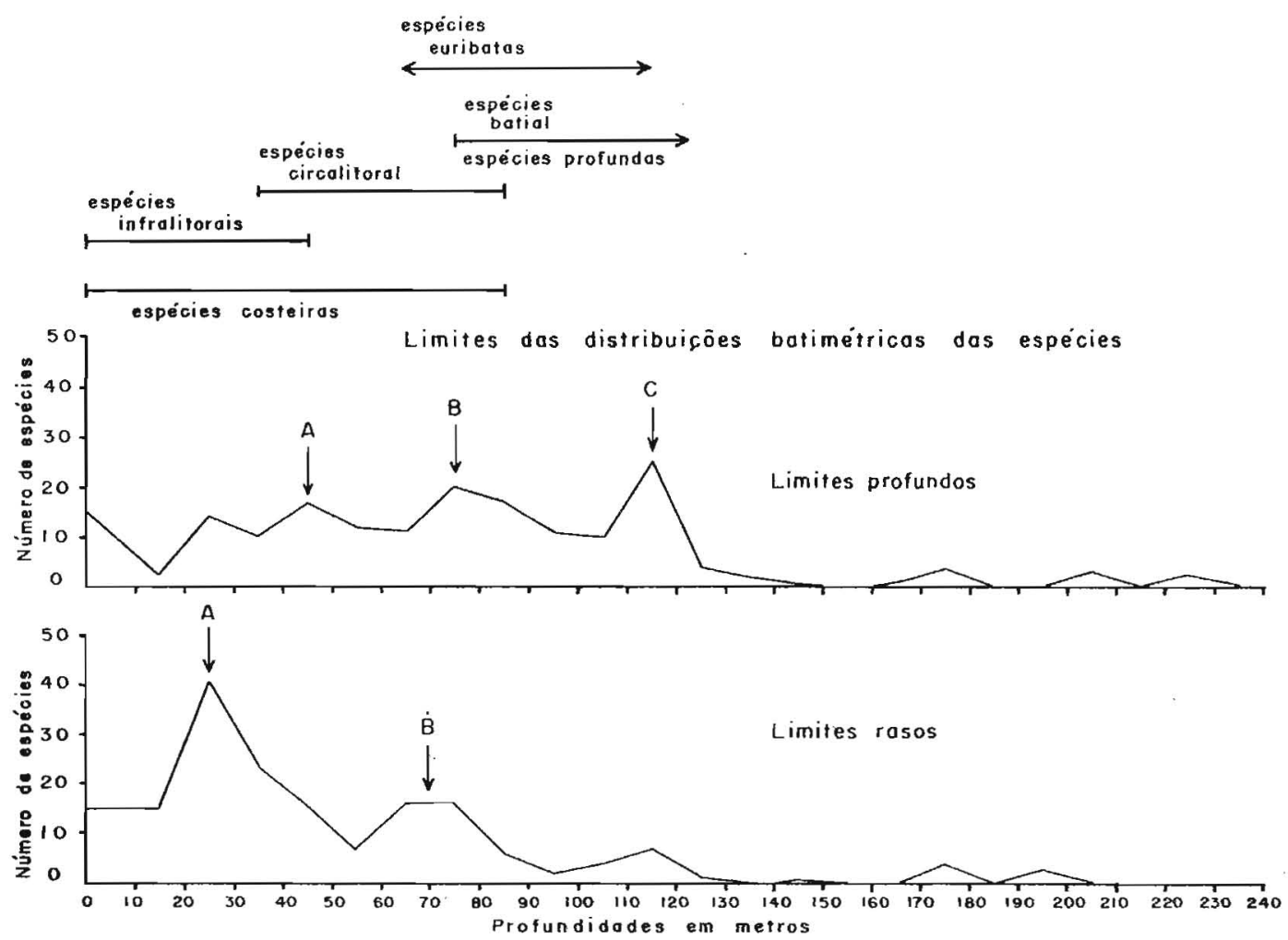

Fig. 10 - Classificacão das espécies em função da distribuição batimétrica. 
quase exclusivamente por espécies vasícolas, outra reunindo espécies vasícolas e arenícolas (estas últimas predominando), uma terceira com espécies vasícolas, arenícolas e cascalhícolas costeiras e euribatadas, uma quarta com espécies cascalhícolas vasícolas e arenícolas, principalmente euribatadas, e a última diferindo das anteriores pelo predomínio de espécies profundas. As áreas ocupadas por estas comunidades apresentam características próprias no que diz respeito aos limites batimétricos, à natureza do substrato, às temperaturas extremas, à salinidade e às comunidades vizinhas.

Por sua vez, cada comunidade possui uma composição faunística peculiar. No estudo desta fauna, foi levada em conta principalmente a frequência das espécies, definida aqui como sendo a relação entre o número de retângulos em que uma dada espécie foi coletada e o número de retângulos em que o povoamento foi encontrado, multiplicado por 10. As espécies de cada povoamento foram classificadas, de acordo com sua frequência, em constantes, comuns e raras. As espécies constantes apresentam frequência igual ou superior a 5 , as espécies comuns possuem frequência entre 2 e 4 e as espécies raras possuem frequência igual a 1. Foram consideradas como características de um determinado povoamento aquelas espécies que são constantes ou comuns no referido povoamento, e raras ou ausentes nos demais povoamentos estudados. Vários autores, como ALLEE \& SCHMITT (1951), THORSON (1957) e PARKER (1964) assinalam a existência de comunidades análogas (caracterizadas por semelhancas faunísticas, florísticas e de organizacão biológica) onde quer que os biótopos se assemelhem. Por este motivo foi realizada uma tentativa de encontrar, nos diversos litorais, e sob os mais diversos climas, comunidades possuindo um grau maior ou menor de afinidade com os povoamentos localizados no litoral equatorial do Brasil.

\subsection{DISTRIBUICEÃO DOS CONJUNTOS FAUNÍSTICOS}

\subsubsection{Espócies Guianenses}

Introdução. - As espécies guianenses formam um conjunto faunístico em que a maioria das espécies é endêmica de uma área 
TABELA $\mid$

DISTRIBUICĀO GEOGRÁFICA GERAL DAS ESPÉCIES GUIANENSES

\begin{tabular}{|c|c|c|c|c|}
\hline \multirow{2}{*}{ Espécies } & \multicolumn{2}{|c|}{ Distribuição geográfica } & \multirow{2}{*}{\multicolumn{2}{|c|}{$\begin{array}{l}\text { Distribuicão } \\
\text { batimétrica }\end{array}$}} \\
\hline & Limite Norte & Limite Sul & & \\
\hline Squilla surinamica & Guianas & Pará & 16 & 32 \\
\hline Squilla lijdingi & Colômbia & Pará & 9 & 182 \\
\hline Discerceis sp. $B$ & Amapá & Pará & 67 & 94 \\
\hline Solenocera geijskesi & Guianas & Maranhão & 25 & 95 \\
\hline Trachypenaeus similis & Luisiana & Pará & 18 & 78 \\
\hline Sicyonia burkenroadi & Carolina do Norte & Amapá & 33 & 177 \\
\hline Leptochela bermudensis & Carolina do Norte & Maranhão & 0 & 1.280 \\
\hline Callianassa latispina & Golfo do México & Pará & 14 & 92 \\
\hline Meticonaxius lemoscastroi & Amapá & Pará & 39 & 85 \\
\hline Dardanus fucosus & Carolina do Norte & Pará & 0 & $124 / 134$ \\
\hline Hepatus scaber & Guianas & Pará & 9 & 92 \\
\hline Calappa nitida & Guianas & Pará & 9 & 109 \\
\hline Pagurus longimanus & Guianas & Amapá & & \\
\hline Clibanarius foresti & Guianas & Pará & 13 & 75 \\
\hline Porcellana sigsbeiana & Massachussetts & Pará & 41 & 393 \\
\hline Hepatus gronovii & Guianas & Pará & 19 & 47 \\
\hline Speocarcinus sp. $C$ & Amapá & Pará & 46 & 75 \\
\hline Portunus rufiremus & Guianas & Pará & 0 & 70 \\
\hline Chasmocarcinus sp. $C$ & Amapá & Pará & 24 & 27 \\
\hline Chasmocarcinus sp. $D$ & Amapá & Pará & 14 & 75 \\
\hline Cycloplax pinnotheroides & Guianas & Pará & 14 & 27 \\
\hline Pinnixa cristata & Carolina do Norte & Amapá & 0 & 23 \\
\hline Uca mordax & Venezuela & Maranhão & & \\
\hline Leiolambrus nitidus & Antilhas & Pará & 0 & 74 \\
\hline Anasimus latus & Carolina do Norte & Amapá & 25 & 161 \\
\hline Mithrax caribbaeus & Antilhas & Pará & 0 & 56 \\
\hline
\end{tabular}


relativamente pequena entre a foz do Orenoco e a foz do Tocantins, com área de reparticão se estendendo para o leste, no máximo até o Maranhão. Algumas destas espécies possuem ainda uma distribuição bem mais ampla, em direcão ao norte, como é o caso das espéoies Porcellana sigsbeiana, Anasimus latus, Pinnixa cristata, Dardanus fucosus, Trachypenaeus similis, Sicyonia burkenroadi e Leptochela bermudensis; estes exemplos não são os únicos e vários outros podem ser tirados dos trabalhos de HOLTHUIS (1959) e GUINOTDUMORTIER (1959-1960). Talvez a distribuição de Pinnixa cristata, espécie bastante difícil de ser coletada, venha a ser ampliada em direcão ao sul, quando forem publicados os resultados dos estudos realizados em outros setores do litoral brasileiro, passando então a fazer parte de um outro conjunto faunístico. Resta ainda o caso de Porcellana sigsbeiana, espécie euribata que ao norte atinge o litoral de Massachussetts. Curiosamente, um dos registros mais profundos desta espécie corresponde ao limite norte da sua área de ocorrência, o que leva a supor que os registros a profundidades menores que 100 metros sejam relativos a ocorrências mais ou menos esporádicas, a espécie sendo principalmente batial; aliás, segundo WILLIAMS (1965) ela ocorre, na Carolina do Norte, junto ao bordo externo da plataforma continental.

De acordo com sua distribuicão batimétrica na área em estudo, as espécies guianenses foram separadas em dois grupos: espécies costeiras e espécies euribatas.

Espécies guianenses costeiras. - Nesta categoria estāo incluídas 18 espécies. Sua distribuicão é mostrada nas Tabelas I e II e na Figura 11. De um modo geral, trata-se de espécies vasícolas, eurialinas $\theta$ estenotermas quentes, seus limites à leste estando aparentemente ligados aos fatores salinidade e tipo de fundo. Com efeito, há uma indicacão de que as ocorrências em locais com salinidade elevada junto ao fundo ou em fundos nāo lamosos poderiam ser consideradas como ocasionais, não representando a "área de abundância" das espécies. Para o largo, o fator batimétrico exerce também sua influência.

Espécies guianenses euribatas. - Nesta categoria estão incluídas apenas 8 espécles. Sua distribuição é mostrada nas Tabelas I e III e na Figura 12. De um modo geral, trata-se de um grupo com franca tendência vasicola, embora não seja possivel esconder sua tolerância com relacão aos tipos de fundo. O caráter eurialino parece menos acentuado que entre as espécies guianenses costeiras; por outro lado, podem ser consideradas como esteno- 


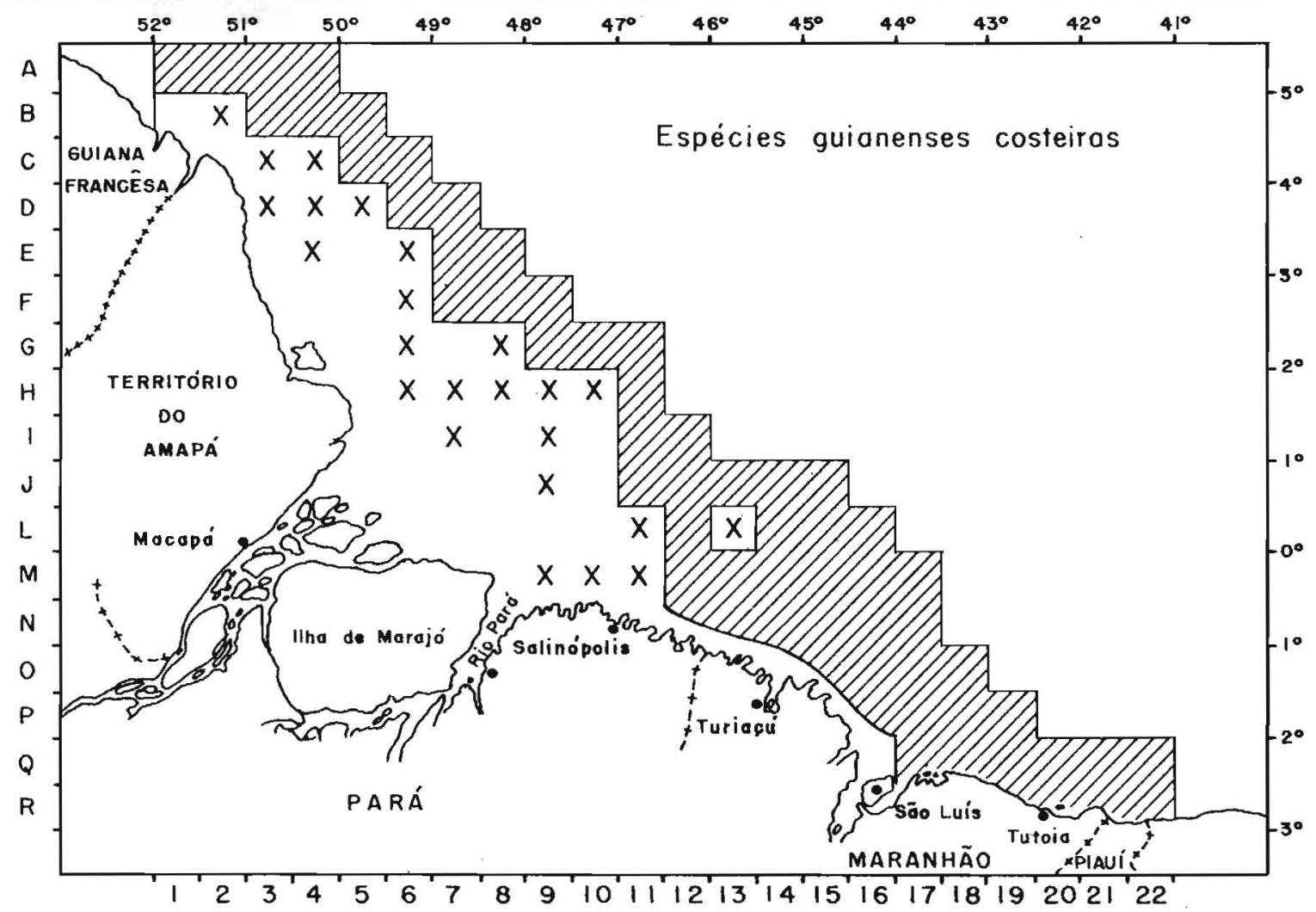

Fig. 11 - Área de ocorrência das espécies guianenses costeiras no litoral Norte do Brasil. 


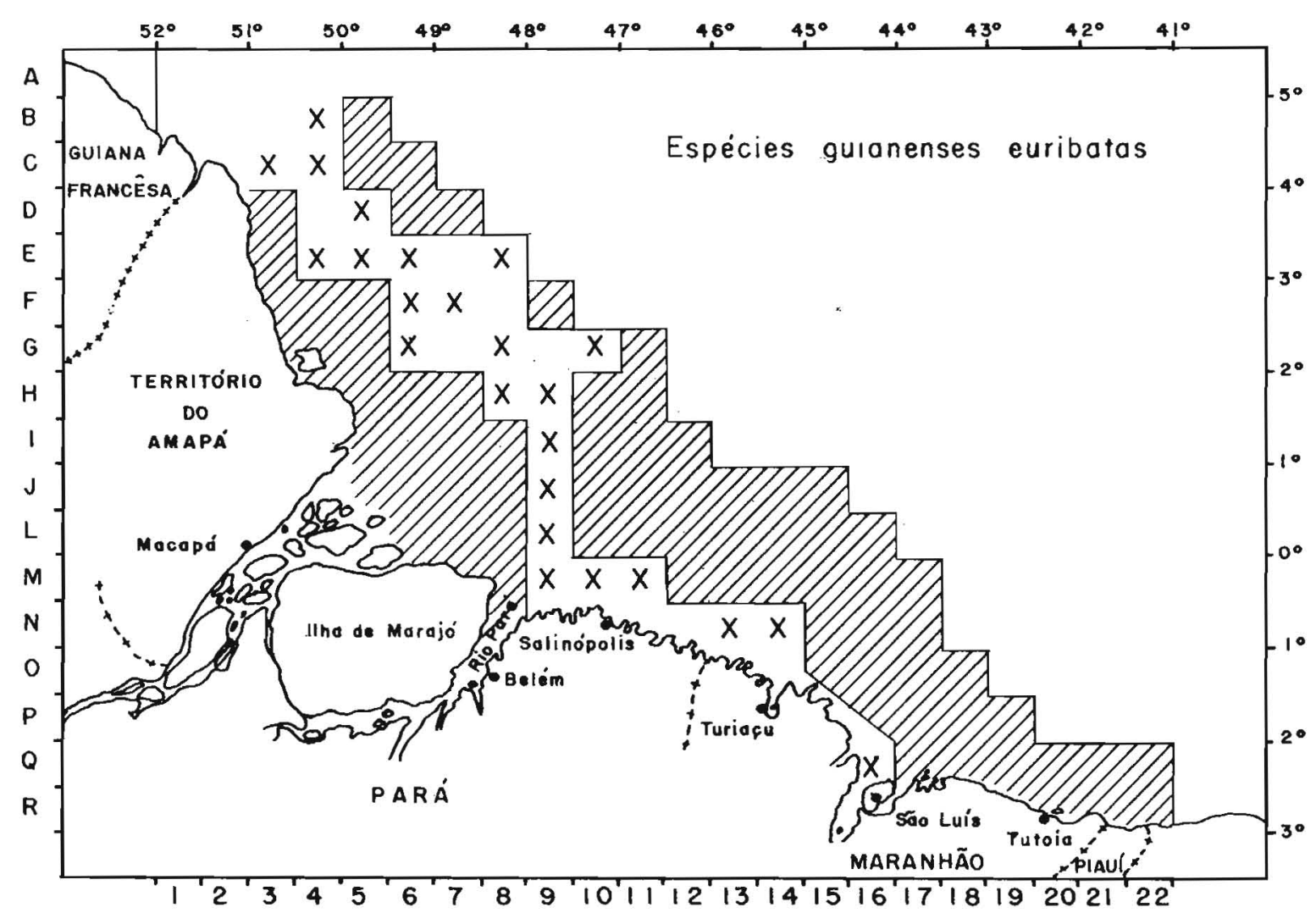

Fig. 12 - Área de ocorrência das espécies guianenses euribatas no litoral Norte do Brasil. 
TABELA \|

DistRIBUIÇÃO ECOLÓGICA DAS ESPÉCIES GUIANENSES EURIBATAS NA ÁREA ESTUDADA

\begin{tabular}{|c|c|c|c|c|c|c|c|c|c|c|c|c|c|c|c|}
\hline \multirow{3}{*}{ Espécies } & \multicolumn{15}{|c|}{ Características do fundo } \\
\hline & \multirow{2}{*}{\multicolumn{2}{|c|}{ Salinidade }} & \multirow{2}{*}{\multicolumn{2}{|c|}{ Temperatura }} & \multirow{2}{*}{\multicolumn{2}{|c|}{ Profundidade }} & \multicolumn{9}{|c|}{ Tipo de fundo } \\
\hline & & & & & & & L & $A / L$ & A & $A / A C$ & $A C$ & $A c / D$ & $D$ & $A / D$ & $?$ \\
\hline Hepatus scaber & 35,677 & 36,484 & 24,42 & 27,66 & 21 & 92 & 8 & - & 6 & - & - & - & - & 1 & 5 \\
\hline Solenocera geijskesi & 35,047 & 36,485 & 24,70 & 27,94 & 25 & 95 & 2 & 2 & 4 & - & - & - & - & - & - \\
\hline Meticonaxius lemoscastroi & 36,146 & 36,484 & 24,42 & 27,37 & 39 & 85 & 1 & - & - & - & - & - & - & 1 & - \\
\hline Callianassa latispina & 35,993 & 35,677 & 25,89 & 27,66 & 44 & 92 & - & - & 2 & - & - & - & - & - & 3 \\
\hline Dardanus fucosus & 35,677 & 36,030 & 25,55 & 27,66 & 45 & 103 & 2 & - & 4 & - & - & - & - & - & 1 \\
\hline Calappa nitida & \multicolumn{2}{|c|}{$\ldots$} & \multirow{2}{*}{\multicolumn{2}{|c|}{$\begin{array}{l}\ldots \\
\ldots\end{array}$}} & 49 & 109 & - & - & - & - & - & - & - & - & 2 \\
\hline Discerceis sp. B & \multicolumn{2}{|c|}{$\ldots$} & & & 67 & 94 & - & - & - & - & - & - & - & 1 & 1 \\
\hline
\end{tabular}


TABELA III

DISTRIBUIÇŌES ECOLÓGICAS DAS ESPÉCIES GUIANENSES COSTEIRAS NA ÁREA ESTUDADA

\begin{tabular}{|c|c|c|c|c|c|c|c|c|c|c|c|c|c|}
\hline \multirow{3}{*}{ Espécies } & \multicolumn{13}{|c|}{ Caracteristicas do fundo } \\
\hline & \multirow{2}{*}{ Salinidade } & \multirow{2}{*}{ Temperatura } & \multirow{2}{*}{\multicolumn{2}{|c|}{ Profundidade }} & \multicolumn{9}{|c|}{ Tipo de fundo } \\
\hline & & & & & L & $A / L$ & A & $\mathrm{A} / \mathrm{AC}$ & Ac & $A c / D$ & $\mathbf{D}$ & A/D & $?$ \\
\hline Cycloplax pimothuroides & $31,115 \quad 34,865$ & $27,22 \quad 28,33$ & 14 & 27 & 6 & - & - & - & - & - & - & - & 5 \\
\hline Squilla surinamica & $31,82036,122$ & $25,26 \quad 28,33$ & 16 & 45 & 6 & - & - & - & - & - & - & - & 4 \\
\hline Hepatus gronovii & $31,820 \quad 35,677$ & $24,46 \quad 28,33$ & 19 & 47 & 2 & - & 3 & - & - & - & - & 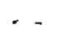 & 1 \\
\hline Pinnixa cristata & 34,115 & 27,22 & \multicolumn{2}{|c|}{23} & 1 & - & - & - & - & - & - & - & - \\
\hline Clibanarius foresti & $34,115 \quad 36,484$ & $25,55 \quad 27,46$ & 13 & 75 & 13 & - & 4 & - & - & 1 & - & - & 5 \\
\hline Chasmocarcinus sp. D & $\ldots$ & $\ldots$ & 14 & 75 & 1 & - & 1 & - & - & - & - & - & 9 \\
\hline Chasmocarcinus sp. C & $34,689 \quad 36,484$ & $27,37 \quad 28,24$ & 24 & 77 & 5 & - & 3 & - & - & - & - & - & 1 \\
\hline Portunus rufiremus & $35,677 \quad 36,122$ & $25,89 \quad 27,66$ & 25 & 70 & 2 & - & 4 & - & - & - & - & - & 2 \\
\hline Anasimus latus & $\ldots$ & $\ldots$ & 25 & 75 & - & - & 1 & - & - & - & - & - & 2 \\
\hline Mithrax caribbaeus & 35,677 & 27,66 & 30 & 56 & - & - & 2 & - & - & - & - & - & - \\
\hline Trachypenaeus similis & $35,968 \quad 36,146$ & $25,26 \quad 27,94$ & 30 & 78 & 2 & 3 & - & - & - & - & - & - & - \\
\hline Leptochela bermudensis & $\ldots$ & $\ldots$ & 43 & 59 & - & - & 1 & - & - & - & - & - & - \\
\hline Squilla lijdingi & $35,677 \quad 36,484$ & $27,37 \quad 27,94$ & 40 & 75 & 2 & 2 & - & - & - & - & - & - & 2 \\
\hline Porcellana sigsbeiana & $35,974 \quad 36,146$ & $26,55 \quad 27,99$ & 41 & 47 & 2 & - & - & - & - & - & - & - & - \\
\hline Leiolambrus nitidos & $\ldots$ & $\ldots$ & 46 & 74 & - & - & - & - & - & - & - & - & 2 \\
\hline Speocarcinus sp. $C$ & 36,146 & 27,94 & 46 & 75 & 2 & - & 1 & - & - & - & - & - & - \\
\hline
\end{tabular}


termas quentes. Seus limites em direcão ao leste parecem mais elásticos que os das espécies guianenses costeiras; elas não ocorrem, no entanto, em áreas costeiras ou de transicão com salinidade elevada.

Conclusōes. - As espécies guianenses formam um conjunto faunístico muito bem caracterizado. Com excecão de Porcellana sigsbeiana, certamente mal colocada, todas são vasícolas (estritas ou tolerantes), estenotermas quentes e eurialinas. Em direcão ao leste, encontram portanto uma barreira dupla: por uma parte, a salinidade constantemente elevada, junto ao fundo, e por outro lado a inexistência de fundos lamosos adequados (a não ser sob a forma de manchas reduzidas e espacadas entre si, na dependência de desembocaduras de pequenos rios costeiros). Em direcão ao largo, existe também uma barreira térmica se sobrepondo ao efeito combinado da salinidade e da natureza do substrato.

\subsubsection{Especies Tropicais Disjuntas}

Introdução. - As espécies tropicais disjuntas são caracterizadas por apresentar uma descontinuidade em sua área de dispersão, geralmente correspondente ao setor entre o. Pará e as pequenas Antilhas. Como a porcão mais profunda da plataforma continental nesta área de descontinuidade é pouco conhecida, as espécies tropicais ocorrendo no Amapá foram separadas em disjuntas e contínuas de acordo com o critério seguinte: foram consideradas como tropicais disjuntas todas as espécies tropicais para as quais há registros de sua ocorrência nas Guianas e que não foram coletas no Amapá à oeste do meridiano $49^{\circ} \mathrm{W}$. Este critério levou a considerar como tropicais disjuntas espécies, que eventualmente poderão vir a ser consideradas tropicais contínuas, e vice-versa.

Para uma melhor compreensão da ecologia de cada espécie, é preferivel considerar separadamente as formas costeiras e as euribatas, levando em conta as preferências manifestadas por condições ligadas à natureza do substrato procurando sempre descobrir qual o fator que causa a interrupcão constatada.

Espécies tropicais disjuntas costeiras. - Nesta categoria estão incluídas 48 espécies, sendo que algumas apresentaram problemas na sua inclusão. Com efeito, embora não haja registros anteriores de ocorrência de certas espécies nas Guianas, os dados de coleta poderiam ser interpretados no sentido de serem "prováveis" tropicais contínuas. Trata-se de espécies como Aepinus 
septemspinosus, Picroceroides tubularis, Coralliope spinipes, Micropanope urinator e Macrocoeloma laevigatum que foram recolhidas ao largo da foz do Amazonas ou do Amapá, o que poderia ser considerado como ocorrência no setor guianense. Além disto, a distribuição batimétrica de $M$. urinator poderia ser interpretada no sentido de considera-la como batial. Mas, como a distribuição destas espécies é pouco conhecida, torna-se difícil separar uma ocorrência normal de uma presença apenas acidental. De qualquer forma, os dados de distribuição estão incluídos nas Tabelas IV e $\mathrm{V}$ e na Fig. 13.

Com ou sem a inclusão das espécies duvidosas, seria possivel subdividir o grupo de acordo com suas preferências por tipo de fundo e por profundidade.

Ebalia cariosa e Aepinus septemspinosus poderiam ser consideradas vasícolas, porém a primeira parece acantonada às porcões menos profundas, enquanto a outra ultrapassa levemente a isóbata de 80 metros, sem no entanto deixar de ocorrer em águas rasas.

Entre as espécies arenícolas, os dados de distribuição batimétrica sugerem a existência de um contigente infralitoral, entre $13 \mathrm{e}$ 42 metros de profundidade, de outro circalitoral, entre 21 e 85 metros de profundidade, ao lado de espécies comuns aos dois niveis, coletadas entre 21 e 75 metros de profundidade (ver Tabela V). Algumas destas espécies, no entanto, foram coletadas apenas em uma ou duas estações, sua distribuição não estando bem conhecida.

Uma divisão semelhante poderia ser realizada entre as espécies cascalhicolas. Em virtude da distribuiçāo batimétrica dos fundos cascalhosos, apenas Microphrys interruptus poderia ser indicada como típica do infralitoral, Macrocoeloma laevigatum e Cirolana parva, como frequentando o infralitoral e o circalitoral; um número mais elevado de espécies estaria restrita ao circalitoral, ocorrendo entre 41 e 85 metros. Deve ficar claro que 2 destas espécies, Micropanope urinator e Periclimenaeus bermudensis são geralmente encontradas fazendo parte da fauna batial; inclusive sua ocorrência na área estudada, entre 75 e 85 metros de profundidade, poderia ser interpretada neste sentido.

O limite oeste da área de ocorrência das espécies tropicais disjuntas no Norte do Brasil é muito variável, havendo muitas espécies que não ultrapassam para o oeste a latitude de São Luís. De um modo geral, seria possível afirmar que a área de ocorrência 


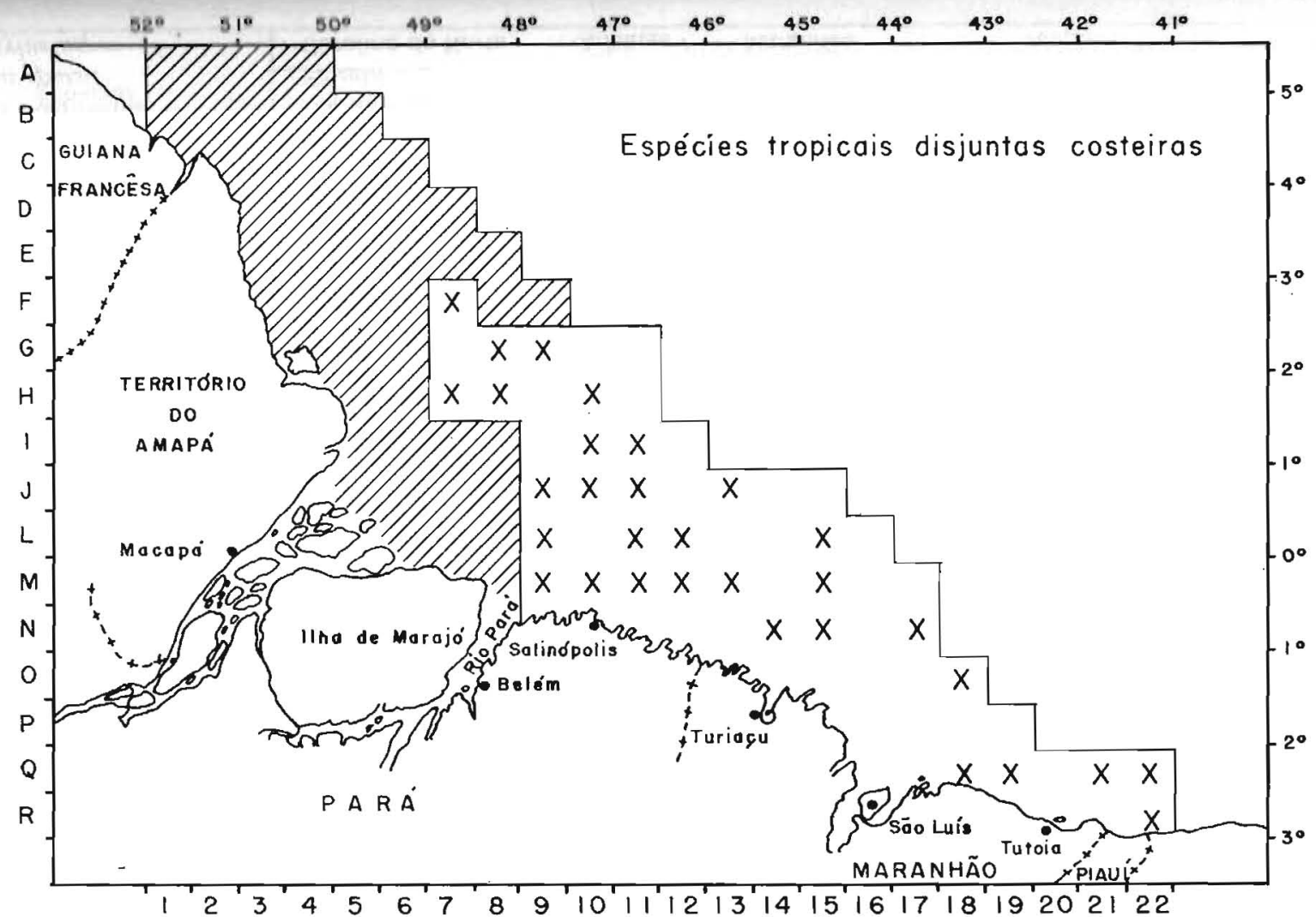

Fig. 13 - Área de ocorrência das espécies tropicais disjuntas costeiras no litoral Norte do Brasil. 
TABELA IV

DISTRIBUIÇÃO GEOGRÁFICA GERAL DAS ESPÉCIES TROPICAIS DISJUNTAS

\begin{tabular}{|c|c|c|c|c|c|c|}
\hline \multirow{3}{*}{ Espécies } & \multicolumn{4}{|c|}{ Distribuigão geográfica } & \multirow{3}{*}{\multicolumn{2}{|c|}{$\begin{array}{l}\text { Distribuigāo } \\
\text { batimétrica }\end{array}$}} \\
\hline & \multicolumn{2}{|c|}{ Área setentrional } & \multicolumn{2}{|c|}{ Area Meridional } & & \\
\hline & Limite Norte & Limite Sul & Limite Norte & Limite Sul & & \\
\hline Pseudosquilla ciliata (1) (2) & Bermudas & Venezuela & Pará & Bahia & 0 & 110 \\
\hline Odontodactylus brevirostris (1) & Antilhas & Venezuela & Maranhão & Espírito Santo & 0 & 309 \\
\hline Gonodactylus lacunatus & Antilhas & Colômbia & Amapá & Rio de Janeiro & 0 & 82 \\
\hline Cirolana parva & Geórgia & Antilhas & Pará & Bahia & 0 & 106 \\
\hline Sicyonia parri & Carolina do Norte & Antilhas & Maranhão & Alagoas & 0 & 83 \\
\hline Periclimenaeus bermudensis & Flórida & Antilhas & Maranhāo & Alagoas & 0 & 75 \\
\hline Periclimenaeus ascidiarum & Flórida & Colômbia & Maranhão & Pernambuco & 0 & 73 \\
\hline Periclimenaeus pearsei & \multicolumn{2}{|c|}{ Flórida } & & & 0 & 52 \\
\hline Periclimenes longicaudatus & Carolina do Norte & Antilhas & Ceará & São Paulo & 0 & 48 \\
\hline Periclimenes americanus & Carolina do Norte & Antilhas & Pará & São Paulo & 0 & 105 \\
\hline Pontonia margarita (3) & Carolina do Norte & Flórida & & & 0 & 60 \\
\hline Anchistioides antiguensis & Flórida & Antilhas & Maranhão & Alagoas & 0 & 83 \\
\hline Alpheus cylindricus & Flórida & Antilhas & & & 0 & 52 \\
\hline Alpheus macrocheles & \multicolumn{2}{|c|}{ Antilhas } & Maranhāo & Pernambuco & 44 & 83 \\
\hline Upogebia omissa & \multicolumn{2}{|c|}{ Panamá } & Maranhāo & São Paulo & 0 & \\
\hline Dardanus venosus & Flórida & Venezuela & Pará & Bahia & 0 & 137 \\
\hline Megalobrachium mortenseni & Antilhas & Panamá & Maranhão & Bahia & 0 & 30 \\
\hline Pachycheles ackleianus & Flórida & Antilhas & Amapá & Bahia & 0 & 82 \\
\hline Hypoconcha sabulosa & Carolina do Norte & Antilhas & Maranhão & Bahia & 0 & 90 \\
\hline Ethusa mascarone americana & Carolina do Norte & Antilhas & Piauí & Bahia & 0 & $85 \% 95$ \\
\hline Osachila antillensis & \multicolumn{2}{|c|}{ Antilhas } & Pará & Alagoas & 28 & 300 \\
\hline Iiacantha intermedia & Carolina do Norte & Venezuela & Maranhão & Bahia & 0 & 37 \\
\hline Iliacantha sparsa & Flórida & Antilhas & Maranhão & Bahia & 23 & 90 \\
\hline Callidactylus asper & Carolina do Norte & Antilhas & Maranhão & Alagoas & 27 & 81 \\
\hline
\end{tabular}




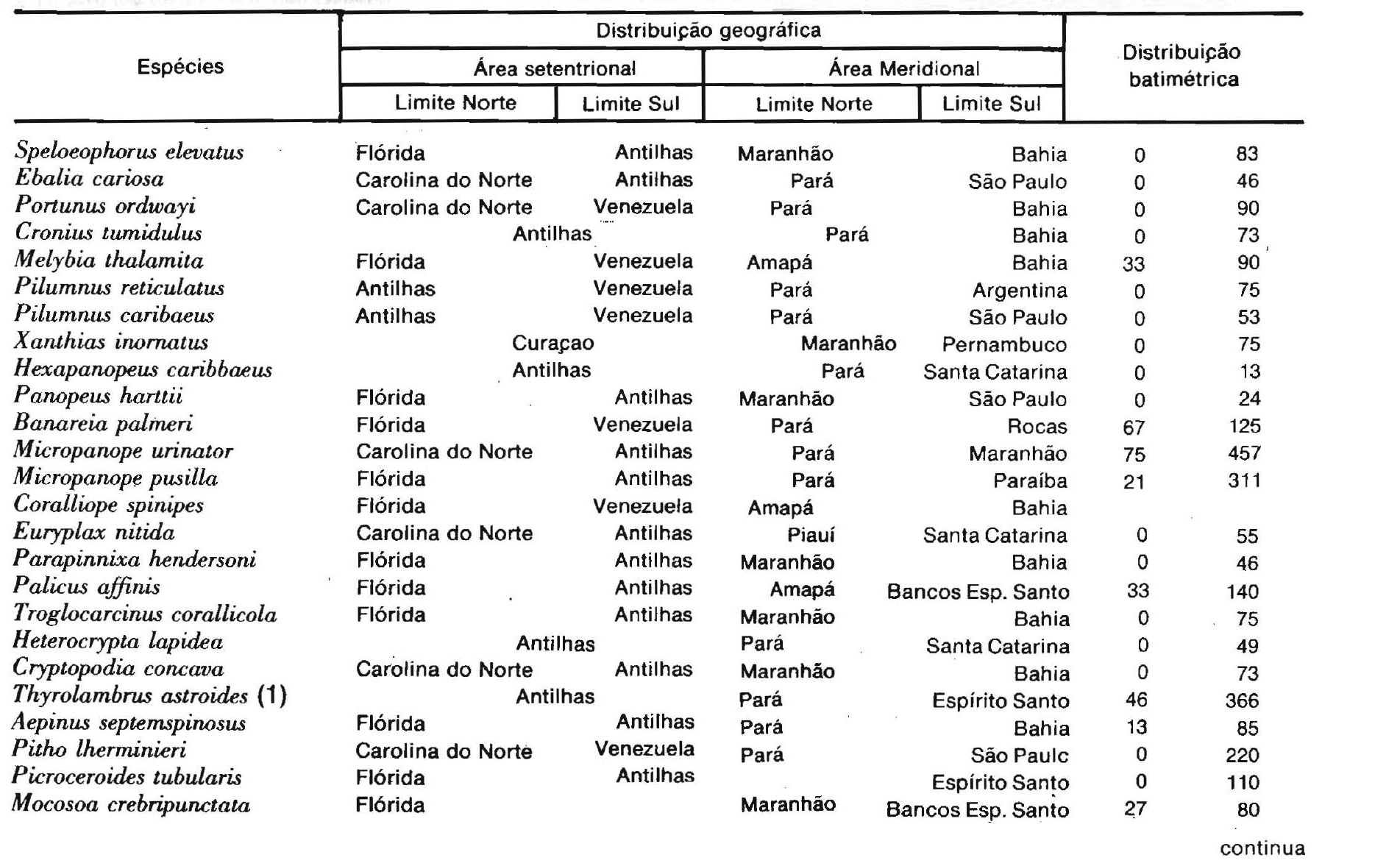




\begin{tabular}{|c|c|c|c|c|c|c|}
\hline \multirow{3}{*}{ Espécies } & \multicolumn{4}{|c|}{ Distribuição geográfica } & \multirow{3}{*}{\multicolumn{2}{|c|}{$\begin{array}{l}\text { Distribuicāo } \\
\text { batimétrica }\end{array}$}} \\
\hline & \multicolumn{2}{|c|}{ Área setentrional } & \multicolumn{2}{|c|}{ Área Meridional } & & \\
\hline & Limite Norte & Limite Sul & Limite Norte & Limite Sul & & \\
\hline & & & $\cdot$ & & & \\
\hline Hemus cristulipes & Flórida & Piauí & Venezuela & Pernambuco & 0 & 69 \\
\hline Mithrax hispidus & Flórida & Pará & Venezuela & São Paulo & 0 & 69 \\
\hline Mithrax forceps & Carolina do Norte & Maranhão & Trinidad & R. de Janeiro & 0 & 154 \\
\hline Microphrys interruptus & Antilhas & & & Alagoas & 0 & 46 \\
\hline Macrocoeloma trispinosum & Carolina do Norte & Piaui & Venezuela & Bahia & 0 & 82 \\
\hline Macrocoeloma laevigatum & Flórida & Pará & Antilhas & Alagoas & 0 & 85 \\
\hline Macrocoeloma eutheca & Flórida & Maranhão & Antilhas & Bancos Esp. Santo & 30 & 214 \\
\hline Macrocoeloma concavum & Antilhas & Mara & & Bahia & 0 & 80 \\
\hline Leptopisa setirostris & Flórida & Maranhão & Antilhas & Alagoas & 0 & 73 \\
\hline
\end{tabular}

1. Ocorre também no Indopacífico

2. Ocorre também na África Ocidental

3. Ocorre também no Pacífico Oriental. 
TABELA V

DISTRIBUIÇĀO ECOLOGGICA DAS ESPÉCIES TROPICAIS DISJUNTAS COSTEIRAS NA ÁREA ESTUDADA

\begin{tabular}{|c|c|c|c|c|c|c|c|c|c|c|c|c|c|}
\hline \multirow{3}{*}{ Espécies } & \multicolumn{13}{|c|}{ Características do fundo } \\
\hline & \multirow{2}{*}{ Salinidade } & \multirow{2}{*}{ Temperatura } & \multirow{2}{*}{\multicolumn{2}{|c|}{ Profundidade }} & \multicolumn{9}{|c|}{ Tipo de fundo } \\
\hline & & & & & L & $A / L$ & A & $\mathrm{A} / \mathrm{AC}$ & $A C$ & $A C / D$ & $\mathrm{D}$ & $A / D$ & $?$ \\
\hline Ebalia cariosa & $30,458 \quad 36,484$ & $27,27 \quad 28,21$ & 23 & 39 & 1 & - & 4 & - & - & - & - & - & - \\
\hline Aepinus septemspinosus & $\ldots$ & $\ldots$ & 29 & 85 & 1 & - & 1 & - & - & - & - & 1 & 1 \\
\hline Pitho Iherminieri & $\ldots$ & $\ldots$ & 23 & 42 & - & - & 5 & - & 1 & - & - & - & - \\
\hline Hexapanopeus caribaeus & \multirow{2}{*}{$\begin{array}{c}\ldots \\
36,537\end{array}$} & \multirow{2}{*}{$\begin{array}{c}\ldots \\
26,27\end{array}$} & \multicolumn{2}{|c|}{13} & - & - & 1 & - & - & - & - & - & - \\
\hline Megalobrachium mortenseni & & & \multicolumn{2}{|c|}{21} & - & - & 1 & - & 1 & - & - & - & - \\
\hline Panopeus hartiii & $36,309 \quad 36,537$ & $26,27 \quad 26,33$ & 21 & 24 & - & - & 1 & - & 1 & - & - & - & - \\
\hline Portunus ordwayi & 34,618 & 28,09 & 21 & 42 & - & - & 3 & - & - & - & - & - & - \\
\hline Periclimenes longicaudatus & 36,814 & 26,79 & 29 & 38 & - & - & 2 & - & - & - & - & - & - \\
\hline Euryplax nitida & $\cdots$ & $\ldots$ & \multicolumn{2}{|c|}{35} & - & - & 1 & - & - & - & - & - & - \\
\hline Iliacantha intermedia & $\ldots$ & $\ldots$ & \multicolumn{2}{|c|}{35} & - & - & 1 & - & - & - & - & - & - \\
\hline Mocosoa crebripunctata & \multirow{2}{*}{$\begin{array}{l}\ldots \\
\ldots\end{array}$} & $\ldots$ & \multicolumn{2}{|c|}{37} & - & - & 1 & - & - & - & - & - & - \\
\hline Hypoconcha sabulosa & & $\ldots$ & & & - & - & 1 & - & - & - & - & - & - \\
\hline Mithrax hispidus & $36,134 \quad 36,304$ & $26,54 \quad 27,08$ & 36 & 51 & - & - & 2 & 1 & - & - & - & - & - \\
\hline Pilumnus caribaeus & 36,212 & 25,72 & 37 & 53 & - & - & 3 & - & - & - & - & - & - \\
\hline Speloeophorus elevatus & $\ldots$ & $\ldots$ & 37 & 83 & - & - & 1 & - & - & 1 & - & - & - \\
\hline Parapinnixa hendersoni & $36,248 \quad 36,818$ & $26,06 \quad 26,79$ & 38 & 46 & - & - & 2 & - & - & - & - & - & - \\
\hline Macrocoeloma eutheca & 36,212 & 25,72 & 40. & 75 & - & - & 2 & - & 1 & 2 & - & - & - \\
\hline Periclimenaeus ascidiarum & 36,304 & 27,08 & & & - & - & 1 & - & - & - & - & - & - \\
\hline Pontonia margarita & 36,134 & 26,54 & & & - & - & - & 1 & - & - & - & - & - \\
\hline Macrocoeloma trispinosum & 36,212 & 25,72 & & & - & - & 1 & - & - & - & - & - & - \\
\hline Picroceroides tubularis & $\ldots$ & $\ldots$ & 63 & 85 & - & - & - & - & - & 1 & 1 & 2 & - \\
\hline Coralliope spinipes & $\cdots$ & $\ldots$ & 75 & 82 & - & - & - & - & - & 1 & - & 1 & - \\
\hline
\end{tabular}




\begin{tabular}{|c|c|c|c|c|c|c|c|c|c|c|c|c|c|}
\hline \multirow{3}{*}{ Espécies } & \multicolumn{12}{|c|}{ Características do fundo } & \multirow[t]{2}{*}{ * } \\
\hline & \multirow{2}{*}{ Salinidade } & \multirow{2}{*}{ Temperatura } & \multirow{2}{*}{\multicolumn{2}{|c|}{ Profundidade }} & \multicolumn{8}{|c|}{ Tipo de fundo } & \\
\hline & & & & & L & $A / L$ & A & $A / A C$ & $A C$ & $A c / D$ & D & $A / D$ & $?$ \\
\hline E. mascarone americana & 36,537 & 26,27 & 21 & $69^{\circ}$ & - & - & 1 & - & 1 & 2 & - & - & - \\
\hline Micropanope pusilla & $36,212 \quad 36,537$ & $25,72 \quad 26,33$ & 21 & 70 & - & - & 5 & - & 1 & 1 & - & $\cdot$ & - \\
\hline Sicyonia parri & 36,537 & 26,27 & 21 & 83 & - & - & 1 & - & 1 & 1 & - & - & - \\
\hline Gonodactylus lacunatus & $36,309 \quad 36,537$ & $26,27 \quad 26,33$ & 21 & 82 & $\cdot$ & - & 1 & - & 2 & 2 & - & 1 & r \\
\hline Pilumnus reticulatus & $\ldots$ & $\ldots$ & 23 & 75 & - & - & 3 & - & - & - & 1 & - & - \\
\hline Mithrax forceps & $36,304 \quad 36,309$ & $26,33 \quad 27,08$ & 24 & 51 & - & - & 4 & - & - & - & - & - & - \\
\hline Leptopise setirostris & 36,134 & 26,54 & 35 & 44 & - & - & 1 & 1 & - & - & - & - & 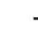 \\
\hline Heterocrypta lapidea & $\ldots$ & $\ldots$ & 35 & 49 & - & - & 2 & - & - & - & - & - & 1 \\
\hline Cryptopodia concava & $36,168 \quad 36,248$ & $25,95 \quad 26,06$ & 35 & 52 & - & - & 3 & - & - & - & - & - & 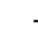 \\
\hline Microphrys interruptus & $\ldots$ & $\ldots$ & 2 & & - & - & - & - & 1 & - & - & - & . \\
\hline Cirolana parva & 36,537 & 26,27 & 21 & 60 & - & - & - & - & 1 & - & - & - & 2 \\
\hline Cronius tumidulus & $\ldots$ & $\ldots$ & 41 & 43 & - & - & - & - & 1 & - & - & - & 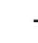 \\
\hline Periclimenaeus pearsei & 36,092 & 26,67 & 5 & & - & - & - & - & - & 1 & - & - & . \\
\hline Alpheus cylindricus & 36,092 & 26,27 & 5 & & - & : & - & - & 1 & - & - & - & 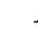 \\
\hline Macrocoeloma concavum & 36,092 & 26,27 & 52 & 63 & - & - & - & - & - & 2 & - & - & - \\
\hline Thyrolambrus astroides & 36,038 & 26,32 & 63 & 85 & - & - & - & - & 1 & 1 & - & - & 1 \\
\hline Pachycheles ackleianus & $\ldots$ & $\ldots$ & 67 & 82 & - & - & - & - & - & 1 & 1 & 2 & r \\
\hline Iliacantha sparsa & $\ldots$ & $\ldots$ & 6 & & - & - & - & - & - & 1 & - & - & . \\
\hline Callidactylus asper & $\ldots$ & $\ldots$ & 6 & & - & - & - & - & - & 1 & - & - & - \\
\hline Xanthias inornatus & $\ldots$ & $\ldots$ & 6 & & - & - & - & - & - & 1 & - & - & . \\
\hline Hemus cristulipes & $\ldots$ & $\ldots$ & 6 & & - & - & - & - & - & 1 & - & - & r \\
\hline Troglocarcinus corallicola & $\ldots$ & $\ldots$ & 7 & & - & - & - & - & - & 1 & - & - & r \\
\hline Periclimenneus bermudensis & $\ldots$ & $\ldots$ & 7 & & - & - & - & $\because$ & - & 1 & - & - & . \\
\hline Micropanope urinalor & $\ldots$ & $\ldots$ & 75 & 85 & - & - & - & - & - & 1 & 1 & - & 1 \\
\hline Macrocoeloma laerigatum & 36,537 & 26,27 & 21 & 85 & - & - & - & - & 1 & - & - & - & 1 \\
\hline
\end{tabular}


destas espécies tropicais disjuntas costeiras corresponde aos fundos arenosos ou organogênicos banhados por água de temperatura e salinidade constantes ou periodicamente elevadas; elas seriam geralmente estenoalinas e estenotermas quentes, embora em grau variável, assim como «não vasícolas". Aparentemente o fator mais importante determinando o limite oeste seria a salinidade, vindo a seguir a temperatura e a natureza do substrato.

Espécies tropicais disjuntas euribatas. - Estas espécies, em número de 10 , deixam uma certa dúvida quanto á sua classificacão biogeográfica. Com excecão de 2 delas, todas podem ainda ser encontradas entre as longitudes de $47-49^{\circ} \mathrm{W}$. Do ponto de vista da zonação, 3 espécies podem ser consideradas comuns ao infra e ao circalitoral, assim como ao batial, enquanto as espécies restantes não ocorreriam no infralitoral. Todas as espécies apresentam uma tendência cascalhícola ou arenícola, são estenotermas quentes e estenoalinas. O caráter estenoterma quente está bem caracterizado pelo que se conhece da distribuição geográfica: apenas Periclimenes americanus ultrapassa para o norte o Sul da Flórida ou para o sul o Espírito Santo (Tabelas IV e VI e Fig. 14). A existência de uma barreira térmica em profundidades compatíveis com a ocorrência destas espécies poderia explicar a sua distribuicão tropical disjunta, desde que nas áreas de menor profundidade, em que a temperatura é favorável, a natureza do substrato e a salinidade da água, no litoral da Província Guianense, impedem sua propagacão.

Conclusōes. - Consideradas em conjunto as espécies tropicais disjuntas habitam no Norte do Brasil área bem individualizada, que pode ser considerada complementar da área ocupada pelas espécies guianenses. Em virtude das exigênciàs ecológicas das espécies, quase todas arenícolas ou cascalhícolas, assim como estenoalinas e estenotermas quentes, sua área de distribuição está condicionada pela presenç de fundos arenosos ou organogênicos banhados por água que possua salinidade constante ou periodicamente superior a $36 \%$ o. A isoalina correspondente a este valor e a isoterma de $25^{\circ} \mathrm{C}$ junto ao fundo obtidas pela expedição N. NE I se assemelham bastante ao limite oeste da área habitada pelas espécies tropicais disjuntas (vide Fig. 8, comparando-a com as Figuras 13 e 14).

\subsubsection{Espécies Batiais}

Nesta categoria estão incluídas 46 espécies. Algumas apresentaram problemas em sua inclusão. Trata-se de espécies que 


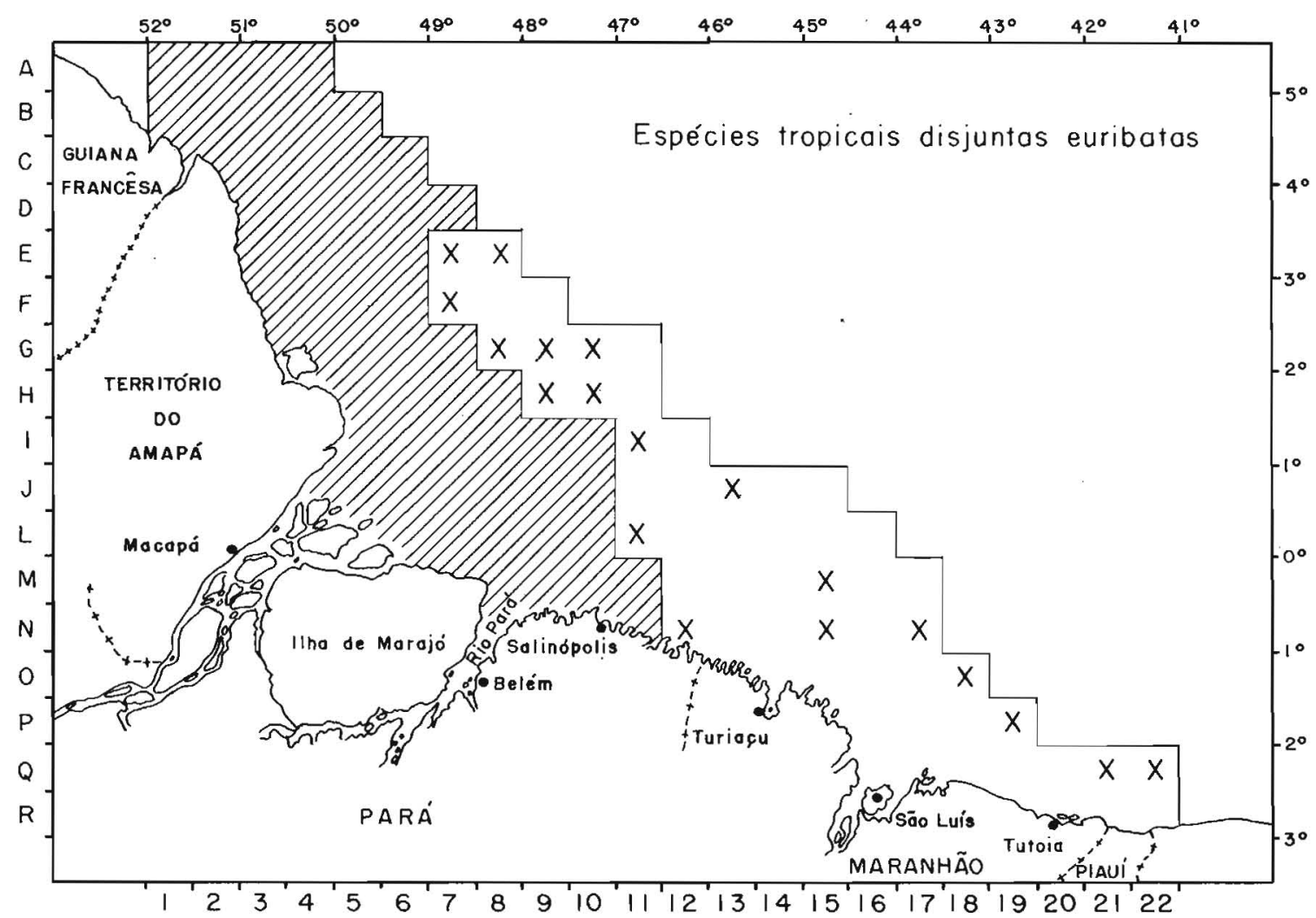

Fig. 14 - Área de ocorrência das espécies tropicais disjuntas euribatas no litoral Norte do Brasil. 
DISTRIBUIÇĀO ECOLÓGICA DAS ESPÉCIES TROPICAIS DISJUNTAS EURIBATAS NA ÁREA ESTUDADA

\begin{tabular}{|c|c|c|c|c|c|c|c|c|c|c|c|c|c|c|c|}
\hline \multirow{3}{*}{ Espécies } & \multicolumn{15}{|c|}{ Características do fundo } \\
\hline & \multirow{2}{*}{\multicolumn{2}{|c|}{ Salinidade }} & \multirow{2}{*}{\multicolumn{2}{|c|}{ Temperatura }} & \multirow{2}{*}{\multicolumn{2}{|c|}{ Profundidade }} & \multicolumn{9}{|c|}{ Tipo de fundo } \\
\hline & & & & & & & L & $A / L$ & A & $\mathrm{A} / \mathrm{AC}$ & $A c$ & $\mathrm{Ac} / \mathrm{D}$ & D & $A / D$ & $?$ \\
\hline Osachila antillensis & \multicolumn{2}{|c|}{36,256} & \multicolumn{2}{|c|}{27,34} & 28 & 125 & - & - & 1 & - & - & - & - & - & 3 \\
\hline Dardanus venosus & 36,084 & 36,212 & 25,72 & 26,54 & 35 & 100 & - & - & 3 & 2 & - & 1 & - & - & - \\
\hline Periclimenes americanus & 36,008 & 36,313 & 21,05 & 26,68 & 36 & 105 & - & - & 1 & - & 1 & 3 & 1 & - & - \\
\hline Alpheus macrocheles & 36,038 & 36,134 & 26,27 & 26,54 & 44 & 90 & - & - & - & - & 3 & 3 & 1 & 2 & - \\
\hline Palicus affinis & 35,968 & 36,146 & 24,42 & 26,54 & 44 & 125 & - & - & 1 & 1 & - & 4 & 2 & 1 & 1 \\
\hline Pseudosquilla ciliata & 36,038 & 36,313 & $\begin{array}{l}24,42 \\
21,05\end{array}$ & $\begin{array}{l}20,04 \\
26,32\end{array}$ & 53 & 93 & - & - & 1 & - & 2 & 3 & 3 & 1 & - \\
\hline Melybia thalamita & \multicolumn{2}{|c|}{$\ldots$} & \multicolumn{2}{|c|}{$\ldots$} & 63 & 118 & - & - & - & - & - & 2 & 2 & 1 & 2 \\
\hline Banareia palmeri & \multirow{2}{*}{\multicolumn{2}{|c|}{$\begin{array}{c}\ldots \\
36,313\end{array}$}} & \multirow{2}{*}{\multicolumn{2}{|c|}{$\begin{array}{c}\ldots \\
21.05\end{array}$}} & 67 & 125 & - & - & - & - & - & 1 & 1 & - & 1 \\
\hline Odontodactylus brevirostris & & & & & \multicolumn{2}{|c|}{80} & - & - & - & - & $i$ & - & - & - & - \\
\hline Anchistioides antiguensis & \multicolumn{2}{|c|}{$\ldots$} & \multicolumn{2}{|c|}{$\ldots$} & \multicolumn{2}{|c|}{83} & - & - & - & - & - & 1 & - & - & - \\
\hline
\end{tabular}


foram coletadas entre as profundidades de 75-80 metros, cuja distribuição se estende, no entanto, até mais além desta profundidade. Estas espécies poderão vir a ser consideradas euribatas, com a intensificação das coletas. Trata-se de Trachycaris restricta, Collodes armatus, Parthenope agona, P. fratercula, Palicus sp. B, Actaea acantha, Ranilia constricta, Calastacus spinosus, Callianassidae n. det., Paranthuridae sp., Sphaeromatidae sp., Discerceis sp. e Cerceis p. de carinata. Os dados sobre distribuição das espécies estão incluidos nas Tabelas VII e VIII e Fig. 15. Por outro lado, certamente há espécies batiais incluídas nos demais conjuntos faunísticos.

São numerosas as coletas destas espécies batiais para as quais não se dispõe de informações precisas sobre a natureza do substrato. Nestas condições, torna-se precária qualquer consideracão à respeito. As informações disponiveis apenas permitem considerar estas espécies como "não vasícolas", sendo de se prever que elas se dividam mais ou menos igualmente entre as arenícolas e as cascalhícolas.

De um modo geral, é possível afirmar que estas espécies batiais vivem apenas em fundos banhados por água de temperatura "subtropical", isto é, abaixo de $24^{\circ} \mathrm{C}$. Esta afirmacão é baseada principalmente no que se conhece sobre a distribuicão geral das espécies. Assim, entre outras, Lipkebe holthuisi, Euprognatha acuta, Anasimus fugax, Palicus sicus, Frevillea hirsuta, Nanoplax xanthiformis, Clythrocerus granulatus, $C$. perpusillus, Fanilia constricta, Munida simplex e $M$. irrasa ocorrem na plataforma continental, porém em águas não tropicais do Sudeste Brasileiro. Por outro lado, todas as espécies aqui consideradas como batiais ocorrem neste tipo de ambiente nas Antilhas, no Golfo do México, ou em água subtropicais da plataforma continental do Leste dos Estados Unidos. Fazem exceção apenas algumas espécies cuja distribuição não está ainda bem conhecida.

É de se lembrar que a ocorrência na plataforma continental destas espécies consideradas aqui como batiais correspondem a um esfriamento da água associada a fenômenos de ressurgência, como ocorre no Amapá e no Pará, ou à própria situacão subtropical da área, como se verifica no Sudeste do Brasil e no Leste dos Estados Unidos. As espécies com este tipo de distribuicão são denominadas "anfisubtropicais" e constituem um exemplo daquilo que PÉRÈS (1961) denomina submersão tropical.

Há uma certa superposição entre a área ocupada pelas espécies batiais e pelas dos grupos vizinhos. Isto se dá não somente 


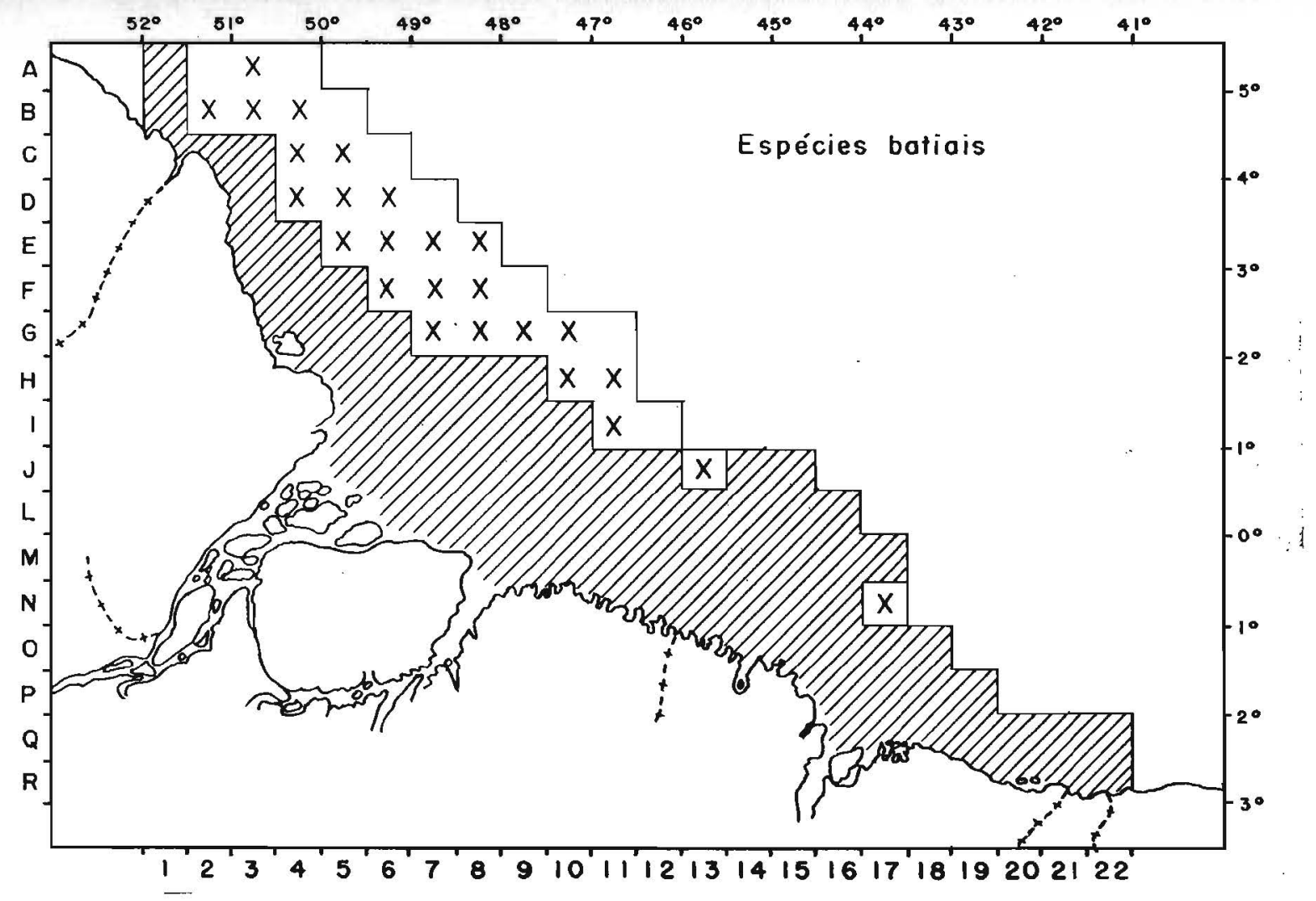

Fig. 15 - Área de ocorrência das espécies batiais no litoral Norte do Brasil. 


\begin{tabular}{|l|l|c|}
\hline \multirow{2}{*}{ Espécies } & \multicolumn{2}{|c|}{ Distribuição geográfica } \\
\cline { 2 - 3 } & Limite Norte & Limite Sul \\
\hline
\end{tabular}

Distribuição

Batimétrica

Gonodactylus torus

Paranthuridae sp.

Cirolanidae sp.

Cirolana minuta

Sphaeromatidae sp.

Discerceis sp.

Cerceis p. de carinata

Astacilla sp. $B$

Cleantis planicauda

Lipkebe holthuisi

Trachycaris restricta

Calastacus spinosus

Calastacus angulatus

Axiopsis p. de spinulicauda

Meticonaxius minutus

Iridopagurus iris

Pylopagurus holthuisi

Pylopagurus discoidalis

Uroptychus minutus

Munidopsis barbarae

Munida irrasa

Munida simplex

Pachycheles rugimanus

Ranilia constricta

Cymonomus quadratus

Clythrocerus stimpsoni

Clythrocerus granulatus

Clythrocerus perpusillus

Pilumnus diomedeae

Actaen acantha

Micropanope sculptipes

Nanoplax xanthiformis

Frevillea hirsuta

Parapinnixa bouvieri

Palicus sicus

Palicus dentatus

Palicus sp. B

Parthenope agona

Parthenope pourtalesii

Parthenope fratercula

Arachnopsis filipes

Euprognatha acuta

Collodes armatus

Collodes trispinosus

Anasimus fugax

Carolina do Norte
Amapá
Amapá
Antilhas
Amapá
Amapá
Amapá
Pará
Geórgia
Golfo do México
Flórida
Amapá
Amapá
Amapá
Amapá

Flórida

Antilhas

Carolina do Norte

Trinidad

Flórida

Carolina do Norte

Antilhas

Carolina do Norte

Flórida

Flórida

Flórida

Carolina do Norte

Carolina do Norte

Antilhas

Flórida

Carolina do Sul

Carolina do Norte

Carolina do Norte

Carolina do Sul

Flórida

Golfo do México

Amapá

Carolina do Norte

New Jersey

Carolina do Norte

Carolina do Norte

Massachussetts

Antilhas

Carolina do Norte

Antilhas
R. Gr. do Norte

Espírito Santo

...

Amapá

Maranhão

Pará

...

...

Paraíba

Espírito Santo

Espírito Santo

...

$\cdots$

$\cdots$

Amapá

Bahia

Pará

Amapá

Amapá

Sáo Paulo

Espírito Santo

Amapá

Rio de Janeiro

Amapá

Amapá

São Paulo

São Paulo

Maranhăo

F. de Noronha

Amapá

Rio de Janeiro

Rio Gr. do Sul

Amapá

Rio de Janeiro

Pará

...

Bahia

Ceará

Maranhão

Bancos R.G.Norte

São Paulo

Maranhāo

Amapá

Rio de Janeiro
10

364

85

204

118

$\begin{array}{rr}113 & 118 \\ 75 & 100\end{array}$

$69 / 77 \quad 85$

$78 / 80 \quad 87 / 88$

50

0

56

25

75 .

108

172

89

116

$15 / 18$

55

134

113

55

53

0

$20 / 30$

184

108

126

27

49

18

27

14

100

0

100

27

78

46

73

7

27

102

104

119

100

94

118

...

91

256

$84 / 92$

959

146

183

475

238

144

$114 / 115$

929

183

370

172

336

125

185

333

89

400

139

111

391

120

201

238

708

150

145

$64 \quad 210$ 
TABELA VIII

DISTRIBUIÇĀO ECOLÓGICA DAS ESPÉCIES BATIAIS NA ÁREA ESTUDADA

\begin{tabular}{|c|c|c|c|c|c|c|c|c|c|c|c|c|c|}
\hline \multirow{3}{*}{ Espécies } & \multicolumn{13}{|c|}{ Características do fundo } \\
\hline & \multirow{2}{*}{ Salinidade } & \multirow{2}{*}{ Temperatura } & \multirow{2}{*}{\multicolumn{2}{|c|}{ Profundidade }} & \multicolumn{9}{|c|}{ Tipo de fundo } \\
\hline & & & & & $\mathrm{L}$. & $A / L$ & A & $A / A C$ & $A C$ & $A c / D$ & D & $A / D$ & $?$ \\
\hline Gonodactylus torus & $\ldots$ & $\ldots$ & 93 & 125 & - & - & - & - & - & 1 & 1 & - & 1 \\
\hline Paranthuridae sp. & 36,146 & 24,42 & \multicolumn{2}{|c|}{85} & - & - & - & - & - & - & - & 1 & - \\
\hline Cirolanidae sp. & $\ldots$ & $\ldots$ & 194 & 204 & - & - & - & - & - & - & - & - & 1 \\
\hline Cirolana minuta & $\ldots$ & $\ldots$ & 113 & 118 & - & - & - & - & - & - & - & - & 1 \\
\hline Sphaeromatidae sp. & 35,936 & 25,28 & 75 & 100 & - & - & - & - & - & 1 & 1 & - & - \\
\hline Discerceis sp. & $\ldots$ & $\ldots$ & $77^{\circ}$ & 85 & - & - & - & - & - & - & - & 1 & 1 \\
\hline Cerceis p. de carinata & $\ldots$ & $\ldots$ & 78 & 88 & - & - & - & - & - & - & - & - & 2 \\
\hline Astacilla sp. A & $\ldots$ & $\ldots$ & \multicolumn{2}{|c|}{103} & - & - & - & - & - & - & - & 1 & - \\
\hline Cleantis planicauda & $\ldots$ & $\ldots$ & 102 & 104 & - & - & - & - & - & - & - & - & 1 \\
\hline Lipkebe holthuisi & $\ldots$ & $\ldots$ & 84 & 98 & - & - & - & 1 & - & - & - & - & 1 \\
\hline Trachycharis restricta & $\ldots$ & $\ldots$ & 85 & 94 & - & - & - & - & - & - & - & - & 2 \\
\hline Callianassidae $n$. det. & 36,146 & 24,42 & 75 & 85 & - & - & 1 & - & - & - & - & 1 & - \\
\hline Ctenocheles sp. & $\ldots$ & $\ldots$ & 194 & 204 & - & - & - & - & - & - & - & - & 1 \\
\hline Calastacus spinosus & $\ldots$ & $\ldots$ & 75 & 94 & - & - & 1 & - & - & - & - & - & 2 \\
\hline Calastacus angulatus & $\ldots$ & $\ldots$ & 108 & 118 & - & - & - & - & - & - & - & - & 1 \\
\hline Axiopsis cf. spinulicauda & $\ldots$ & $\because$ & \multicolumn{2}{|c|}{172} & - & - & - & - & - & - & - & - & 1 \\
\hline Meticonaxius minutus & $\ldots$ & $\cdots$ & 89 & 91 & - & - & - & - & - & - & - & 1 & 1 \\
\hline Iridopagurus iris & $\ldots$ & $\ldots$ & \multicolumn{2}{|c|}{116} & - & - & - & - & - & - & - & 1 & - \\
\hline Pylopagurus holthuisi & $\ldots$ & $\ldots$ & 84 & 92 & - & - & - & - & - & - & - & - & 1 \\
\hline Pylopagurus discoidalis & 36,047 & 24,70 & 95 & 224 & - & - & 1 & - & - & - & - & 1 & 5 \\
\hline Pylochelidae n. det. & $\ldots$ & $\ldots$ & 194 & 204 & - & - & - & - & - & - & - & - & 1 \\
\hline Uroptychus minutus & $\ldots$ & $\ldots$ & \multicolumn{2}{|c|}{146} & - & - & - & - & - & - & - & - & 1 \\
\hline Munidopsis barbarae & $\ldots$ & $\ldots$ & 113 & 118 & - & - & - & - & - & - & - & $\cdot$ & 1 \\
\hline
\end{tabular}




\begin{tabular}{|c|c|c|c|c|c|c|c|c|c|c|c|c|c|}
\hline \multirow{3}{*}{ Espécies } & \multicolumn{13}{|c|}{ Caracteristicas do fundo } \\
\hline & \multirow{2}{*}{ Salinidade } & \multirow{2}{*}{ Temperatura } & \multirow{2}{*}{\multicolumn{2}{|c|}{ Profundidade }} & \multicolumn{9}{|c|}{ Tipo de fundo } \\
\hline & & & & & $\mathbf{L}$ & A/L & A & A/AC & Ac & $A c / D$ & $\mathbf{D}$ & A/D & $?$ \\
\hline Munida irrasa & $\cdots$ & $\ldots$ & 84 & 170 & - & - & - & - & - & - & - & - & 2 \\
\hline Munida simplex & $\ldots$ & $\ldots$ & 80 & 125 & - & - & - & - & 1 & 2 & 1 & 1 & 7 \\
\hline Pachycheles rugimanus & $\ldots$ & $\ldots$ & 113 & 118 & - & - . & - & - & - & - & - & - & 1 \\
\hline Ranilia constricta & $\cdots$ & $\ldots$ & 72 & 115 & - & - & - & - & - & - & - & - & 2 \\
\hline Cymonomus quadratus & $\ldots$ & $\ldots$ & 194 & 204 & - & - & - & - & - & - & - & - & 1 \\
\hline Clythrocerus perpusillus & $\ldots$ & $\ldots$ & \multicolumn{2}{|c|}{172} & - & - & - & - & - & - & - & - & 1 \\
\hline Clythrocerus granulatus & $\ldots$ & $\ldots$ & \multicolumn{2}{|c|}{$17 \overline{2}$} & - & - & - & - & - & - & - & - & 1 \\
\hline Clythrocerus stimpsoni & $\ldots$ & $\ldots$ & 108 & 118 & - & $\because$ & - & - & - & - & - & - & 1 \\
\hline Pilumnus diomedeae & 36,313 & 21,05 & 80 & 120 & - & - & - & - & 1 & - & 1 & - & - \\
\hline Actaea acantha & $\ldots$ & $\ldots$ & 75 & 120 & - & - & - & - & 1 & - & 3 & - & 5 \\
\hline Micropanope sculptipes & $\ldots$ & $\ldots$ & 113 & 118 & - & - & - & - & - & - & $\sim$ & - & 1 \\
\hline Nanoplax xanthiformis & $\ldots$ & $\ldots$ & 92 & 120 & - & - & - & - & - & - & - & - & 3 \\
\hline Frevillea hirsuta & $\ldots$ & $\ldots$ & \multicolumn{2}{|c|}{174} & - & - & - & - & - & - & - & - & 1 \\
\hline Parapinnixa bouvieri & $\ldots$ & $\ldots$ & \multicolumn{2}{|c|}{82} & - & - & - & - & - & - & - & 1 & - \\
\hline Palicus sp. $B$ & $\ldots$ & $\ldots$ & 78 & 111 & - & - & - & - & - & - & - & - & 2 \\
\hline Palicus dentatus & \multicolumn{2}{|l|}{$\ldots$} & 85 & 105 & - & - & - & - & - & - & 1 & 1 & 3 \\
\hline Palicus sicus & $\ldots$ & $\ldots$ & 122 & 132 & - & - & - & - & - & - & - & - & 1 \\
\hline Parthenope fratercula & $35,968 \quad 36,313$ & $21,05 \quad 26,49$ & 77 & 118 & - & - & 3 & - & 1 & - & - & 2 & 5 \\
\hline Parthenope pourtalesii & $\ldots$ & $\ldots$ & 84 & 120 & - & - & - & - & - & - & 1 & - & 2 \\
\hline Parthenope agona & 35,938 & 26,63 & 76 & 90 & - & - & - & - & - & - & - & 1 & 2 \\
\hline Anasimus fugax & $\ldots$ & $\ldots$ & 108 & 118 & - & - & - & - & - & - & - & - & 1 \\
\hline Collodes trispinosus & $\ldots$ & $\ldots$ & \multicolumn{2}{|c|}{120} & - & - & - & - & - & - & 1 & - & - \\
\hline Collodes armatus & $\ldots$ & $\ldots$ & 75 & 92 & - & - & - & - & - & 1 & - & - & 1 \\
\hline Euprognatha acuta & $\ldots$ & $\ldots$ & \multicolumn{2}{|c|}{105} & - & - & - & - & - & - & 1 & - & - \\
\hline Arachnopsis filipes & $\ldots$ & $\ldots$ & 111 & 132 & - & - & 1 & - & - & - & - & - & 1 \\
\hline
\end{tabular}


como decorrência do inevitável agrupamento de estacões realizadas à profundidades muito diferentes, porém localizadas num mesmo retângulo, como também porque as espécies euribatas, por sua própria definição, ocorrem também no andar batial.

\subsubsection{Especies Tropicais Contínuas}

Introdução. - As espécies tropicais contínuas apresentam uma área de dispersão ininterrupta ao longo do litoral leste das Américas. Como ainda não está bem conhecida a plataforma continental nas Guianas, foram consideradas como contínuas todas as espécies com registros de ocorrência nas Guianas ou coletadas pelo N. Oc. Almirante Saldanha no litoral do Amapá à oeste do meridiano de $49^{\circ} \mathrm{W}$. Embora pareça pouco provável, é possível que o critério adotado tenha colocado erradamente alguma espécie tropical disjunta entre as contínuas.

Como nos conjuntos anteriormente estudados, a distribuição das espécies costeiras e euribatas será considerada em separado.

Espécies tropicais contínuas costeiras. - Os dados de distribuição das espécies tropicais contínuas costeiras estão incluídos nas Tabelas IX e X e na Figura 16.

Seria possivel subdividir o grupo de acordo com suas preferências por tipo de fundo e por profundidades. Nesta análise não estão incluídas as espécies obtidas apenas em coletas manuais na costa do Maranhão, em número de 7.

Entre as 36 espécies coletadas, 20 poderiam ser classificadas como vasícolas. Dentre elas, 7 espécies, coletadas entre 13 e 44 metros, indicariam o infralitoral, ao passo que oito outras seriam indicadoras do circalitoral, pois ocorrem entre 39 e 75 metros e as 5 restantes, no entanto, poderiam ser consideradas como frequentadoras do infra e do circalitoral, sua dsitribuicão batimétrica se estendendo entre 0 e 85 metros.

Entre as espécies arenícolas apenas 2 parecem limitada ao infralitoral, 4 foram coletadas entre 35 e 83 metros, sendo consideradas como representantes do circalitoral, e 7, encontradas entre 0 e 82 metros, constituem elemento comum ao infra e ao circalitoral.

Algumas destas espécies, arenícolas ou vasícolas, foram coletadas em apenas 1 ou 2 estaçōes, e sua distribuição, portanto, não está bem conhecida. 


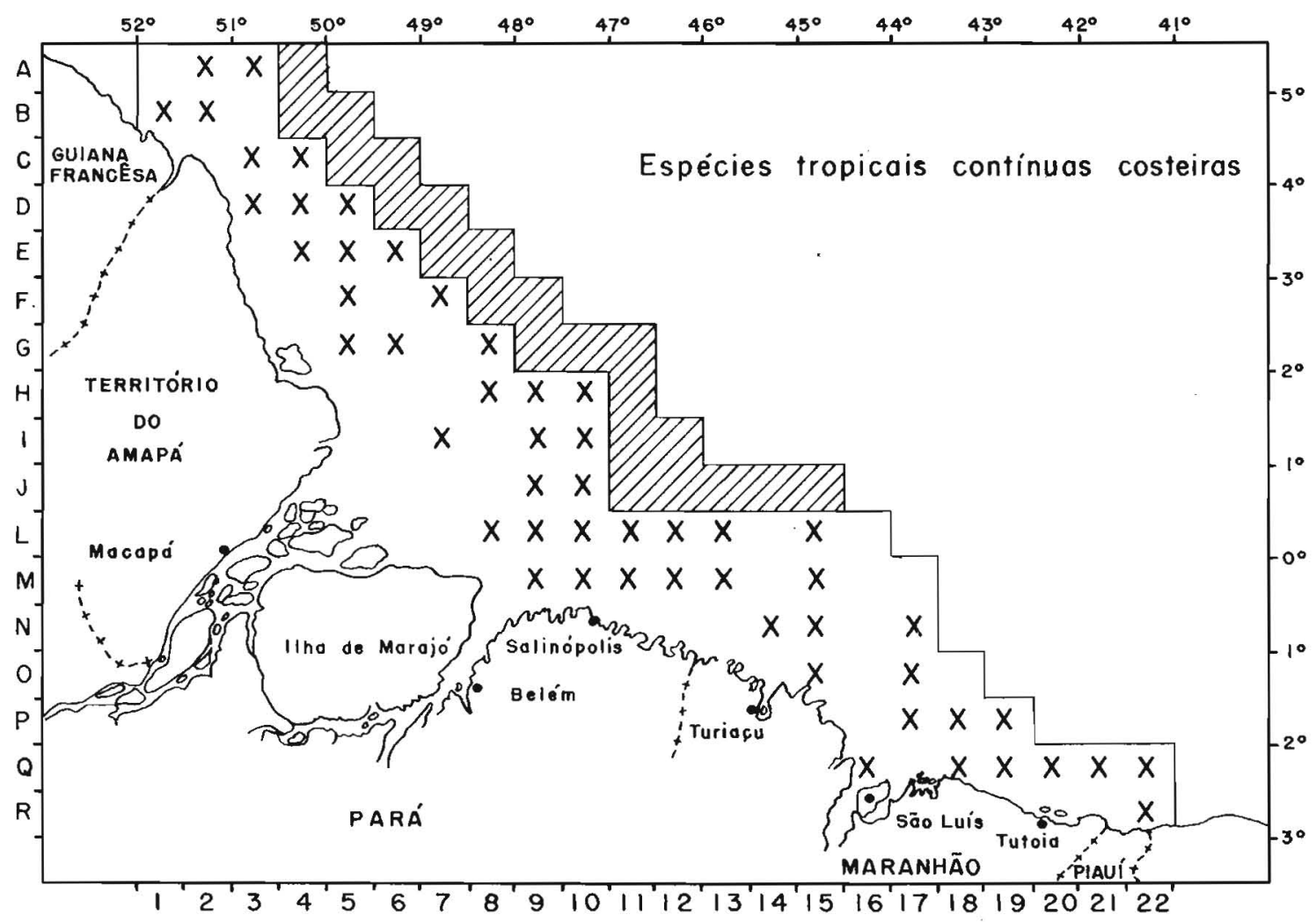

Fig. 16 - Área de ocorrência das espécies tropicais contínuas costeiras no litoral Norte do Brasil. 
TABELA IX

DISTRIBUIÇĀO GEOGRÁFICA GERAL DAS ESPÉCIES

TROPICAIS CONTINUAS

\begin{tabular}{l|c|c|c}
\hline \multirow{2}{*}{ Espécies } & \multicolumn{2}{|c|}{ Distribuição geográfica } & \multirow{2}{*}{$\begin{array}{l}\text { Distribuição } \\
\text { Batimétrica }\end{array}$} \\
\cline { 2 - 3 } & Limite Norte & Limite Sul & Bation \\
\hline
\end{tabular}

Meiosquilla quadridens

Meiosquilla schmitti

Squilla obtusa

Accalathura crenulata (1)

Cirolana gracilis

Excorallana oculata

Alcirona krebsii (2)

Rocinela signata (2)

Discerre is linguicauda

Ancinus ciepressus (2)

Serolis sp.

Stenetrium occidentale

Trachypenaeus constrictus

Xiphopencueus kroyeri

Metapenaeopsis goodei

Metapenaeopsis martinella

Sicyonia dorsalis

Sicyonia laevigata

Acetes americanus

Leptochela carinata

Leptochela serratorbita

Alpheus intrinsecus

Alpheus floridanus

Exhippolysmata oplophoroides Carolina do Norte

Callianassa marginata

Scyllarus chacei

Clibanarius vittatus

Petrochirus diogenes

Porcellana sayana

Minyocerus angustus

Petrolisthes galathinus (2)

Petrolisthes armatus (1) (2)

Albunea paretii (1)

Symethis variolosa

Raninoides loevis

Hypoconcha arcuata

Hepatus pudibundus

Cycloes bairdii (2)

Calappa ocellata

Calappa sutcata

Iliacantha subglobosa

Persephona finneganae

Persephona punctata

Ebalia stimpsoni

Callinectes ornatus
Carolina do Norte

Flórida

Porto Rico

Antilhas

Antilhas

Antilhas

Flórida

Golfo do México

G. do México

Massachussetts

Amapá

Antilhas

Virginia

Carolina do Norte

Carolina do Norte

Antilhas

Carolina do Norte

Carolina do Norte

Carolina do Norte

Golfo do México

Carolina do Norte

Antilhas

Flórida

Flórida

Carolina do Norte

Virgínia

Carolina do Norte

Carolina do Norte

Honduras

Carolina do Norte

Flórida

Carolina do Norte

Flórida

Flórida

Carolina do Norte

Geórgia

Carolina do Norte

Carolina do Norte

Carolina do Norte

Carolina do Norte

Antilhas

Antilhas

Carolina do Norte

New Jersey
R. Gr. do Norte

Rio de Janeiro

Bahia

São Paulo

São Paulo

Espirito S.

Pernambuco

Sāo Paulo

Maranhão

R. G. do Sul

Espírito Santo

Pernambuco

Santa Catarina

Santa Catarina

Espírito Santo

Pernambuco

Alagoas

Alagoas

Alagoas

Alagoas

São Paulo

São Paulo

Bahia

Sāo Paulo

Rio de Janeiro

Bahia

Santa Catarina

São Paulo

R. G. do Sul

Santa Catarina

Sāo Paulo

Santa Catarina

Santa Catarina

Bahia

Alagoas

Espírito Santo

Santa Catarina

Espirito Santo

Rio de Janeiro

Alagoas/Sergipe

Alagoas/Sergipe

São Paulo

São Paulo

Bahia

São Paulo
137

100

0

0

13

0

7

24

21

0

44

0

38

0

25

13

0

0

0

0

0

13

19

0

0

0

40

16

0

100

$97 / 100$

49

50

25/30

90

110

196

82

49

200

52

183

232

90

$40 / 50$

$90 / 100$

73

continua 
TABELA IX continuacāo

DISTRIBUICÃO GEOGRÁFICA GERAL DAS ESPÉCIES

TROPICAIS CONTÍNUAS

\begin{tabular}{|c|c|c|c|c|}
\hline \multirow{2}{*}{ Espécies } & \multicolumn{2}{|c|}{ Distribuiçāo geográfica } & \multirow{2}{*}{\multicolumn{2}{|c|}{$\begin{array}{l}\text { Distribuição } \\
\text { Batimétrica }\end{array}$}} \\
\hline & Limite Norte & Limite Sul & & \\
\hline Callinectes bocourti & Flórida & Santa Catarina & 0 & 20 \\
\hline Cronius ruber (1) (2) & Carolina do Norte & Santa Catarina & 0 & 105 \\
\hline Portunus spinicarpus & Carolina do Norte & Sāo Paulo & 0 & 380 \\
\hline Portunus anceps & Carolina do Norte & Bahia & 0 & 130 \\
\hline Hexapanopeus paulensis & Carolina do Sul & Santa Catarina & 0 & $46 / 47$ \\
\hline Paractaea rufopunctata & Carolina do Norte & Rio de Janeiro & 5 & 212 \\
\hline Micropanope nuttingi & Carolina do Norte & Bahia & 0 & 183 \\
\hline Panoplax depressa & Flórida & Pernambuco & 0 & 77 \\
\hline Pinnixa sayana & Massachussetts & São Paulo & 0 & 75 \\
\hline Dissodactylus crinitichelis & Carolina do Norte & Argentina & 0 & 33 \\
\hline Ocypode quadrata & Rhode Island & Santa Catarina & & 0 \\
\hline Uca maracoani & Venezuela & Rio de Janeiro & & 0 \\
\hline Uca rapax & Flórida & Santa Catarina & & 0 \\
\hline Uca leptodactyla & Flórida & Santa Catarina & & 0 \\
\hline Pachygrapsus gracilis (1) & Flórida & Rio de Janeiro & & 0 \\
\hline Mesorhoea sexspinosa & Carolina do Norte & São Paulo & 0 & 100 \\
\hline Parthenope serrata & Carolina do Norte & Bahia & 0 & 110 \\
\hline Euprognatha gracilipes & Flórida & Sāo Paulo & 69 & 368 \\
\hline Collodes inermis & Antilhas & Bahia & 25 & 105 \\
\hline Podochela gracilipes & Carolina do Norte & Santa Catarina & 6 & 111 \\
\hline Stenorhynchus seticornis (1) & Carolina do Norte & Santa Catarina & 0 & $\ldots$ \\
\hline Inachoides forceps & Carolina do Norte & Santa Catarina & 0 & 75 \\
\hline Mithrax acuticornis & Flórida & Pernambuco & 0 & 69 \\
\hline
\end{tabular}

1. Ocorre também no Atlântico oriental

2. Ocorre também no Pacífico ocidental 
TABELA $X$

DISTRIBUICẢO ECOLÓGICA DAS ESPÉCIES TROPICAIS CONTINNUAS COSTEIRAS

\begin{tabular}{|c|c|c|c|c|c|c|c|c|c|c|c|c|c|c|c|}
\hline \multirow{3}{*}{ Espécies } & \multicolumn{15}{|c|}{ Caracteristicas do fundo } \\
\hline & \multirow{2}{*}{\multicolumn{2}{|c|}{ Salinidade }} & \multirow{2}{*}{\multicolumn{2}{|c|}{ Temperatura }} & \multirow{2}{*}{\multicolumn{2}{|c|}{ Profundidade }} & \multicolumn{9}{|c|}{ Tipo de fundo } \\
\hline & & & & & & & $\mathbf{L}$ & A/L & A & A/Ac & Ac & $\mathrm{Ac} / \mathrm{D}$ & D & A/D & $?$ \\
\hline Exhyppolysmata oplophoroides & 31,820 & 35,713 & 26,99 & 28,33 & 0 & 45 & 5 & - & 1 & - & - & - & - & - & 1 \\
\hline Hexapanopeus paulensis & \multicolumn{2}{|c|}{36,653} & \multicolumn{2}{|c|}{27,17} & 13 & 43 & - & 1 & 3 & - & $\sim$ & - & - & - & - \\
\hline Trachypenaeus constrictus & \multicolumn{2}{|c|}{$\ldots$} & \multicolumn{2}{|c|}{$\ldots$} & 25 & 39 & 1 & 1 & - & - & - & - & - & - & - \\
\hline Callinectes bocourti & \multicolumn{2}{|c|}{33,852} & \multicolumn{2}{|c|}{26,65} & \multicolumn{2}{|c|}{20} & - & - & - & - & - & - & - & - & 1 \\
\hline Alpheus intrinsecus & \multicolumn{2}{|c|}{$\ldots$} & \multicolumn{2}{|c|}{$\cdots$} & \multicolumn{2}{|c|}{27} & 1 & - & - & - & - & - & - & - & - \\
\hline Dissodactylus crinitichelis & \multicolumn{2}{|c|}{$\ldots$} & \multicolumn{2}{|c|}{$\ldots$} & \multicolumn{2}{|c|}{28} & - & - & - & - & $\sim$ & - & - & - & 1 \\
\hline Persephona punctata & 35,974 & 36,484 & 26,55 & 27,37 & 39 & 41 & 2 & - & - & - & - & - & - & - & - \\
\hline Porcellana sayana & \multicolumn{2}{|c|}{36,484} & \multicolumn{2}{|c|}{27,37} & 39 & 72 & 1 & - & - & - & - & - & - & - & 1 \\
\hline Persephona finneganae & 35,974 & 36,484 & 25,89 & 27,94 & 39 & 75 & 4 & - & 2 & - & - & - & - & - & 1 \\
\hline Calappa sulcata & \multicolumn{2}{|c|}{35,974} & \multicolumn{2}{|c|}{26,55} & \multicolumn{2}{|c|}{41} & 1 & - & - & - & - & - & - & - & - \\
\hline Hepatus pudibundus & \multicolumn{2}{|c|}{$\ldots$} & \multicolumn{2}{|c|}{$\ldots$} & \multicolumn{2}{|c|}{43} & - & 1 & - & - & - & - & - & - & - \\
\hline Mesorchoea sexspinosa & \multicolumn{2}{|c|}{$\ldots$} & &. & 43 & 50 & - & 1 & - & - & - & - & - & - & 1 \\
\hline Scyllarus chacei & $\ldots$ & & &.. & & & - & - & - & - & - & - & - & - & 1 \\
\hline Raninoides loevis & 36 & 150 & & 3,27 & 49 & 67 & 1 & - & 2 & - & - & - & - & - & 1 \\
\hline Callinectes ornalus & 34,115 & 36,499 & 25,89 & 27,30 & 0 & 70 & 2 & - & 3 & - & - & - & - & - & 2 \\
\hline Leptochela serratorbita & 34,865 & 36,653 & 25,92 & 28,47 & 19 & 67 & 3 & 1 & 9 & - & - & 1 & 1 & - & - \\
\hline Sicyonia dorsalis & 34,865 & 36,256 & 25,56 & 27,94 & 19 & 75 & 5 & 3 & 2 & - & - & - & - & - & - \\
\hline Sicyonia laevigata & 35,833 & 36,537 & 25,72 & 27,63 & 21 & 85 & - & 1 & 7 & - & 1 & - & - & 2 & - \\
\hline Pinnixa sayana & 34,149 & 36,484 & 25,92 & 27,37 & 23 & 75 & 4 & - & - & - & - & - & - & - & 1 \\
\hline Calappa ocellata & 36,006 & 36,499 & 25,92 & 27,30 & 15 & 52 & 1 & - & 1 & - & - & - & - & - & - \\
\hline Petrolisthes galathinus & 30,458 & 36,437 & 27,67 & 28,21 & 0 & 31 & - & - & 3 & - & - & - & - & - & 1 \\
\hline Acetes americanus & 31,820 & 36,814 & 26,79 & 28,33 & 19 & 38 & - & - & 1 & - & - & - & - & - & 1 \\
\hline Alpheus floridanus & 36 & 437 & & .67 & 23 & 75 & - & - & 2 & - & - & - & - & 2 & - \\
\hline
\end{tabular}




\begin{tabular}{|c|c|c|c|c|c|c|c|c|c|c|c|c|}
\hline \multirow{3}{*}{ Espécies } & \multicolumn{12}{|c|}{ Características do fundo } \\
\hline & \multirow{2}{*}{ Salinidade } & \multirow{2}{*}{ Temperatura } & \multirow{2}{*}{ Profundidade } & \multicolumn{9}{|c|}{ Tipo de fundo } \\
\hline & & & & L & $A / L$ & A & A/AC & $\overline{A C}$ & $\mathrm{Ac} / \mathrm{D}$ & D & $A / D$ & $?$ \\
\hline
\end{tabular}

Metapenaeopsis goodei

Parthenope serrata

Ebalia stimpsoni

Petrochirus diogenes

Hypoconcha arcusta

Minyocérus angustus

Albunea paretii

Panoplax depressa

Inachoides forceps

Meiosquilla quadridens

Squilla obtusa

Stenetrium occidentale

Metapenaeopsis martinella

\begin{tabular}{|c|c|c|c|c|c|}
\hline \multicolumn{2}{|c|}{$\ldots$} & \multicolumn{2}{|c|}{$\ldots$} & \multicolumn{2}{|l|}{24} \\
\hline 36,168 & 36,212 & 25,72 & 25,95 & 35 & \\
\hline \multicolumn{2}{|c|}{$\ldots$} & \multicolumn{2}{|c|}{$\ldots$} & 35 & \\
\hline \multicolumn{2}{|c|}{36,038} & \multicolumn{2}{|c|}{26,07} & 55 & \\
\hline \multicolumn{2}{|c|}{$\ldots$} & \multicolumn{2}{|c|}{$\ldots$} & 0 & \\
\hline 36,132 & 36,499 & 26,73 & 27,30 & 15 & \\
\hline 36,132 & 36,304 & 26,21 & 27,17 & 21 & \\
\hline 36,212 & 36,537 & 25,72 & 26,27 & 21 & \\
\hline \multicolumn{2}{|c|}{36,437} & \multicolumn{2}{|c|}{27,67} & 23 & \\
\hline \multicolumn{2}{|c|}{$\ldots$} & \multicolumn{2}{|c|}{$\ldots$} & & 38 \\
\hline \multicolumn{2}{|c|}{$\ldots$} & \multicolumn{2}{|c|}{$\ldots$} & & 75 \\
\hline \multicolumn{2}{|c|}{36,537} & \multicolumn{2}{|c|}{26,27} & 21 & \\
\hline \multicolumn{2}{|c|}{36,092} & \multicolumn{2}{|c|}{26,27} & 52 & \\
\hline
\end{tabular}

75
75
83
72
82
59
72
77
75

69
75


De um modo geral, pode-se afirmar que as espécies tropicais contínuas costeiras ocorrem principalmente em fundos arenosos ou lamosos, banhados por água sujeita a variacões de salinidade.

Espécies tropicais contínuas euribatas. - Com a mesma ressalva de uma ou outra espécie não ter sido ainda coletada nas Guianas, são consideradas aqui como tropicais contínuas euribatas 25 espécies. Seria possível dividir o grupo de acordo com suas preferências por tipo de fundo e por profundidade, como mostram os dados contidos na Tabela XI. A distribuicão geográfica é apresentada na Tabela IX e na Fig. 17.

Collodes inermis e Xiphopenaeus kroyeri, consideradas vasícolas, ocorrem desde 13 até 118 metros de profundidade, sendo comuns aos andares infralitoral, circalitoral e batial.

As espécies restantes são incluídas na categoria de arenícolas. Mas, enquanto algumas ocorrem desde o infralitoral até o batial, outras são restritas ao circalitoral e ao batial. As primeiras, coletadas entre 15 e 172 metros, são em número de nove e as segundas, coletadas entre 43 e 224 metros, constituem um grupo de 9 espécies.

É de se notar que parece bastante frequente a ocorrência destas espécies em fundos organogênicos.

A área de ocorrência destas espécies euribatas arenícolas constitui verdadeira "ponte" entre as províncias brasileira e antilhana. Em função da existência de biótopos adequados, nos horizontes mais profundos da plataforma continental da provincia guianense, é encontrada uma faixa, certamente contínua, habitada por este grupo de espécies tropicais porém relativamente tolerante quanto à temperatura e à profundidade.

Conclusões. - As espécies tropicais contínuas incluem formas vasícolas e arenícolas, todas mais ou menos eurialinas ou euritermas. Elas constituem elemento comum à várias províncias biogeográficas, não podendo portanto ser consideradas como características de nenhuma delas.

\subsubsection{Espécies Brasileiras}

Introdução. - Este conjunto faunístico é constituído essencialmente pelas espécies endêmicas do Hemisfério Sul. Por causa da simetria observada no litoral atlântico das Américas, de cada 


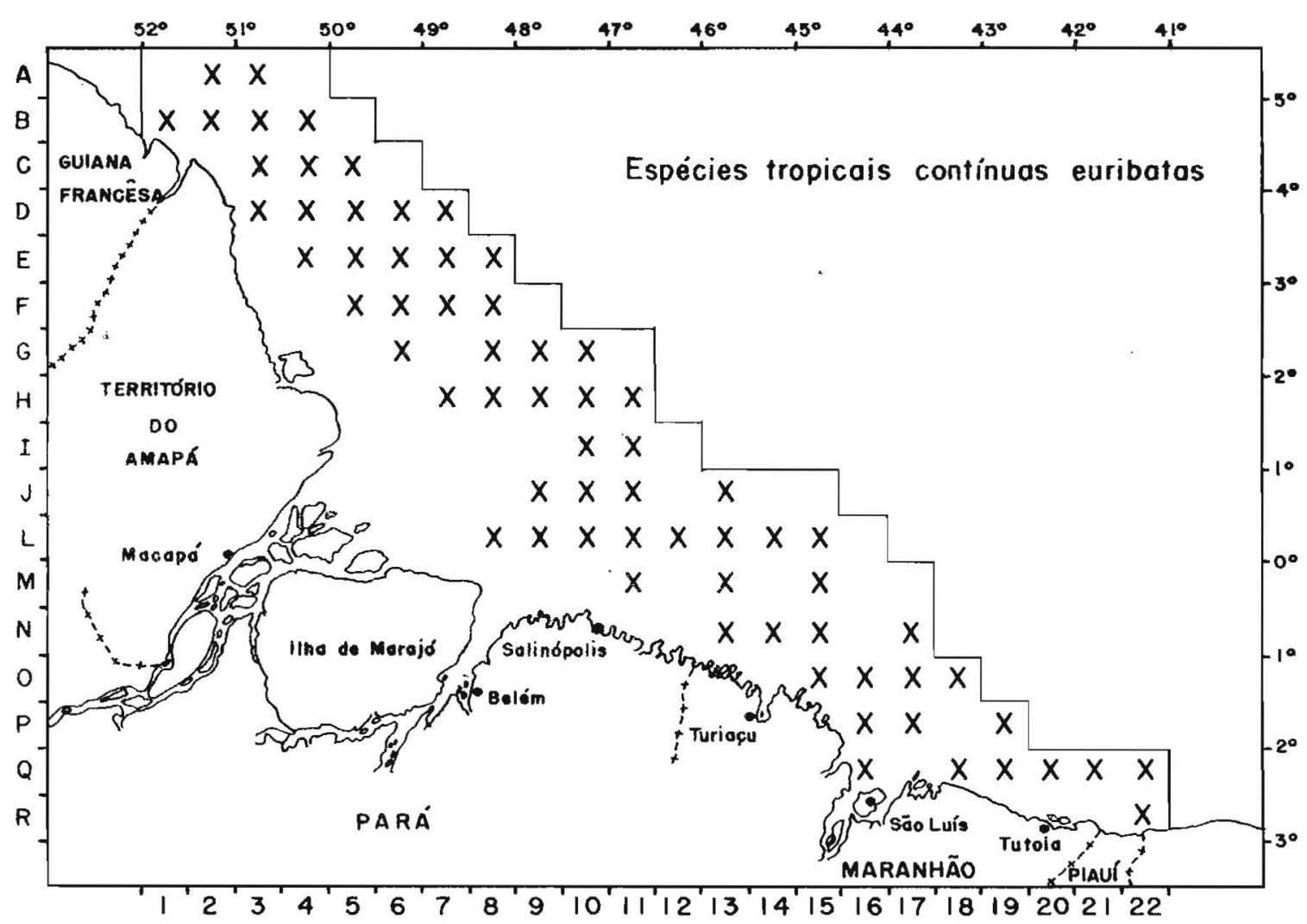

Fig. 17 - Área de ocorrência das espécies tropicais contínuas euribatas no litoral Norte do Brasil. 


\section{TABELA XI}

DISTRIBUIÇĀO ECOLÓGICA DAS ESPÉCIES TROPICAIS CONTINUAS EURIBATAS NA ÁREA ESTUDADA

\begin{tabular}{|c|c|c|c|c|c|c|c|c|c|c|c|c|c|c|c|}
\hline \multirow{3}{*}{ Espécies } & \multicolumn{15}{|c|}{ Caracteristicas do fundo } \\
\hline & \multirow{2}{*}{\multicolumn{2}{|c|}{ Salinidade }} & \multirow{2}{*}{\multicolumn{2}{|c|}{ Temperatura }} & \multirow{2}{*}{\multicolumn{2}{|c|}{ Profundidade }} & \multicolumn{9}{|c|}{ Tipo de fundo } \\
\hline & & & & & & & $\mathbf{L}$ & $A / L$ & A & A/Ac & Ac & $\mathrm{Ac} / \mathrm{D}$ & D & A/D & $?$ \\
\hline Xiphopenaeus kroyeri & 31,820 & 36,327 & 24,99 & 28,24 & 13 & 118 & 11 & 1 & 2 & - & - & - & 1 & - & - \\
\hline Collodes inermis & 35,904 & 36,038 & 25,89 & 26,55 & 25 & 105 & 2 & - & 6 & - & - & - & 1 & - & 2 \\
\hline Meiosquilla schmitti & \multicolumn{2}{|c|}{$\ldots$} & \multicolumn{2}{|c|}{$\ldots$} & 35 & 100 & 1 & - & 4 & - & 1 & 4 & 1 & 1 & 1 \\
\hline Leptochela carinala & 34,618 & 36,814 & 25,96 & 28,47 & 13 & 100 & - & - & 18 & - & - & 1 & 1 & 1 & - \\
\hline Portunus anceps & 35,677 & 36,499 & 24,38 & 27,66 & 15 & 103 & - & - & 12 & - & - & - & - & - & - \\
\hline Micropanope nullingi & 36,216 & 36,537 & 25,72 & 26,33 & 21 & 118 & - & - & 4 & - & 1 & 3 & 1 & 2 & 3 \\
\hline Accalathura crenulata & 36,008 & 36,537 & 26,27 & 26,68 & 21 & 120 & - & - & 1 & 1 & 1 & 2 & 2 & 1 & 5 \\
\hline Alcirona krebsii & \multicolumn{2}{|c|}{36,537} & \multicolumn{2}{|c|}{26,27} & 21 & 172 & - & - & 1 & - & 1 & - & - & - & 2 \\
\hline Excorallana oculata & 35,936 & 36,327 & 21,59 & 25,72 & 24 & 100 & - & - & 5 & - & 1 & - & 1 & - & 2 \\
\hline Cycloes bairdii & 36,084 & 36,653 & 24,42 & 26,69 & 24 & 120 & - & - & 10 & 2 & - & 2 & 3 & 4 & 4 \\
\hline Rocinela signata & \multicolumn{2}{|c|}{36,008} & \multicolumn{2}{|c|}{26,68} & 24 & 125 & - & - & + & - & - & 1 & 1 & 3 & 7 \\
\hline Callianassa marginata & \multicolumn{2}{|c|}{36,248} & \multicolumn{2}{|c|}{26,06} & 46 & 224 & - & - & 2 & - & - & - & - & 1 & 4 \\
\hline Stenorhynchus seticornis & 35,968 & 36,313 & 21,05 & 26,49 & 29 & 93 & - & 1 & 3 & - & 1 & 1 & 2 & 3 & - \\
\hline Podochela gracilipes & 35,938 & 36,212 & 24,38 & 26,63 & 53 & 111 & - & - & 5 & - & - & - & 1 & 2 & 2 \\
\hline Mithrax acuticornis & 36,146 & 36,313 & 21,05 & 25,72 & 53 & 120 & - & - & 2 & - & 1 & 3 & 3 & 2 & 10 \\
\hline Paractaea rufopunctata & \multicolumn{2}{|c|}{$\ldots$} & \multicolumn{2}{|c|}{$\ldots$} & 53 & 120 & - & * & 2 & - & 1 & 1 & 3 & 2 & 3 \\
\hline Euprognatha gracilipes & 35,986 & 36,146 & 24,42 & 24,99 & 69 & 118 & - & - & 1 & - & - & 1 & 2 & 1 & - \\
\hline lliacantha subglobosa & \multicolumn{2}{|c|}{$\ldots$} & \multicolumn{2}{|c|}{$\ldots$} & 73 & 109 & - & - & 2 & - & - & - & 1 & - & 4 \\
\hline Symethis variolosa & 36,008 & 36,134 & 26,27 & 26,68 & 44 & 92 & - & - & - & 1 & - & 5 & - & 1 & 3 \\
\hline Cronius ruber & \multicolumn{2}{|c|}{$\ldots$} & \multicolumn{2}{|c|}{$\ldots$} & 63 & 105 & - & - & 1 & - & - & 3 & 1 & 1 & 1 \\
\hline Cirolana gracilis & 35,959 & 36,146 & 24,42 & 26,68 & 50 & 103 & - & - & - & - & - & 3 & 2 & 3 & 6 \\
\hline Discerceis linguicauda & \multicolumn{2}{|c|}{$\ldots$} & \multicolumn{2}{|c|}{$\ldots$} & 70 & 118 & - & - & - & - & - & - & 1 & - & 4 \\
\hline Ancinus depressus & \multicolumn{2}{|c|}{$\ldots$} & \multicolumn{2}{|c|}{$\ldots$} & 19 & 101 & - & - & - & - & - & - & - & - & 2 \\
\hline Serolis sp. & \multicolumn{2}{|c|}{$\ldots$} & \multicolumn{2}{|c|}{$\ldots$} & 38 & 118 & - & - & - & - & - & - & - & - & 2 \\
\hline
\end{tabular}


lado da Província Guianense existe um setor com fauna endêmica, antilhana ao norte, e brasileira ao sul. As exigências e/ou as tolerâncias de algumas delas, no entanto, permitem que colonizem áreas vizinhas, como os setores caroliniano e virginiano da América do Norte (no caso das espécies antilhanas), ou guianense, paulista e argentino (no caso das espécies brasileiras).

As espécies brasileiras costeiras e euribatas estão estudadas separadamente nas linhas que se seguem.

Espécies brasileiras costeiras. - Este agrupamento é constituído por 20 espécies. Sua distribuicão é mostrada nas Tabelas XII e XIII e na Figura 18. Trata-se de especies estenotermas quentes, com exigências e tolerâncias diferentes no que diz respeito ao tipo de fundo, à profundidade e à salinidade.

Seis espécies podem ser consideradas vasícolas. Entre elas, quatro ocorrem entre 0 e 43 metros, sendo incluídas entre as indicadoras do infralitoral. Outras três, encontradas entre 0 e 82 metros, seriam comuns ao infra e ao circalitoral.

Um grupo mais numeroso de espécies pode ser considerado como arenícola; entre estas, 6 , coletadas apenas entre 0 e 42 metros, indicariam o infralitoral, 3 outras, ocorrendo entre 35 e 68 metros indicariam o circalitoral e as quatro restantes são consideradas comuns ao infra e ao circalitoral.

Há finalmente um grupo constituído por 3 espécies cascalhícolas, sendo uma infralitoral e duas circalitorais.

Espécies brasileiras euribatas. - Apenas doze espécies estão incluidas nesta categoria, sendo sete arenícolas, ocorrendo desde o infralitoral até o batial, duas outras arenícolas, comuns ao circalitoral e ao batial, e três espécies cascalhícolas, comuns ao circalitoral e ao batial. Os dados concernentes a estas espécies podem ser encontradas nas Tabelas XII e XIV e na Figura 19.

Conclusōes. - É possível constatar uma prodigiosa diminuição no número de espécies brasileiras de leste para oeste. Enquanto no Piauí ocorrem ou são susceptiveis de ocorrer 28 espécies, apenas 6 conseguem alcancar as Guianas, além das fronteiras do Brasil, a saber: Paradasygyius tuberculatus, Notolopas brasiliensis, Libinia ferreirae, Pilumnus quoy, Persephona lichtensteinii e Paguristes erythrops.

Esta lista é bastante semelhante à das espécies costeiras vasícolas, ou seja, o caráter vasícola é geralmente associado com 


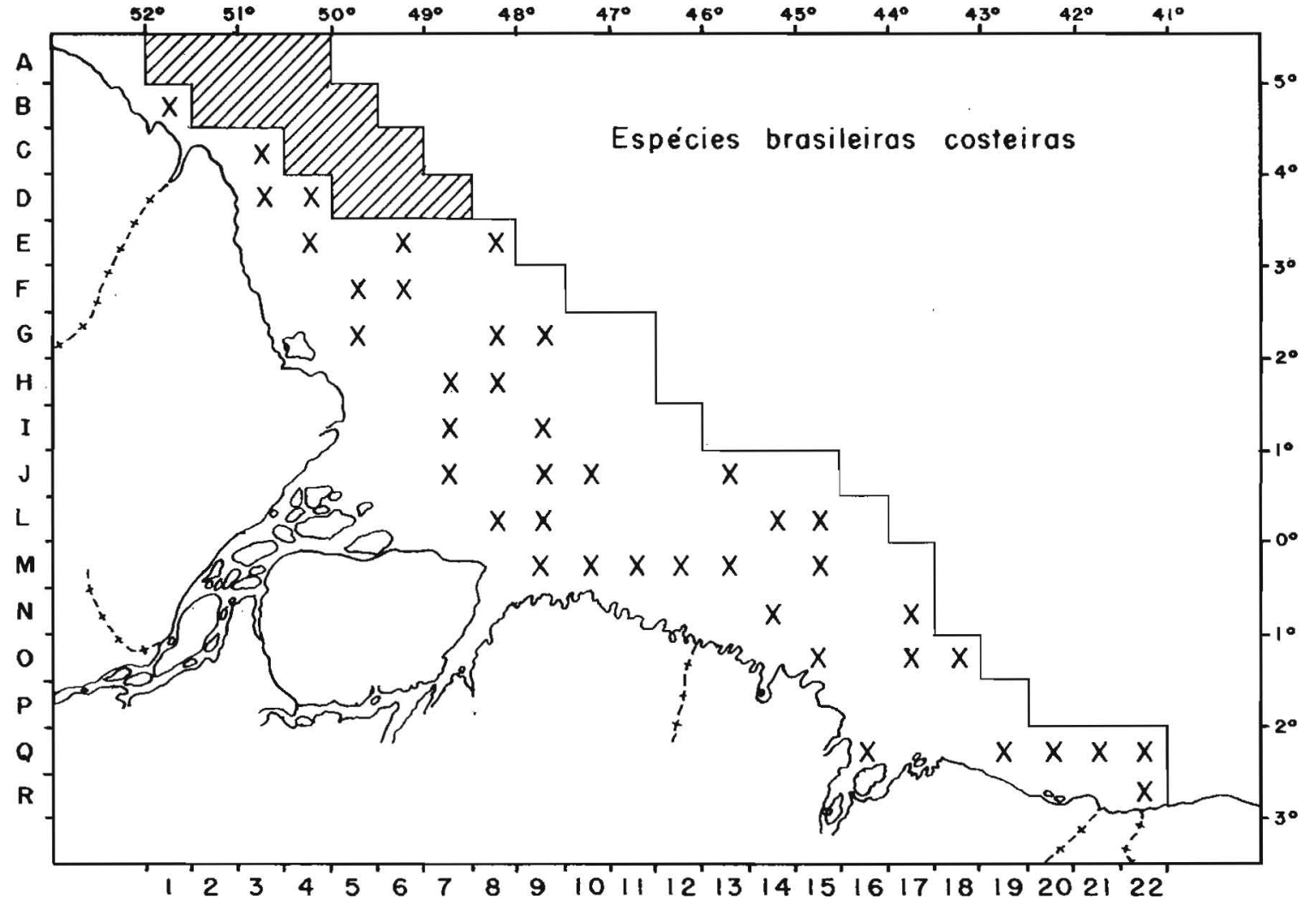

Fig. 18 - Area de ocorrência das espécies brasileiras costeiras no litoral Norte do Brasil. 


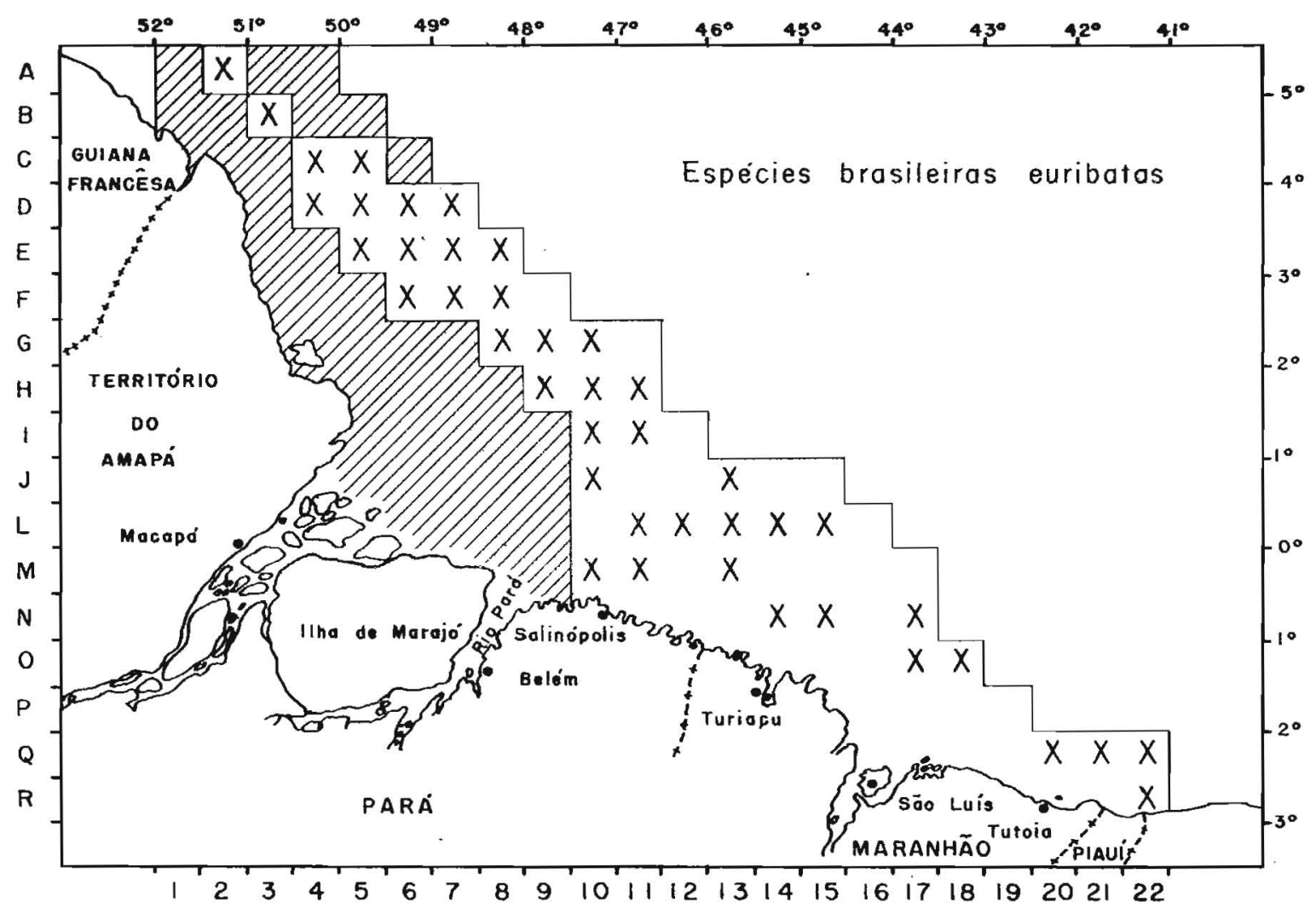

Fig. 19 - Área de ocorrência das espécies brasileiras euribatas no litoral Norte do Brasil. 


\begin{tabular}{c|c|c|c}
\hline \multirow{2}{*}{ Espécies } & \multicolumn{2}{|c|}{ Distribuição geográfica } & \multirow{2}{*}{$\begin{array}{l}\text { Distribuição } \\
\text { Batimétrica }\end{array}$} \\
\cline { 2 - 3 } & Limite Norte & Limite Sul & Bation \\
\hline
\end{tabular}

Anthuridae sp.

Cyathura sp.

Excorallana costata

Excorallana sp.

Excorallana richardsonae

Cymodoce australis

Chaetilinae $\mathrm{n}$. det.

Palaemon schmitti

Upogebia acanthura

Upogebia marina

Upogebia brasiliensis

Callianassa guara

Iridopagurus violaceus

Paguristes erythrops

Munida brasiliae

Pisidia sp. B

Pisidia sp. A

Clythrocerus analogus

Clythrocerus carinatus

Persephona lichtensteinii

Ebalia vertiginosa

Ebalia obliqua

Ebalia conica

Pilumnus quoyi

Lophopanopeus sp.

Euryozius bouvieri (1)

Chasmocarcinus sp. $B$

Pinnixa sp. $D$

Batrachonotus brasiliensis

Podochela algicola

Paradasygyius tuberculatus

Epialtoides rostratus

Notolopas brasiliensis

Pelia rotunda

Libinia ferreirae
Pará

Amapá

Amapá

Amapá

Amapá

Amapá

Pará

Guianas

Pará

Piauí

Pará

Pará

Pará

Guianas

Amapá

Maranhāo

Pará

Maranhão

Pará

Guianas

Pará

Pará

Amapá

Guianas

Amapá

Amapá

Amapá

Pará

Pará

Maranhāo

Guianas

Maranhão

Guianas

Pará

Guianas

$\begin{array}{lrr}\text { Maranhão } & 21 & 60 \\ \text { São Paulo } & 1,4 & 166 \\ \text { São Paulo } & 0 & 118 \\ \text { Pernambuco } & 0 & 117 \\ \text { Rio de Janeiro } & 0 & 94 \\ \text { Espirito Santo } & 0 & 92 \\ \text { Maranhão } & 30 & 73 \\ \text { Alagoas } & 5 & 60 \\ \text { Banc. Esp. Santo } & 68 & 70 \\ \text { Sergipe } & 0 & 25 \\ \text { São Paulo } & 0 & \ldots \\ \text { São Paulo } & 0 & 43 \\ \text { Bahia } & 29 & 88 \\ \text { Sāo Paulo } & 0 & 53 \\ \text { R. Gr. do Norte } & 49 & 90 \\ \text { Pernambuco } & 0 & 5 \\ \text { Pernambuco } & 0 & 31 \\ \text { Espírito Santo } & 52 & 75 \\ \text { Pernambuco } & 19 & 4143\end{array}$

$\begin{array}{lll}\text { Pernambuco } & 19 & 41 / 43\end{array}$

Alagoas/Sergipe 051

Bahia $\quad 23 \quad 92$

Pernambuco $3 \quad 50 / 53$

Banc. Esp. Santo $35 \quad 131$

São Paulo $\quad 0 \quad 100$

Alagoas $\quad 9 \quad 91$

Ceará $0 \quad 120$

R. G. do Norte $\quad 21 \quad 92$

Pernambuco $\quad 0 \quad 25$

Rio de Janeiro $\quad 12 \quad 73$

Rio de Janeiro $\quad 24 \quad 90$

R. G. do Norte $\quad 0 \quad 41$

Alagoas $\quad 19 \quad 54$

Bahia $\quad 0 \quad 73 / 82$

Argentina $\quad 0 \quad 85$

Santa Catarina $\quad 0 \quad 35$

1. Ocorre também na África Ocidental. 
DISTRIBUIÇĂO ECOLÓGICAS DAS ESPÉCIES BRASILEIRAS COSTEIRAS

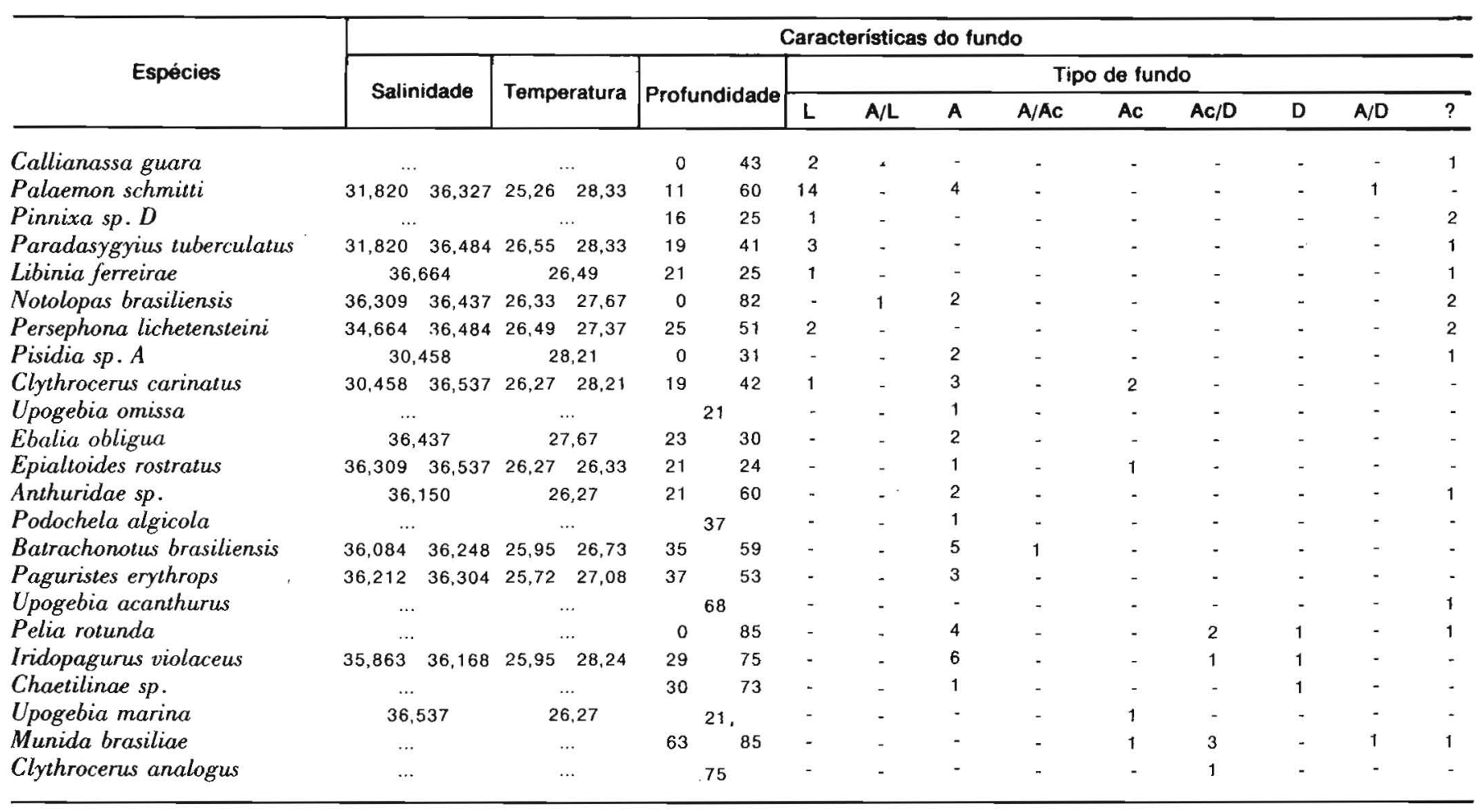


TABELA XIV

DISTRIBUICĀO ECOLÓGICA DAS ESPÉCIES BRASILEIRAS EURIBATAS NA ÁREA ESTUDADA

\begin{tabular}{|c|c|c|c|c|c|c|c|c|c|c|c|c|c|c|c|}
\hline \multirow{3}{*}{ Espécies } & \multicolumn{15}{|c|}{ Caracteristicas do fundo } \\
\hline & \multirow{2}{*}{\multicolumn{2}{|c|}{ Salinidade }} & \multirow{2}{*}{\multicolumn{2}{|c|}{ Temperatura }} & \multirow{2}{*}{\multicolumn{2}{|c|}{ Profundidade }} & \multicolumn{9}{|c|}{ Tipo de fundo } \\
\hline & & & & & & & $\mathbf{L}$ & A/L & A & $A / A C$ & $A c$ & $A c / D$ & D & $A / D$ & $?$ \\
\hline Cyathura sp. & 35,959 & 36.537 & 26,01 & 26.54 & 21 & 94 & - & 1 & 5 & 1 & - & 2 & 3 & 3 & - \\
\hline Excorallana richardsonae & 36,008 & 36,134 & 26,54 & 26,68 & 23 & 94 & - & 1 & 7 & 1 & - & 2 & - & 2 & - \\
\hline Excorallana sp. & \multicolumn{2}{|c|}{36,212} & \multicolumn{2}{|c|}{25,72} & 37 & 117 & - & 1 & 6 & - & - & - & - & - & - \\
\hline Chasmocarcinus sp. $B$ & 36,437 & 36.537 & 26,27 & 27,67 & 21 & 92 & - & - & 1 & - & 1 & - & - & - & 2 \\
\hline Cymodoce australis & \multicolumn{2}{|c|}{35,982} & \multicolumn{2}{|c|}{25,76} & 24 & 92 & - & - & 3 & - & - & - & - & - & - \\
\hline Excorallana costata & \multicolumn{2}{|c|}{36,008} & \multicolumn{2}{|c|}{26,68} & 24 & 118 & - & - & 4 & - & - & 2 & - & 4 & - \\
\hline Pilumnus quoyi & \multicolumn{2}{|c|}{36,212} & \multicolumn{2}{|c|}{27,72} & 27 & 101 & - & - & 2 & - & - & - & 2 & 1 & 1 \\
\hline Ebalia conica & 35,968 & 36,146 & 24,42 & 27,42 & 35 & 118 & - & - & 3 & - & - & - & 1 & 2 & 2 \\
\hline Euryosius bouvieri & \multicolumn{2}{|c|}{$\ldots$} & \multicolumn{2}{|c|}{$\ldots$} & 63 & 120 & - & - & - & - & - & 2 & 2 & 1 & - \\
\hline Ebalia vertiginosa & \multicolumn{2}{|c|}{36,313} & \multicolumn{2}{|c|}{21,05} & 67 & 92 & - & - & - & - & 1 & 1 & - & 1 & 1 \\
\hline Lophopanopeus sp. & \multicolumn{2}{|c|}{$\ldots$} & \multicolumn{2}{|c|}{$\cdots$} & 69 & 103 & - & - & - & - & 1 & 2 & 1 & 1 & 4 \\
\hline
\end{tabular}


- grau de eurialinidade necessário para colonizar as Guianas. É curioso o fato de que estas seis espécies brasileiras nāo conseguirem se tornar tropicais contínuas. No presente momento não há possibilidade de verificar se estas estão expandindo sua área de ocorrência em direcão ao setor caraíba, ou, ao contrário, se sua presenca nas Guianas depende de movimentos migratórios ocasionais de adultos ou de povoamentos esporádicos por larvas provenientes do Brasil

\subsection{DESCRICAÃO DOS POVOAMENTOS}

Com base nos conhecimentos atuais sobre distribuigão das espécies, foi possivel reconhecer no litroral equatorial cinco povoamentos de crustáceos, cuja distribuição é mostrada na Figura 20 a saber:

\section{Povoamentos costeiros}

Povoamentos dos fundos terrígenos

Povoamento dos fundos lamosos ou areno-lamosos

Povoamento dos fundos arenosos

Povoamentos dos fundos organogênicos

Povoamento dos fundos organogênicos costeiros

Povoamento dos fundos organogênicos de transição Povoamentos profundos

Povoamentos dos fundos arenosos ou organogênicos profundos

Dados sobre a frequência das espécies podem ser encontrados no anexo II.

\subsubsection{Comunidades dos fundos terrigenos costeiros}

Localização. - A fauna dos fundos terrígenos costeiros é encontrada desde a linha da costa até uma profundidade variável, que raramente ultrapassa os 80 metros. A faixa habitada por estes povoamentos possui largura irregular, podendo atingir 120 milhas ao largo da foz do Rio Amazonas, e é limitada ao largo ou pelo território da fauna dos fundos organogênicos ou pelo do povoamento dos fundos arenosos ou organogênicos profundos.

Fatores externos. - O território em que a presente fauna é encontrada apresenta diversas características essenciais. 
O fundo é geralmente de origem terrígena, as poucas estacões com fundo organogênico presentes sendo resultado do arredondamento implícito no método de mapeamento adotado. Há uma variação no teor de lama existente no sedimento, que diminui de oeste para leste e da costa para o largo.

A salinidade da água apresenta variacões, que são mais acentuadas nos mesmos locais em que o teor de lama no sedimento é mais acentuado, e que diminuem no mesmo sentido que a referida lama. É que ambos, salinidade da água e teor de lama do sedimento, refletem a influência fluvial.

A temperatura da água é elevada tanto na superfície como junto ao fundo, não se registrando valores abaixo de $25^{\circ} \mathrm{C}$.

Composição faunística. - A fauna inclui 34 famílias, entre as quais se salientam as famílias Sergestidae, Ogyrididae e Pinnotheridae, não encontradas na fauna dos fundos organogênicos do litoral equatorial brasileiro. De acordo com a importância tomada pelas espécies vasícolas ou pelas espécies arenícolas na constituicão dos povoamentos, é possivel separar dois povoamentos principais: o primeiro é caracterizado pela predominância de espécies vasícolas e ocorre nos fundos lamosos ou areno-lamosos e o segundo é caracterizado pelo predomínio de espécies arenícolas, e ocorre nos fundos arenosos. Algumas espécies, no entanto, poderiam ser consideradas características dos povoamentos dos fundos terrígenos em geral: Pisidia sp. A, Hepatus gronovii, Persephona finneganae, Trachypenaeus constrictus e Callianassa guara.

Povoamentos afins. - As espécies que caracterizam a fauna dos fundos terrígenos do Norte do Brasil permitem a localizacão de faunas afins em várias partes do mundo, Há, inicialmente, dois elementos endêmicos, o brasileiro representado por Pisidia $\mathrm{sp}$. A e por Callianassa guara, e o guianense por Hepatus gronovii, Persephona finneganae e Trachypenaeus constrictus, com maior área de dispersão, indicam a existência de povoamentos afins desde o Leste dos Estados Unidos até o Sudeste do Brasil. Maiores detalhes, no entanto, devem ser procurados no estudo de cada povoamento em particular. De um modo geral, no entanto, estes povoamentos correspondem aos da "Area B» da plataforma continental da Carolina do Norte, tal como descritos por CERAME-VIVAS \& GRAY (1966). 
Fig. 20

POVOAMENTOS FAUNISTICOS DO LITORAL EQUATORIAL BRASILEIRO

\section{Povoamentos costeiros}

Comunidades dos fundos terrígenos costeiros

Comunidade dos fundos lamosos ou areno-lamosos

Fáceis sujeita à influência fluvial acentuada

Fáceis sujeita à influência fluvial moderada

Comunidade dos fundos arenosos costeiros

Fáceis sujeita à influência fluvial moderada

Fáceis sujeita à influência fluvial atenuada

Comunidades dos fundos organogênicos

Comunidades dos fundos organogânicos de transicão

Fáceis guiano-brasileira de transição

Fáceis brasileira de transicão

Comunidade dos fundos organogânicos costeiros

Povoamentos profundos 


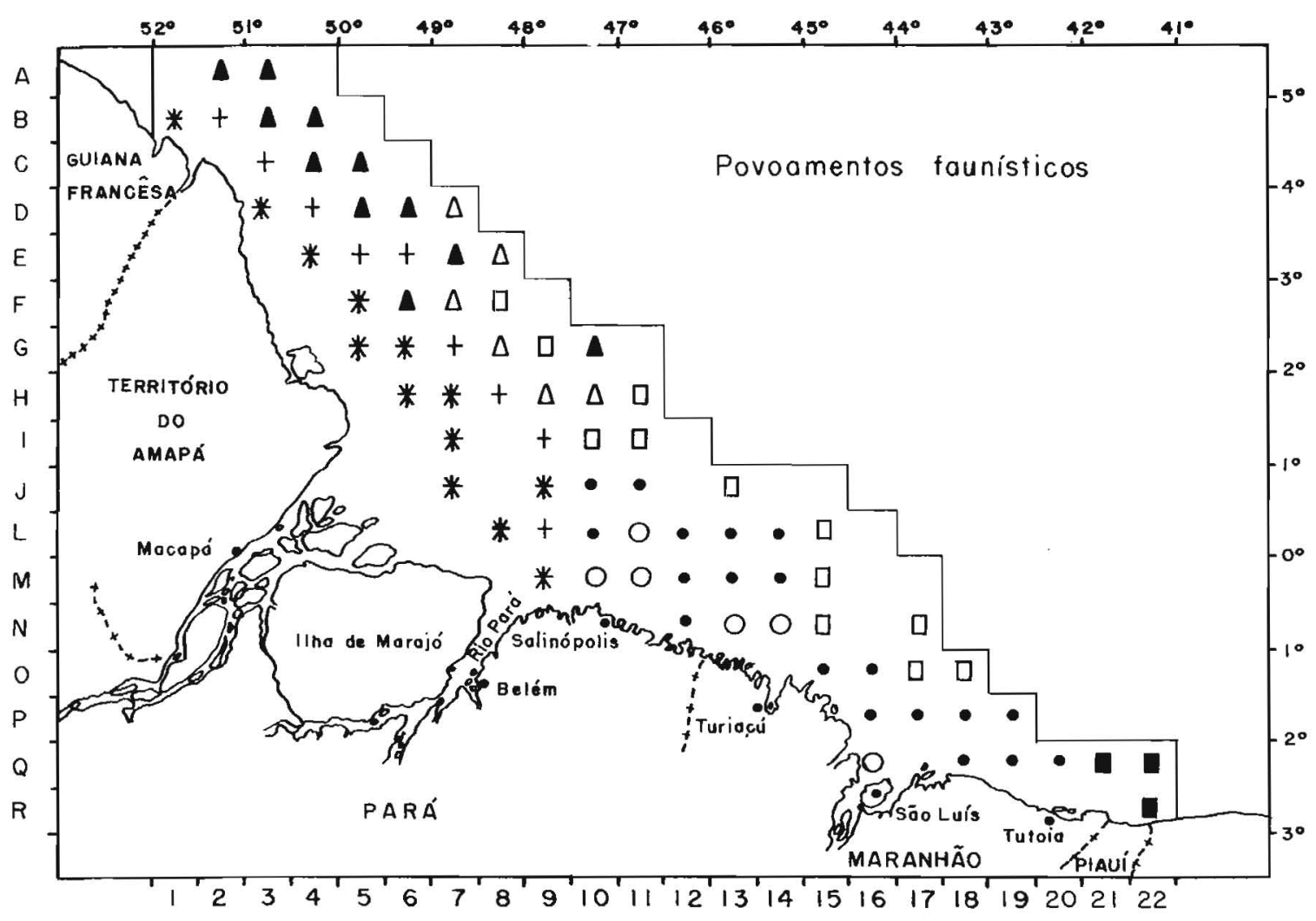

Fig. 20 - Povoamentos faunísticos do litoral equatorial brastleiro. 


\subsubsection{Comunidade dos fundos lamosos ou areno-lamosos}

Localizaçāo. - A fauna dos fundos lamosos ou areno-lamosos sob influência fluvial, portanto terrígena, é encontrada numa vasta área costeira correspondente ao Amapá e parte do Pará, de formato aproximadamente triangular. Os dois eixos principais, norte-sul e noroeste-sudeste, possuem respectivamente 120 milhas e $\mathbf{4 2 0}$ milhas náuticas de extensão. Os limites batimétricos das coletas realizadas se estendem desde 9 até 92 metros de profundidade.

Fatores externos. - A área habitada por esta fauna possui características próprias quanto ao tipo de fundo, a salinidade e a temperatura da água.

O sedimento é caracterizado pela presença de uma fracão fina mais ou menos importante. Nos retângulos mais costeiros, a fracão "lama" constitui $80 \%$ a $99,9 \%$ das partículas; mais ao largo, no entanto, torna-se variável a importância da lama, que ora representa $95 \%$ do sedimento, mas que pode valer apenas $3,7 \%$. De um modo geral, é possível reconhecer dois setores, um mais interno, de fundos lamosos, e outro mais ao largo, de fundos areno-lamosos ou arenosos, os fundos lamosos constituindo excecão.

A salinidade da água da superfície oscila entre 36,393 e $9,093 \%$ oo e da água do fundo entre 36,484 e $21,318 \%$ oo. As variacões da salinidade são uma consequência da diluicão da água do mar pela água dos grandes rios que desembocam neste trecho do litoral.

Em decorrência da posição geográfica e da pequena profundidade, a temperatura da água é elevada. O limite ao largo da área da comunidade, com efeito, coincide com o limite da área de ressurgência, com suas temperaturas menos elevadas junto ao fundo.

Este território assim caracterizado se delimita ao largo com os dos povoamentos profundos e dos povoamentos dos fundos organogênicos, e a leste com o dos povoamentos dos fundos arenosos. 
Composição faunistica. - Este povoamento foi encontrado em 22 retângulos. Foram encontrados representantes de 30 famílias. É de se salientar a total ausência de espécies da família Gonodactylidae entre os estomatópodos, Anthuridae e Serolidae entre os isópodos, Galatheidae, Dorippidae, Grapsidae e Hapalocarcinidae entre os Decápodos. Pelo contrário, as famílias Pinnotheridae e Goneplacidae alcancam grande variedade neste povoamento. É possível reconhecer fácies principais, uma constituída por uma fauna com cerca de $2 / 3$ das espécies vasícolas, e outra com apenas metade das espécies vasícolas na sua fauna. Na primeira destas fácies, as espécies características são Cycloplax pinnotheraides, Exhippolysmata opplophoroides, Ogyrides sp., Palaemon schmitti e Paradasy gyius tuberculatus, e noutra Chasmocarcinus sp. D., e Portunus rufiremus. Algumas espécies, no entanto, poderiam ser consideradas como caracterizando o conjunto da fauna: Callinectes ornatus, Pinnixa sayana, Squilla surinamica e Xiphopenaeus kroyeri. Com efeito, estas espécies alcancam frequência elevada no povoamento dos fundos lamosos e areno-lamosos, e ocorrem apenas de maneira acidental noutros povoamentos, a primeira no povoamento dos fundos arenosos e as outras 3 no povoamento dos fundos profundos.

Callinectes ornatus é uma espécie cuja ecologia é bastante conhecida. Como as outras espécies pertencentes ao gênero Calli nectes, ela é eurialina, sendo encontrada em ambiente marinho e estuarino. No mar, ocorre em fundos costeiros de lama ou de areia, numa variedade de condiçōes de salinidade. Squilla surinamica é menos conhecida, parecendo ser endêmica destes fundos lamosos ou areno-lamosos da Província Guianénse. Quanto a Xiphopenaeus kroyeri e a Pinnixa sayana, sua ecologia é semelhante à de C. ornatus, porém as ocorrências em fundos arenosos são consideradas ocasionais.

Povoamentos afins. - Na costa brasileira, os fundos lamosos e areno-lamosos estão perfeitamente mapeados em escala suficiente para uma comparacão com o presente estudo. E, $C$. ornatus, Pinnixa sayana e $X$. kroyeri têm sido coletados na maioria dos casos em que material biológico proveniente destes fundos chegou até o LACIMAR para estudo. Esta evidência, embora incompleta, permite reconhecer uma certa afinidade em todos os povoamentos dos fundos terrígenos lamosos e areno-lamosos localizados entre a costa leste dos Estados Unidos e a costa sudeste do Brasil, 
ou seja, no interior da área de ocorrência das 3 espécies. Dada a importância destes fundos para a pesca comercial de crustáceos (COELHO \& RAMOS, 1973b), seu estudo geral fica reservado para uma publicação à parte.

Considerando estes tipos de fundo como pertencentes ao circalitoral, PÉRÈS (1961) assinala a sua existência em todos os oceanos e sob todas as latitudes, cada vez que haja um depósito de lama terrígeria.

\section{A. Fácies sujeita à influência fluvial acentuada}

Localização. - Esta fácies do povoamento em estudo é encontrada numa vasta área costeira que se estende para oeste a partir da foz do Rio Tocantins, atingindo uma largura máxima, da ordem das 90 milhas, ao largo da foz do Rio Amazonas. Os limites batimétricos das coletas realizadas se estendem entre 9 e 53 metros.

Fatores externos. - A área habitada por esta fauna caracterizase principalmente pela natureza do substrato e por condicões hidrológicas peculiares.

O substrato é constituído principalmente por fundos lamosos. Trata-se de uma lama fluida, com teores de areia e de calcário muito reduzidos. Algumas estacōes, no entanto, possuem fundos de natureza areno-lamosa ou arenosa, em virtude do inevitável arredondamento trazido pelo método empregado no mapeamento.

A salinidade da água de superfície oscila entre 9,093 e $36,393 \%$ oo e a da água junto ao fundo entre 11,374 e $36,484 \%$ o. Estas variaçōes da salinidade são consequência da influência dos grandes rios que desembocam na costa, diluindo a água do mar até os limites da área em que esta fácies é encontrada.

A temperatura da água de superfície oscila entre 27,45 e $28,61^{\circ} \mathrm{C}$, uma consequência da posição geográfiça e da pequena profundidade.

Composiçāo faunística. - A fauna é constituída por 53 espécies, agrupadas em 23 famílias. Os estomatópodos e os isópodos estão 
mal representados, contando os primeiros com 2 e os segundos com 5 espécies, porém 2 estomatópodos, Squilla surinamica e $S$. lijdingi são considerados espécies acompanhantes. A maior parte da fauna, no entanto, é constituída por Decápodos. As famílias Penaeidae e Pinnotheridae salientam-se pelo máior número de espécies, cada uma estando representada por 5 espécies. Entre os Penaeidae, todas as espécies são acompanhantes. A família Pinnotheridae está representada apenas pelo gênero Pinnixa, e a frequência de cada espécie é baixa, embora a dominância possa ser elevada. Os caranguejos pertencentes a este gênero são frequentemente habitantes de tubos ou tocas de outros animais vasícolas, o que explicaria a sua baixa frequência.

Foram examinados mais de 720 especimens, sendo que as espécies vasícolas que correspondem a $73,5 \%$ da fauna, contavam com a metade dos espécimens. As espécies arenícolas, equivalentes a $16,9 \%$, vêm em segundo lugar, enquanto as espécies cascalhícolas, batiais e não classificadas, reunidas, representam $9,2 \%$ das espécies.

Entre as espécies constantes, deve-se salientar Xiphopenaeus kroyeri, Palaemon schmitti, Cycloplax pinnotheroides, e entre as comuns, Squilla surinamica, Ogyrides sp., Exhippolysmata oplophoroides, Clibanarius foresti, Hepatus scaber Callinectes ornatus e Paradasygyius tuberculatus. Entre estas espécies, são escolhidas Palaemon schmitti, Ogyrides sp., Exhippolysmata oplophoroides, Cycloplax pinnotheroides e Paradasygyius tuberculatus como espécies características da presente fauna, pelo fato de serem râras oú ausentes noutras faunas.

Povoamentos afins. - A espécie mais característica dos fundos lamosos sob influência"fluvial acenturada, ou seja, Cycloplax pinnotheroides, possui distribuicão geográfica relativamente restrita. Ela é conhecida apenas da Guiana Francesa, do Amapá e do Pará

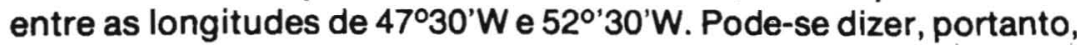
que a espécie é característica exclusiva da presente fauna. As outras espécies características, ao contrário, possuindo uma área de ocorrência mais vasta, permitem localizar povoamentos afins em vários pontos do litoral das Américas. Assim, Palaemon schmitti e Paradasygyius 'tuberculatus são conhecidas desde as Guianas até o Nordeste do Brasil. $P$. schmitti é um camarão muito comum em fundos lamosos e em estuários em toda a Província Guianense, porém, também foi coletado diante da foz do São Francisco, nos 
limites entre Alagoas e Sergipe, num fundo de lama sob influência fluvial. $P$. tuberculatus, embora menos frequente na Provincia Guianense, ocorrendo apenas no pré-litoral, porém conhecido também do Ceará e do Rio Grande do Norte. Finalmente Exhippolysmata oplophoroides possui uma vasta área de dispersão desde a Carolina do Norte até Sẳo Paulo, porém tem sido coletada realmente apenas em algumas localidades da Carolina do Norte, da Carolina do Sul, da Georgia, do Texas, de Pernambuco e de São Paulo, além de ocorrer sem interrupcão na Província Guianense, tanto nos fundos de lama da plataforma continental como nos estuários. Desta forma, o que se conhece sobre a distribuição destas quatro espécies permite não só delimitar a fácies sob influência fluvial acentuada do povoamento dos fundos lamosos ou areno-lamosos, como também reconhecer a existência de povoamentos afins, sempre localizados em fundos costeiros de lama, desde a Carolina do Norte até São Paulo (o interessante estudo das semelhancas entre estas comunidades, no entanto, ultrapassa os limites do presente estudo).

O gênero Cycloplax pertence à família Goneplacidae e é monotípico, porém os outros gêneros não o são. $O$ gênero Paradasygyius, colocado na família Majidae, é exclusivamente americano e possui duas espécies, uma atlântica ( $P$. tuberculatus) e outra no Pacífico, vivendo em fundos lamosos ou areno-lamosos, desde o Golfo da California até a Colômbia (ver GARTH, (1959). P. schmitti pertence a um subgênero Nematopalaemon, que possui mais três espécies vasícolas e costeiras, uma no Indo-Pacífico, outra náa África Ocidental e outra na América Ocidental, onde ocorrem igualmente espécies do gênero Exhippolysmata. Estes fatos indicam que comunidades afins devem ser procuradas nos fundos lamosos dos litorais tropicais.

\section{B. Fácies sujeita à influência fluvial moderada}

Localização. - Esta fácies é encontrada numa faixa relativamente èstreita que parte da costa do Pará em direcão ao norte, até cerca de 120 milhas da costa, e a seguir toma a direcão noroeste, sempre constituindo o limite externo do povoamento sob influência fluvial acentuada. A largura da área habitada é de aproximadamente 30 milhas e nela as coletas realizadas se distribuem entre os limites batimétricos de 28 e 92 metros. 
Fatores externos. - A área habitada pela fácies caracteriza-se por ser de transição entre os fundos costeiros e profundos, de um lado, e entre o setor constantemente submetido à influência fluvial e o periodicamente sujeito a influência fluvial.

O substrato não é conhecido na maioria das estacões realizadas. Há, no entanto, registros de fundos lamosos, areno-lamosos, arenosos e biodetrítico-arenosos; se o maior número de estacōes representasse o predomínio em área, seria possível afirmar que os fundos lamosos e os fundos arenosos ocupariam a maior parte do território.

A salinidade da água de superfície oscila entre 15,356 e $35,917 \%$, e a da água próximo ao fundo entre 35,556 e $36,146 \%$ os. Estas variações da salinidade são consequência da moderada influência fluvial.

A temperatura da água de superfície apresenta valores elevados, entre 27,08 e $28,93^{\circ} \mathrm{C}$, como não poderia deixar de ser levando em conta a latitude e a pequena profundidade.

Composição faunística. - A fauna é constituída por 68 espécies, agrupadas em 27 famílias. Entre os estomatópodos, reunidos numa única família, Squillidae, e um único gênero Squilla, saienta-se $S$. surinamica. Entre os isópodos é necessário saientar a família Cirolanidae, apresentando um gênero Excorallana, com 4 espécies. Os decápodos, no entanto, constituem a maior parte da fauna. Dentre as numerosas famílias, 4 merecem referência especial. A família Penaeidae por exemplo, apresenta 6 espécies, dentre as quais 4 são comuns. Outra família que não deve deixar de ser mencionada é a Portunidae, com apenas 4 espécies, porém uma sendo caracteristica (Portunus rufiremus). Outra espécie característica, Chasmocarcinus sp. D, pertence à família Goneplacidae, que apresenta ainda 4 outras espécies; finalmente, a familia Parthenopidae alcança aqui também alguma significacão.

Foram identificados mais de 450 espécimens. As espécies vasícolas representam metade do número de espécies e 2/3 do. número de exemplares, vindo em segundo lugar as espécies arenícalas, correspondendo a $38,2 \%$ da fauna, os $11,6 \%$ restantes estando repartido entre as espécies batiais cascalhicolas e não classificadas. 
Apenas Persephona finneganae e Chasmocarcinus sp. D merecem, pela sua frequência, ser consideradas constantes, enquanto, entre as espécies comuns, são mais frequentes Squilla surinamica, Xiphopenaeus kroyeri, Callianassa latispina, Dardanus fucosus, Clibanarius foresti, Hepatus gronovii, Portunus rufiremus e Chasmocarcinus sp. D. e Portunus rufiremus, duas espécies que são raras noutros povoamentos.

As duas espécies características do povoamento possuem ocorrências acidentais no seio de outras faunas: Chasmocarcinus $s p$. $D$, com efeito, foi coletada fazendo parte das faunas dos fundos lamosos sob influência fluvial acentuada, organogênicos de transição guiano-brasileira e arenosos e organogênicos profundos, e $P$. rúfiremus nos povoamentos dos fundos lamosos sob influência fluvial acentuada e arenosos sob influência fluvial moderada.

Povoamentos afins. - O que se conhece sobre a área de ocorrência das espéciẹs características, Chasmocarcinus sp. $D$ e Portunus rufiremus, tem que ser aproveitado na procura de povoamentos afins. A primeira delas, no entanto, é conhecida apenas do litoral brasileiro no trecho abrangido pelo Amapá e pelo Pará. É possível, no entanto, lembrar aqui que sua presenca em outros povoamentos, embora considerada acidental, pode revelar sempre alguma afinidade faunística. Portunus rufiremus possui distribuicão geográfica menos restrita: ocorre também no Suriname, entre 7 e 42 metros de profundidade, geralmente em fundos de lama. A presente fauna deve ser considerada como fácies de transicão dos povoamentos dos fundos lamosos ou areno-lamosos da Província Guianense, sendo de se esperar que, em torno de cada uma das comunidades afins, existentes noutras unidades biogeográficas, ocorram povoamentos ecologicamente afins, porém faunísticamente diferentes.

Dada a variabilidade das exigências ecológicas das espécies do gênero Portunus, em que há espécies bênticas e espécies pelágicas, não devem ser utilizadas as espécies afins do ponto de vista taxonômico na procura de povoamentos afins. Quanto ao gênero Chasmocarcinus, encontrado no Atlântico Ocidental, no Pacífico Oriental e no Indopacífico, pouco se sabe sobre a ecologia de suas espécies: geralmente, no entanto, ocorrem em fundos lamosos ou areno-lamosos, ou associados à fracão fina em fundos organogênicos. 


\subsubsection{Comunidade dos fundos arenosos costeiros}

Localização. - A fauna dos fundos arenosos costeiros é encontrada numa vasta área do litoral do Pará e em todo o litoral do Maranhão sujeita à influência fluvial moderada ou fraca, e de formato grosseiramente triangular. Os dois eixos principais nortesul e leste-oeste medem respectivamente cerca de 120 e 390 milhas náuticas. Os limites batimétricos das coletas realizadas na área habitada pela fauna se estendem desde o nível da baixa-mar até 75 metros de profundidade. Corresponde, assim, ao infralitoral e ao circalitoral.

Fatores externos. - O sedimento da área onde esta fauna é encontrada caracteriza-se pela presença de uma fração arenosa mais ou menos importante, muitas vezes associada a uma fracão de cascalho, e sempre com uma certa proporcão de lama. De um modo geral, a porcentagem de areia e cascalho, reunidas, ultrapassa $94 \%$ É possível reconhecer duas sub-áreas, uma com um teor de lama no sedimento geralmente em torno de 4 a $7 \%$, e outra com menos de $3 \%$ de lama. Há, no entanto, uma certa variacão em torno dos valores normais em cada área.

A salinidade da água, durante as coletas, variou entre $36,790 \mathrm{e}$ $17,883 \%$ oo na superfície e entre 36,814 e $30,458 \%$ o junto ao fundo. As variações da salinidade ocorrem em consequência da diluição pela água dos rios que desembocam na área, e aumentam no sentido leste-oeste.

A temperatura da água é constantemente elevada, não havendo referência a fenômenos de esfriamento junto ao fundo.

Este território assim caracterizado se delimita ao largo com o dos povoamentos dos fundos organogênicos e a oeste com o dos povoamentos dos fundos lamosos e areno-lamosos.

Composição faunística. - Este povoamento foi localizado em 24 retângulos. Foram encontrados representantes de 29 famílias. É de se salientar a total ausência, entre os decápodos, das famílias Galatheidae, Palicidae, Hapalocarcinidae. Ao contrário, as famílias Cirolanidae, Penaeidae, Calappidae, Portunidae e Parthenopidae alcancam grande variedade neste povoamento. É possível reco- 
nhecer duas fácies principais, a primeira com menor número de espécies arenícolas que a segunda. Na primeira destas fácies, as espécies características são Petrolisthes galathinus, Hexapanopeus pau. lensis e Pilumnus reticulatus; no outro, não há espécies características. O que caracteriza ambas fácies é a ausência praticamente total das espécies cascalhícolas e de especies batiais, além da importância reduzida das espécies vasícolas. Há duas espécies cuja presença está sempre ligada à presença de uma fracão arenosa no substrato e que, embora acompanhantes em vários povoamentos, atingemı sua maior frequência nestes povoamentos dos fundos arenosos costeiros: trata-se de Albunea paretti e Leptochela carinata.

Povoamentos afins. - Os fundos arenosos costeiros, com seu povoamento característico, se estendem ao longo da costa brasileira, em direcão ao leste, além dos limites da área estudada (KEMPF, 1970). Há, no entanto, variacões na constituição da fauna, sendo possível que haja a necessidade de dividi-la em fácies ou em recon'hecer a existência de faunas distintas, no momento em que for realizado estudo aprofundado. Estão presentes comunidades paralelas nas Antilhas, e daí para o norte. De acordo com o que se conhece sobre a distribuição das espécies, povoamentos com afinidades faunísticas podem ser encontrados nos fundos arenosos desde o Leste do Estados Unidos até o Sudeste do Brasil, mas não no setor guianense.

Para uma comparacão maior, torna-se necessário verificar as distribuições das duas espêcies mais importantes dos povoamentos: Albunea paretti e Leptochela carinata.

A. paretii pertence a uma família, Albuneidae e uma superfamília, Hippidea, em que as espécies são exclusivamente endopsâmicas. O gênero Albunea contém, segundo BALSS (1957a), 12 espécies, espalhadas nos mares quentes do globo. No Atlântico Oriental, A. paretii, A. carabus e A. intermedia fazem parte do povoamento dos fundos arenosos costeiros (MONOD, 1956). A. paretii, a única espécie do gênero que ocorre no Brasil, é encontrada no Atlântico Ocidental desde a Carolina do Norte até São Paulo, exclusivamente em fundos arenosos, porém é euribata.

L. carinata, ao contrário, pertence à família Pasiphaeidae, cujas espécies são geralmente profundas, embora umas sejam bênticas, 
e outras pelágicas (BALSS, 1957a); CROSNIER \& FOREST, 1973). O gênero Leptochela, no entanto, constitui excecão, e suas espécies são predominantemente costeiras ou euribatas (BALSS, 1957a); CHACE, 1972). L. carinata, espécie a qual pertencem $10 \%$ dos espécimens coletados nos fundos arenosos costeiros do Norte do Brasil, é encontrada no Atlântico Ocidental desde o Leste dos Estados Unidos até o Nordeste do Brasil, geralmente em fundos organogênicos.

Desta forma, a ocorrência destas duas espécies, $A$. paretii $\Theta L$. carinata indica uma afinidade entre os fundos arenosos costeiros $\theta$ profundos, de um lado, e entre os fundos arenosos costeiros e os fundos organogênicos, de outro lado. Torna-se necessário, no entanto, uma comparacão mais aprofundada entre as listas faunisticas, antes de tentar estabelecer um critério de afinidade entre os diversos povoamentos dos fundos arenosos.

\section{A. Fácies sujeita a influência fluvial moderada}

Localizaçāo. - A fácies sob influência fluvial moderada do povoamento dos fundos arenosos costeiros é encontrada numa faixa, de largura variável, situada entre as proximidades da llha de São Luís, no Maranhão, e as vizinhanças da foz do Rio Tocantins, no Pará. Corresponde assim ao setor oriental da costa do Pará, e ao setor ocidental da costa do Maranhão e se estende, por vezes, até 60 milhas da costa. Os limites batimétricos das coletas se estendem até $\mathbf{4 1}$ metros de profundidade, o que significa que a fácies corresponde ao infralitoral. Na presente.análise não serão levadas em conta as coletas costeiras.

Fatores externos. - $O$ território definido acima apresenta apenas fundos de natureza arenosa. A salinidade da água, no entanto, apresenta certas variaçóes. Na superfície, ela oscila entre 17,883 e $36,653 \%$ o e junto ao fundo entre 30,458 e $36,653 \%$ oo. Estas variaçōes são devidas à diluicão das águas do mar pela água dos rios que desaguam neste trecho da costa, ou em sua vizinhança. A. temperatura da água, na superfície, apresenta valores elevados, e o mesmo acontece junto ao fundo; os valores oscilam entre 27,01 e $28,85^{\circ} \mathrm{C}$.

Composição faunística. - A fácies é constituída por 53 espécies, agrupadas em 22 famílias. Não foi coletada nenhuma espécie de 
estomatópodo, e os isópodos estão mal representados, com excecão dos pertencentes à família Cirolanidae. Entre os decápodos, predominam as famílias Penaeidae e Majidae, a primeira com 5 e a segunda. com 8 espécies.

Ocorrem 8 espécies de isópodos, entre as quais 2 da família Anthuridae e 4 da família Cirolanidae. Entre os Cirolanidae é de se salientar o gênero Excorallana, que abrange 3 espécies.

O predomínio dos decápodos, em número de 46 espécies, é muito acentuado.

Foram identificados 340 espécimens, sendo que as espécies arenícolas, que constituem cerca de $2 / 3$ da fauna, estão representadas por $7 / 10$ dos exemplares. $O$ restante dos espécimens e das espécies é constituído por espécies vasícolas. É de se salientar a total ausência de espécies cascalhícolas e de espécies batiais.

A predominância de espécies arenícolas indica a importância da natureza do substrato na constituição do povoamento, porém a presença de certa fração de lama e a ocorrência de períodos de salinidade baixa são atestados pela presenca de espécies vasícolas e/ou eurialinas.

Várias espécies são constantes no povoamento, tais como Cyathura sp., Rocinela signata, Solenocera geijskesi, Leptochela carinata, Clibanarius foresti, Petrolisthes galathinus, Albunea paretii, Clythrocerus carinatus, Hepatus scaber, Pilumnus reticulatus e Pitho lherminieri e entre elas, Petrolisthes galathinus e Pilumnus reticulatus são escolhidas, como espécies características pela sua raridade ou ausência noutros povoamentos do litoral estudado; enquanto $P$. galathinus se apresenta como característica exclusiva, $P$. reticulatus apresenta ocorrência de carácter acidental nos fundos organogênicos do largo.

Comunidades afins. - As peculiaridades da constituicão da presente fácies tornam precária qualquer tentativa de localizar comunidades afins. Considerando inicialmente os fatores abióticos, é de se notar que, se os fundos arenosos estão muito espalhados por toda a parte, o regime de salinidade a que o povoamento está submetido é encontrado, quase sempre, apenas 
em estuários. Além disto, as duas espécies características possuem ecologia geral que não ajuda muito nesta tentativa. Realmente, Petrolisthes galathinus possue uma distribuição geográfica muito vasta, sendo conhecido do Atlântico Ocidental (Carolina do Norte, Golfo do México, Antilhas, América Central, Norte da América do Sul, Guianas e Brasil: Pará, Ceará, Paraíba, Pernambuco, Alagoas, Bahia, Rio de Janeiro, São Paulo) e do Pacífico Oriental (desde a Costa Rica até o Equador). Esta espécie é geralmente encontrada em coletas manuais realizadas em substrato rochoso, e em dragagens em fundos arenosos de pequena profundidade. Parece, no entanto, que o habitat principal sejam os fundos rochosos costeiros. Pilumnus reticulatus, por seu lado, ocorre em várias localidades desde as Antilhas até a Patagônia. A maioria das coletas mencionadas na literatura parece ter sido realizada manualmente, em substrato duro, e pelo menos algumas delas em locais de salinidade variável. Dai se conclui que sua ecologia não deve ser diferente da de $P$. galathinus, no que diz respeito às preferências por tipo de fundo.

A distribuição de espécies como Clibanarius foresti, Hepatus gronovii, Persephona finneganae e Solenocera geijskesi mostra que há uma certa afinidade entre os povoamentos dos fundos sujeitos à influência fluvial, não importando a natureza do substrato. Por outro lado, as espécies arenícolas, que constituem a maioria do povoamento, indicam a importância da natureza do substrato. Desta forma, é melhor considerar a fauna como sujeita a um jogo complexo de fatores, e que dificilmente podem ser encontrados povoamentos afins.

\section{B. Fácies sujeita a influência fluvial atenuada}

Localização. - A fácies sob influência fluvial atenuada do povoamento dos fundos arenosos costeiros, é encontrada no Pará e no Maranhão, geralmente ao largo da fácies sob influência fluvial moderada do povoamento dos fundos arenosos, porém tocando a costa leste do Maranhão. Para o largo, assim como em direcão do leste, é limitado por povoamentos dos fundos organogênicos; para oeste, no entanto, chega a se encontrar com o povoamento dos fundos lamosos e areno-lamosos. Foram realizadas coletas entre 21 e 75 metros de profundidade, o povoamento abrangendo o infra e o circalitoral. 
Fatores externos. - A fácies é encontrada num território onde predominam fundos arenosos ( $90 \%$ das estącōes), porém com alguma ocorrência de vários tipos de fundos organogênicos.

A água possui uma salinidade que oscila pouco, atingindo junto á superfície valores entre 34,618 e 36,790 e próximo ao fundo entre 34,618 e $36,814 \%$. A temperatura da água é elevada, e pouco varia durante $O$ ano: 26,06 e $28,52^{\circ} \mathrm{C}$.

Composiçāo faunística. - A fácies é constituída por 57 espécies, agrupadas em 28 famílias. Os estomatópodos estão representados por duas espécies, ambas raras. Entre os isópodos, a família Cirolanidae, com 6 espécies, corresponde a $50 \%$ da fauna. Todos os isópodos são raros. Como nas outras comunidades, os decápodos constituem o grupo dominante. As famílias Parthenopidae e Calappidae salientam-se pelo número de espécies, cada uma estando representada por 4 espécies. Se a significacão das espécies frequentemente não é conhecida, a das famílias o é: ambas são constituídas por formas exclusivamente endopsâmicas. A fauna caracteriza-se também pela pequena importância ou pela ausência de certas famílias como Penaeidae, Palaemonidae, Callianassidae, Porcellanidae, Goneplacidae, Pinotheridae... A familia Pasiphaeidae, ao contrário, alcanca aqui sua máxima importância, com 3 espécies, entre as quais está a espécie com maior índice de frequência (Leptochela carinata). A família Majidae, no entanto, é a que apresenta maior número de espécies (7), todas elas com índice de frequência diminuto.

Foram examinados mais de 220 exemplares. Cerca de $4 / 5$ da fauna é constituída por espécies arenícolas, que correspondem a igual proporcão de exemplares examinados. As espécies vasícolas e as de ecologia pouco conhecida correspondem ao restante do material. É de se salientar a total ausência de espécies batiais.

Nenhuma espécie mereceu ser considerada de frequência constante, e apenas 5 espécies são comuns: Leptochela carinata, Leptochela serratorbita, Albunea paretii, Ebalia stimpsoni e Portunus anceps. Nenhuma delas pode ser considerada característica. Umas poucas espécies que foram capturadas exclusivamente neste povoamento, por sua raridade não servem para caracteriza-lo.

A composicão da fauna indica claramente a influência predominante da natureza do substrato. 
Comunidades afins. - A inexistência de espécies características impede a procura de comunidades afins. Os autores consideram que este povoamento é uma fácies degradada do povoamento dos fundos arenosos costeiros do Nordeste do Brasil. Com efeito, entre as espécies presentes neste povoamento estão algumas das espécies mais frequentes nos fundos arenosos costeiros do Nordeste.

\subsubsection{Comunidades Dos Fundos Organogenicos}

Localização. - A fauna dos fundos organogênicos habita uma faixa ao longo da porcão externa da plataforma continental do Piauí, do Maranhāo, do Pará e de parte do Amapá, que se estende de sudeste a noroeste, numa extensão de 630 milhas náuticas, com uma largura média de 60 milhas. Os limites batimétricos das coletas realizadas nesta área se estendem desde 21 até 224 metros de profundidade.

Fatores externos. - $O$ sedimento é caracterizado pela presença de uma fracão de cascalho, entre 0 e $40 \%$, além de blocos maiores, geralmente não considerados no peneiramento. Devido ao tamanho dos retângulos utilizados, há um número inevitável de estaçōes com características particulares: fundos de areia, e também fundos de lama. De acordo com os dados disponíveis, em $64 \%$ das estações o fundo é organogênico, porém em $32 \%$ das estacões é arenoso e em 4\% é areno-lamoso ou lamoso. Estes números não dão informacōes concretas sobre a área coberta por cada tipo de fundo, porém fornecem uma indicacão aproximada, a ser usada com certas reservas. É possível também que certas estações mencionadas como possuindo fundo de natureza não organogênica na realidade apresentem um fundo biodetrítico muito arenoso ou lamoso.

Embora haja uma certa variacão da salinidade da água superficial, junto ao fundo ela permanece elevada o ano inteiro, com variacōes muito reduzidas.

A temperatura da água, na superfície, é constantemente elevada, porém junto ao fundo há um resfriamento da água, correspondendo a uma espécie de ressurgência, que não atinge a superfície do mar. 
Um outro fator a ser considerado é a presença ou ausência de algas calcárias, e seu papel na construcão do substrato: algas calcárias vivas (às vezes associadas à areia quartzosa, e quase sempre de mistura com algas calcárias mortas) foram encontradas exclusivamente à oeste do meridiano de $47^{\circ} 30^{\prime}$.

Composição faunística. - A fauna inclui 34 famílias, entre as quais se salientam Cirolanidade (Isopoda), Palaemonidae, Xanthidae, Parthenopidae e Majidae (Decapoda). É importante a presenca das famílias Galatheidae, Axiidae, Scyllaridae, Hapalocarcinidae, que não são encontradas nos fundos terrígenos. Certas familias alcancam maior variedade nestes povoamentos: Gonodactylidae, Paranthuridae, Sphaeromatidae, Xanthidae, por exemplo. De acordo com a presença ou a ausência de espécies batiais, são reconhecidos dois grupos principais de povoamentos: os povoamentos costeiros, desprovidos de espécies batiais, e os povoamentos de transicão, em que as espécies batiais formam uma fracão da fauna a ser considerada. Algumas espécies, no entanto, podem ser consideradas características da fauna dos fundos organogênicos em geral: trata-se de Accalathira crenulata, Alpheus macrocheles, Gonodactylis lacunatus, Palicus affinis, Pseudosquilla ciliata, Symethis variolosa, Metapenaeopsis martinella, Euryozius bouvieri, Panoplax depressa e Melybia thalamita. A esta lista seria possível acrescentar algumas espécies encontradas exclusivamente nesta fauna e na dos fundos profundos: Lophopanopeus sp., Mithrax acuti cornis, Ebalia conica, Euprognatha gracilipes e Paractaea rufopuncatata.

Povoamentos afins. - A grande quantidade de espécies caracterizando a fauna dos fundos organogênicos permite a localização de fundos com faunas afins em várias partes do mundo. Em primeiro lugar, há um elemento endêmico do Brasil, constituído por Ebalia conica e Lophopanopeus sp. A distribuição das demais espécies aponta para povoamentos afins noutros litorais, compreendendo a costa pacífica do Panamá, o litoral leste da América desde $34^{\circ} \mathrm{N}$ até $23^{\circ} \mathrm{S}$, nas ilhas do Cabo Verde e do Golfo de Biafra e uma vasta área do Indopacífico. Há uma semelhança muito grande entre o território assim delimitado e o ocupado pelas formacões coralinas (vide WELLS, 1957).

Parece haver, desce a Carolina do Norte até São Paulo, ou talvez um pouco mais ao sul (digamos, entre as latitudes $34^{\circ} \mathrm{N} \theta$ 
$24^{\circ} \mathrm{S}$ - novamente a simetria em torno da Província Guianense!), um contingente faunístico básico, euribata ou batial, associado aos fundos cascalhosos ou areno-cascalhosos (que geralmente são de origem organogênica), existentes junto ao bordo externo da plataforma continental, em nível correspondente ao circalitoral e ao comeco do batial. Nos lugares em que, por motivos vários ( $p$. ex., melhores condicões para o desenvolvimento das algas calcárias), este tipo de fundo alcanca locais menos profundos, é a fauna enriquecida por contingentes de espécies costeiras (infralitorais, ou comuns ao infralitoral e ao circalitoral) - Nordeste do Brasil, Antilhas. O hiato existente na área de ocorrência das espécies tropicais disjuntas e os endemismos (espécies brasileiras / espécies antilhanas) teriam muito que ver com esta hipótese.

\subsubsection{Comunidade dos fundos organogenicos costeiros}

Localização. - Este povoamento é encontrado numa pequena área correspondente a parte do litoral do Piauí, $\theta$ de formato grosseiramente triangular, talvez com $60 \times 60$ milhas. Os limites batimétricos das coletas realizadas são 21 e 69 metros.

Fatores externos. - A área habitada pelo povoamento caracteriza-se principalmente por condiçōes de salinidade $\theta$ de natureza do substrato.

O substrato é de natureza bastante variada. Em apenas 8 estacōes de coleta, 5 foram realizadas em fundos arenosos, 2 em fundos biogênico-detríticos e 1 em fundos biogênicos; as estacões em fundos areposos, no entanto, produziram pouco material biológico.

A salinidade da água de superfície, durante as coletas, mostrou-se sempre superior a $36 \%$, tanto na superficie, quanto junto ao fundo, o que permite caracterizar a área como de influência fluvial praticamente inexistente. A temperatura da água esteve sempre acima de $25^{\circ} \mathrm{C}$.

Composiçāo faunística. - A fauna é constituída por 76 espécies, agrupadas em 26 famílias. Os estomatópodos contam com apenas 3 espécies e os isópodos com 10 espécies, enquanto os decápodos apresentam 64 espécies. Uma espécie de estomatópodo, no 
entanto, apresenta grande importância, sendo considerada caracteristica do povoamento: Gonodactylus lacunatus. Entre os decápodos é de se salientar a ausência dos Galatheidae e destacam-se pelo menos 4 famílias. A família Dorippidae, por exemplo, apresenta apenas duas espécies, porém uma delas, Ethusa mascarone americana, é característica do povoamento. A família Goneplacidae possui importância gracas a Panoplax depressa, uma das espécies características. Mas são as famílias Xanthidae e Majidae que dominam o povoamento. $O$ total de representantes destas duas famílias é: 10 espécies de Xanthidae e 19 espécies de Majidae, ou seja, quase metade da fauna de decápodos.

Foram examinados mais de 470 espécimens, sendo que as espécies arenícolas, constituem $2 / 3$ da fauna $\theta 9 / 10$ dos exemplares. $1 / 4$ da fauna é constituido por espécies cascalhícolas e 0 restante por espécies vasícolas.

Não foram éncontradas espécies batiais nem de ecologia pouco conhecida.

Como o povoamento foi encontrado em apenas 3 retângulos, é necessário considerar como constantes as espécies com frequência 10, comuns as com frequência 7 e raras as com frequência 3. Uma vez aceito este critério, passariam a ser consideradas constantes as espécies Gonodactylus lacunatus, Ethusa mascarone americana, Micropanope pusilla $\odot$ Micropanope nuttingi. Além disto, as espécies comuns seriam Pseudosquilla ciliata, Cyathura sp., Excorallana sp., Sicyonia parri, Sicyonia laevigata, Iridopagurus violaceus, Paguristes erythrops, Dardanus venosus, Cycloes bairdii, Ebalia stimpsoni, Panopeus hartii, Panoplax depressa, Parthenope serrata, Cryptopodia concava, Collodes inermis, Stenorhynchus seticornis, Pitho lherminieri, Epialtoides rostratus, Mithrax acuticornis, Mithrax forceps, Macrocoeloma eutheca e Leptopisa setirostris. Seguindo o mesmo critério adotado noutros povoamentos, foram selecionados 11 espécies como características da fauna: Gonodactylus lacunatus, Sicyonia parri, Paguristes erythrops, Ethusa mascarone americana, Micropanope pusilla, Panopeus hartii, Pilumnus caribbaeus, Parthenope serrata, Cryptopodia concava, Epialtoides rostratus e Mithrax forceps.

Povoamentos afins. - O que se conhece sobre a distribuicão das espécies caracteristicas permite localizar povoamentos afins 
em vários trechos do litoral. As espécies características são frequentes no setor antilhano e no Brasil, desde o Piauí até Pernambuco. Nenhuma é encontrada ao norte da Carolina do Norte ou ao sul do Rio de Janeiro, nem no setor guianense (com exceção de uma ocorrência acidental de Panoplax depressa no Amapá).

Estas espécies ocorrem dentro de limites batimétricos restritos. No litoral brasileiro, estas espécies raramente são encontradas em profundidades que ultrapassam a isóbata de 80 metros, podendo assim ser consideradas características dos fundos costeiros. Estas espécies são encontradas em fundos organogênicos costeiros, e algumas frequentam também os fundos arenosos costeiros e as formaçōes recifais.

Os gêneros a que pertencem as espécies características possuem distribuição circuntropical (Gonodactylus, Sicyonia, Paguristes, Ethusa, Pilumnus, Cryptopodia, Parthenope) ou tropical americana (Micropanope, Epialtoides, Mithrax).

\subsubsection{Comunidade dos fundos organogenicos de transiçto}

Localização. - Estes povoamentos são encontrados nas proximidades do bordo externo da plataforma continental, em profundidades geralmente em torno dos 80 metros.

Fatores externos. - Há uma grande variedade de tipos de fundo. Predominam os fundos organogênicos, porém há uma certa porçāo de estaçōes com fundos arenosos; ocasionalmente também foram encontradas estacões com fundos lamosos $\theta$ areno-lamosos.

A salinidade da água pouco varia, tanto na superfície como junto ao fundo, os valores extremos observados durante as coletas tendo sido 35,760 e $36,313 \%$ oo. A temperatura, ao contrário, apresentou fortes variacōes junto ao fundo: entre 21,05 e $28,24^{\circ} \mathrm{C}$.

Composição faunística. - Estes povoamentos fóram localizados em 18 retângulos. Foram encontrados representantes de 31 famílias. É de se salientar a variedade em espécies das famílias Squillidae $\Theta$ Gonodactylidae (Stomatopoda), Cirolanidae (Isopo- 
da), Palaemonidae, Galatheidae, Xanthidae e Parthenopidae (Decapoda). É possível reconhecer dois povoamentos principais, o primeiro totalmente desprovido de espécies guianenses, e o segundo com uma porcentagem relativamente importante de espécies guianenses. $O$ povoamento destituído de espécies guianenses apresenta Munida brasiliae como espécie característica, ao contrário do povoamento com proporcão apreciável de espécies guianenses, em que a espécie característica é Discerceis sp. A. Algumas espécies podem ser consideradas como características dos povoamentos de transigão em geral; entre as mais importantes, estão Munida brasiliae, Pachycheles ackleianus, Picroceroides tubularis, Meiosquilla schmitti, Ebalia vertiginosa, Banareia palmeri, Batrachonotus brasiliensis.

Comunidade afins. - Analizando a distribuição destas espécies nas águas brasileiras observa-se que todas elas são típicas dos fundos organogênicos, porém Banareia palmeri, Picroceroides tubularis e Munida brasiliae não são coletadas entre 0 e 39 metros de profundidade, enquanto Batrachonotus brasiliensis não é coletada além da isóbata dos 80 metros. Além disto, Pachycheles ackleianus, Ebalia vertiginosa, Batrachonotus brasiliensis e Banareia palmeri são mais frequentes entre as isóbatas de 40 e 80 metros do que noutras profundidades.

Inicialmente, Ebalia vertiginosa, Batrachonotus brasiliensis e Munida brasiliae são espécies endêmicas das águas brasileiras, cuja distribuição, ao norte, não ultrapassa o Amapá, nem ao sul o Rio de Janeiro. A área de ocorrência destas espécies indica que os povoamentos em questão estão localizados, no litoral brasileiro, entre as latitudes das localidades citadas, e geralmente além da isóbata de 40 metros. As demais espécies ocorrem no Brasil dentro do território assim delimitado, e também no setor antilhano, ou seja, desde a Flórida até a Venezuela, sem que seja possível, no momento, realizar uma análise de suas preferências. Além disto, $B$. brasiliensis é representada no setor antilhano por uma espécie afim, $B$. fragosus.

Desta forma, estas espécies delimitam uma faixa desde a Flórida até o Rio de Janeiro, correspondente ao circalitoral, e com um hiato no setor guianense, em que comunidades afins são encontradas. $\mathrm{O}$ que se conhece sobre a ecologia e a distribuição 
dos gêneros a que pertencem as espécies características não permite muitas comparacōes com outros litorais. Com efeito, se os gêneros Pachycheles, Ebalia e Munida são encontrados tanto no Atlântico como no Índico, como no Pacífico, estāo representados por numerosas espécies de ecologias diversas, e os demais gêneros sāo exclusivamente americanos.

\section{A. Fácies brasileiro de transiçāo}

Localização. - Esta fauna é encontrada nas proximidades do bordo externo da plataforma continental do Maranhão e do Pará, ou seja, a uma distância da costa entre 60 e 150 milhas. As profundidades das coletas foram variáveis, oscilando entre 33 e 223 metros, porém mais frequentemente em torno dos 80 metros.

Fatores externos. - A área habitada pela fauna caracteriza-se principalmente pela natureza do substrato. Cerca de 2/3 das estacôes revelaram a presenca de fundos organogênicos, e 0 1/3 restante corresponde aos fundos arenosos. Em todas as estacões há um teor maior ou menor de cascalho, e em 1/2 delas há presença de uma certa fração de areia quartzosa.

A salinidade da água pouco oscila, sendo constantemente superior a 35\% \%o. A temperatura da água de superfície é elevada, porém junto ao fundo sentem-se os efeitos da ressurgência com temperaturas de até $21,05^{\circ} \mathrm{C}$ por ocasiāo das coletas.

Composição faunística. - O povoamento é constituído por 79 espécies, agrupadas em 26 famílias. Os estomatópodos alcancam aqui grande variedade. Entre eles, destaca-se Meiosquilla schmitti. Os isópodos são constituídos principalmente por representantes da familia Cirolanidae, entre os quais destacam-se 4 espécies: Excorallana costata, E. richardsonae, Rocinela signata e Cirolana gracilis. Como sempre, os decápodos abrangem a major parte da fauna. Pela variedade da fauna merecem mencão especial as famílias Palaemonidae, Xanthidae, Parthenopidae e Majidae, que juntas, correspondem a quase metade da fauna.

Foram examinados mais de 420 espécimens, $50 \%$ dos quais correspondem às espécies arenícolas que constituem $50 \%$ da fauna. Um terco da fauna é constituído por espécies cascalhícolas e 1/7 por espécies batiais. A ocorrência de espécies vasícolas não é importante. 
A importância das espécies cascalhícolas e das espécies batiais caracteriza a fauna como de transicão entre os povoamentos costeiros e profundos dos fundos organogênicos.

Duas espécies são consideradas constantes neste povoamento: Cyathuira sp., e Cycloes bairdii. O número de espécies comuns é mais elevado. Pela sua frequência, salientam-se Meiosquilla schmitti, Accalathura crenulata, Leptochela carinata, Alpheus macrocheles, Munida brasiliae, Symethis variolosa e Palicus affinis. Torna-se difícil escolher entre elas uma espécie característica, pois as espécies constantes e comuns apresentam frequências relativamente elevadas noutros povoamentos. Foi escolhida como espécie característica Munida brasiliae, levando em conta o fato de que, entre as espécies mencionadas, é a que possui distribuição mais restrita.

Comunidades afins. - Munida brasiliae, a espécie característica do povoamento possui distribuibuicão geográfica pouco conhecida. O material estudado até o presente mostra que ela é muito comum nas proximidades do bordo externo da plataforma continental, rara entre as profundidades de 40-50 metros, e completamente inexistente entre $0-40$ metros. Trata-se assim de excelente candidata à caracterização dos povoamentos dos fundos organogênicos existentes nas proximidades do bordo externo da plataforma continental.

\section{B. Fácies Guiano-Brasileiro de Transição}

Localizaçāo. - Este povoamento é encontrado numa faixa de formato irregular, situada entre os territórios das Províncias Brasileira e Guianense, constituindo uma área de transifão entre seus povoamentos. Nesta área foram realizadas coletas entre as profundidades de 35 e 167 metros.

Fatores externos. - 0 território habitado pelo povoamento possui uma grande variedade de tipos de fundo. $\mathrm{Em} 3 / 4$ das estacões foi encontrado fundo de natureza organogênica e no restante das estacões predominam fundos arenosos. A salinidade da água apresenta pequenas oscilacões, tanto na superfície, como junto ao fundo: entre 35,839 e $36,146 \%$ oo. A temperatura, ao contrário, apresenta maiores variaģões junto ao fundo, pois o povoamento habita um setor sujeito ao fenômeno da ressurgência; durante as coletas do material estudado, a temperatura junto ao fundo foi, no entanto, sempre igual ou superior a $24,0^{\circ} \mathrm{C}$. 
Composição faunística. - O povoamento é constituído por 70 espécies, agrupadas em 25 famílias. Os estomatópodos e os isópodos alcancam aqui grande variedade, os primeiros com 5 e os segundos com 13 espécies. Entre os segundos convém salientar o papel dos Cirolanidae, com 6 espécies. Os decápodos estão representados por 52 espécies, entre os quais é preciso lembrar as famílias Xanthidae ( 8 espécies) e Majidae (8 espécies).

Foram examinados mais de 300 exemplares. Cerca de $1 / 2 \mathrm{da}$ fauna é constituído por espécies arenícolas, que correspondem a $2 / 3$ do material examinado. O restante das espécies está distribuído entre as vasícolas, cascalhícolas e batiais.

Um certo número de espécies são constantes no povoamento. Entre os estomatópodos, é possível citar Meiosquilla schmitti e Pseudosquilla ciliata. Já os isópodos se fazem representar por Acca. lathura crenulata, Cirolana gracilis e Excorallana richardsonae. Finalmente, entre os decápodos, devem ser referido Cycloes bairdii, Cronius ruber, Paractaea rufopunctata e Lophopanopeus sp.

Entre as espécies comuns, as de maior frequência são Cyathura sp., Excoralla costata, Excoralla sp., Discerceis sp. A., Leptochela carinata, Alpheus macrocheles, Pachycheles ackleianus, Albunea paretii, Ebalia conica, Ebalia stimpsoni, Melybia thalamita, Palicus affinis, Euprognatha gracilipes, Stenorhynchus seticornis, Picroceroides tubularis e Mithrax acuticomis.

A única espécie que poderia ser considerada como característica é Discerceis sp. A., espécie conhecida apenas do presente povoamento, onde ela é comum. Este fato torna difícil a procura de povoamentos afins.

É de se considerar o povoamento como fácies de transição entre duas províncias biogeográficas.

\subsubsection{Povoamentos Profundos}

Localização. - A fauna profunda foi localizada em 3 setores isolados da área estudada: 1) ao largo da costa do Amapá, na altura dos cabos Orange, Caciporé e do Norte; 2) ao largo da costa do Amapá, no "canyon submarino" do Amazonas; 3) ao largo da costa do Pará, nas alturas da llha de Marajó. Em direcão à costa, 
estes setores são limitados pelas áreas dos povoamentos dos fundos lamosos ou areno-lamosos e dos povoamentos dos fundos organogênicos de transicão. Foram realizadas coletas entre 68 e 224 metros de profundidade.

Fatores externos. - Na maioria das estacōes realizadas no território habitado pela fauna (4/7) não foram ainda divulgados os dados sobre tipos de fundo. Nos $3 / 7$ restantes, $1 / 7$ corresponde a fundos organogênicos e 2/7 a fundos arenosos, o que faz supor que apenas $1 / 3$ da área seja coberto por fundos organogônicos.

Junto ao fundo, a salinidade da água, é sempre superior a $35 \%$ oo, porém a temperatura cai abaixo de $24^{\circ} \mathrm{C}$. Estas temperaturas são mais baixas que as encontradas nos outros povoamentos estudados.

Composição faunística. - Este povoamento foi localizado em 11 retângulos, sendo composto por 31 famílias. Comparando com a fauna das comunidades costeiras ou de transicão, a fauna dos povoamentos profundos apresenta várias singularidades. Em primeiro lugar, há que notar a total ausência no material estudado de representantes de várias familias de isópodos (Stenetriidae e Bopyridae) e de Decápodos (Sergestidae, Alpheidae, Ogyrididae, Scyllaridae, Albuneidae, Dromiidae, Grapsidae e Hapalocarcinidae) ou o pequeno número de espécies de certas famílias de estomatópodos (Gonodactylidae) de isópodos (Anthuridae e Paranthuridae) e de decápodos (Pasiphaeidae, Palaemonidae, Porcellanidae, Leucosiidae, Portunidae, Xanthidae, Pinnotheridae, Parthenopidae e Majidae). Ao contrário, as famílias Pylochelidae e Chirostylidae são exclusivas, e as famílias Sphaeromatidae e Axiidae são melhor representadas que nos povoamentos dos fundos costeiros e de transição.

O que caracteriza a fauna é a abundância de espécies batiais, correspondendo a $43,3 \%$ do número de espécies.

Foram examinados mais de 550 espécimens, correspondendo a 106 espécies, sendo que as espécies batiais constituem $39,8 \%$ do número de exemplares e $43,3 \%$ do número de espécies. Vêm a seguir as espécies arenícolas (1/3 do número de espécies), as vasicolas ( $15 \%$ do número de espécies) e as cascalhícolas (quase $5 \%$ do número de espécies, porém apenas cerca de $2 \%$ do número de exemplares). 
Como espécies constantes é possível citar apenas Munida simplex e Illiacantha subglobosa, porém entre as espécies comuns, apresentaram frequência mais elevada: Cirolana gracilis, Rocinela signata, Pylopagurus discoidalis, Cycloes bairdii, Ebalia conica, Nanoplax xanthiformis, Micropanope nuttingi, Paractaea rufopunctata, Actaea acantha, Palicus dentatus, Parthenope pourtalesii, Parthenope fratercula, Collodes inermis, Podochela gracilipes e Mithrax acuticornis. Dentre estas espécies de maior frequência são consideradas como características Pylopagurus discoidalis, Iliacantha subglobosa, Nanoplax xanthiformis, Palicus dentatus, Parthenope pourtalesii e Podochela gracilipes, que são raras ou ausentes nos outros povoamentos da área estudada.

Comunidade afins. - O que se conhece sobre a distribuicão das espécies características permite localizar povoamentos afins noutras localidades. Em primeiro lugar, Parthenope pourtalesii e Pylopagurus discoidalis são espécies batiais, cuja ocorrência em água mais rasas em certos pontos de sua área de dispersão deve ser considerada excepcional. Por este motivo, no entanto, sua distribuicão geográfica conhecida é limitada ao hemisfério norte, entre - Leste dos Estados Unidos e as proximidades da linha equatorial. Palicus dentatus e Nanoplax xantiformis possuem distribuicão semeIhante. Deve-se porém acrescentar que $N$. xantiformis é referido por RATHBUN (1930), também para as vizinhancas do Cabo Frio, no Rio de Janeiro, onde foi coletado a 108 metros de profundidade. Finalmente, Iliacantha subglobosa e Podochela gracilipes são espécies tropicais contínuas euribatas, a primeira conhecida desde a Carolina do Norte até a foz do São Francisco e a segunda desde a Carolina do Norte até Santa Catarina.

Podochela gracilipes é referida para O Brasil por COELHO \& RAMOS (1973a), RODRIGUES DA COSTA (1968) e RATHBUN (1925). RATHBUN refere-se a material coletado pelo "Hassler" diante do Cabo Frio, Rio de Janeiro, a 64 metros de profundidade. RODRIGUES DA COSTA (1968) refere-se a material de São Paulo e de Santa Catarina entre 6 e 26 metros de profundidade. Finalmente COELHO \& RAMOS (1973a) e COELHO (1971a) referem-se a material coletado entre o Amapá e Rio de Janeiro incluindo os bancos ao largo de Espírito Santo. $O$ texto de COELHO \& RAMOS (1973a) saiu incorreto quanto a profundidade do material coletado e deve ser corrigido para 53 - 103 metros, como se vê em Coelho (1971a), além de ser retirada a referência ao Rio de Janeiro. Foram 
realmente examinados pelos autores espécimens provenientes de 16 estacōes ao longo da costa brasileira, sendo que apenas 4 estacōes entre 53 e 69 metros (Piauí, Ceará, Bahia e Espírito Santo) e as 12 restantes entre 70 e 111 metros de profundidade (Amapá, Pará, Ceará e Bancos ao largo do Espirito Santo). Afora algumas estacóes em fundos arenosos ou lamosos localizados no Amapá, no Pará e no Piauí, todas as coletas foram realizadas em fundos organogênicos. Destes dados é possível concluir que $P$. gracilipes, no Brasil, habita as proximidades do bordo externo da plataforma continental desde o Amapá até o Rio de Janeiro e a plataforma continental, junto à costa, em São Paulo - Santa Catarina. Também o material referido por RATHBUN (1925) como tendo sido obtido entre a costa e a isóbata de 70 metros foi todo coletado ao norte da latitude de $20^{\circ} \mathrm{N}$, ou seja, em latitudes ecologicamente semelhantes à do Sudeste do Brasil. Trata-se, portanto, de espécie amfisubtropical.

Iliacantha subglobosa é conhecida do Brasil gracas aos trabalhos de COELHO (1971a,b) e COELHO \& RAMOS (1973a), onde é exclusivamente batial. RATHBUN (1937) confirma que no Hemisfério Norte a espécie é predominantemente batial, porém ocasionalmente capturada em águas mais rasas.

Em resumo, a distribuição das espécies características mostra que há uma analogia da fauna existente nas proximidades do bordo externo da plataforma continental desde o Leste dos Estados Unidos até o Sudeste do Brasil, porém que algumas das espécies típicas deste povoamento são encontradas em águas mais rasas nas proximidades dos limites extremos de sua distribuição geográfica.

\subsection{CONCLUSÕES}

\subsubsection{Divlsáo Blogeografica do Litoral}

O exame dos mapas da distribuição mostra que, partindo do centro da área estudada, se acentuam os caracteres distintivos de 3 regiōes habitadas por fauna diferente. À leste, ocorrem espécies costeiras ou euribatas, brasileiras, tropicais continuas e tropicais disjuntas; à oeste, sāo encontradas espécies costeiras ou euribatas, guianenses, tropicais contínuas e algumas brasileiras. 
Para o largo, nas áreas banhadas por águas frias, predominam espécies batiais e euribatas. Isto conduz naturalmente a distinguir três unidades biogeográficas e a estabelecer, no limite entre as áreas ocupadas pelas espécies guianenses, tropicais disjuntas e batiais, a fronteira entre as unidades zoogeográficas assim estabelecidas (Fig. 21). Como existe uma certa superposicão nas áreas ocupadas pelos conjuntos faunísticos que definem as províncias em questão, é reconhecida uma faixa de transicão, com 60 - 120 milhas de largura.

Cada uma destas províncias pode ser subdividida em comunidades faunísticas ocupando setores restritos (Fig. 19). Impöe-se, no momento, apenas um estudo da composicão faunística das duas áreas.

Num total de 238 espécies, 89 foram capturadas no trecho brasileiro da Província Guianense.

Na porcão estudada da província Brasileira, foram recolhidas 158 espécies.

Convém lembrar ainda que o trecho estudado da Província Brasileira corresponde a uma área de empobrecimento; as diferenças entre as Províncias certamente sāo maiores que o presente estudo pode revelar.

\subsubsection{Interpretaçăo Dos Limites Biogeọgráficos}

No litoral norte estão presentes faunas contrastantes. De um lado, há um grupo de espécies vasícolas costeiras ou euribatas, eurialinas, estenotermas quentes, habitando exclusivamente a Província Guianense. De outro lado, estão espécies arenícolas ou cascalhícolas, costeiras ou euribatas, estenoalinas, estenotermas quentes. Para o largo, existem espécies euritermas, euribatas ou profundas. Isto tudo sugere um limite associado à salinidade da água, à natureza do substrato e à temperatura.

A barreira da salinidade, que pode ser considerada equivalente à posicão da isoalina de $36 \%$ oo, muda de posicão durante 0 ano, ocupando posiçōes extremas em novembro-dezembro e em abril; a posição junto ao fundo desta isoalina no período novem- 


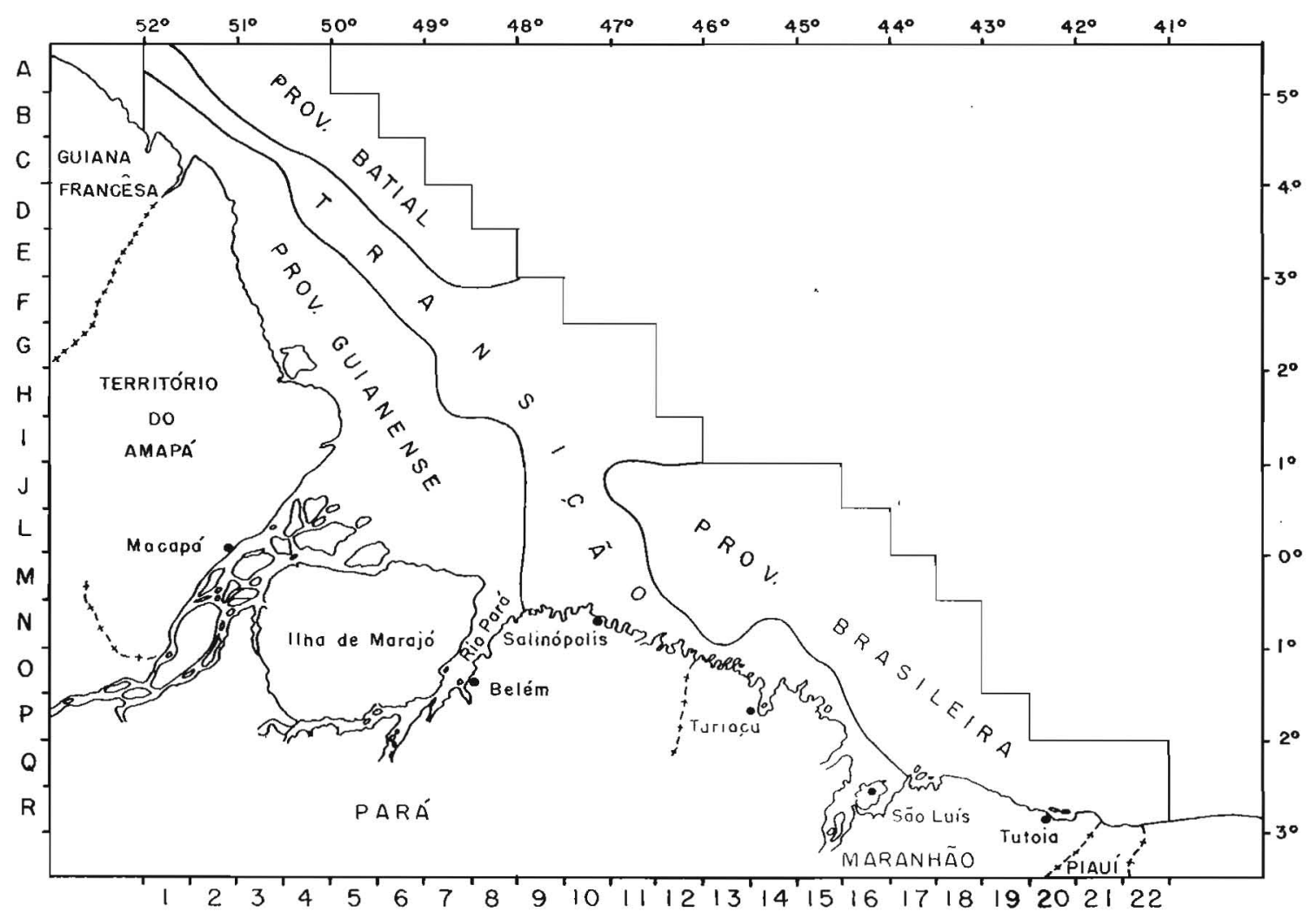

Fig. 21 - Divisão biogeográfica do litoral equatorial brasileiro. 
bro-dezembro, tal como mostrada pela expedicão NORTE-NORDESTE I, foi escolhida para representar o limite da área de salinidade constantemente baixa (cf. o ítem 4.1). Este seria, portanto, o limite máximo para oeste, do ponto de vista da salinidade, permitido para as espécies estenoalinas. Esta linha, no entanto, não serve para limitar as espécies eurialinas, pois à leste a salinidade é baixa durante parte do ano, permitindo sua dispersão neste sentido.

A barreira de salinidade pode ser considerada como bastante antiga, existindo desde a época em que os grandes rios equatoriais comecaram a correr na direcão atual, possivelmente desde 0 terciário (AB'SABER, 1964).

A natureza do substrato aparentemente possui limites bem precjsos; no entanto, é preciso levar em conta que as espécies vasícolas tolerantes podem ocorrer, e de fato ocorrem, inclusive às vezes em maior abundância, nos fundos arenosos e organogênicos. Por outro lado, as espécies arenícolas também frequentam os fundos organogênicos. Desta forma, a natureza do substrato deve constituir fator limitante da Província Brasileira, e não da Província Guianense.

As condicões "salinidade constantemente baixa" e "fundos lamosos" coincidem bastante no espaco, aproximadamente formando um limite único para a Província Brasileira.

O limite leste da Província Guianense parece difícil de estabelecer. Ele corresponde, com bastante aproximacão, à posição da isoalina de $35 \%$ junto ao fundo obtida durante a comissão NORTE-NORDESTE II. No que diz respeito à salinidade superficial, corresponde, igualmente com uma aproximação muito grande, a uma linha que a separaria da área em que, durante o ano, 6 meses ou mais possuem salinidade superior a $36 \%$ os meses com salinidade abaixo de $36 \%$ na totalidade da área da Província Guianense no Brasil seriam marco - julho. Desta forma, o limite leste da Província Guianense, embora corresponda a uma barreira de salinidade, não coincide com o da Província Brasileira.

Realmente, o que acontece é um empobrecimento progressivo da Província Brasileira desde o Ceará até as proximidades da 
foz do Rio Amazonas, paralelo ao aumento da variacão anual da salinidade, deixando vastas áreas pouco povoadas. As espécies da Província Guianense, então, podem se misturar com um povoamento brasileiro rarefeito, numa área de transicão.

Com relação às espécies euribatas, aparece uma distinção entre as espécies tropicais disjuntas e tropicais contínuas, completando a demarcacão dos limites da Província Brasileira. Trata-se do fato que as espécies tropicais contínuas euribatas geralmente são também euritermas, encontrando na área de ressurgência existente junto ao bordo externo da plataforma continental, na Província Guianense, condicões de temperatura e de tipos de fundo semelhantes às existentes na plataforma continental no Leste dos Estados Unidos ou no Sudeste do Brasil. As espécies tropicais disjuntas euribatas, que geralmente são estenotermas quentes, se vêm limitadas pelas baixas temperaturas junto ao fundo.

Em resumo, o limite entre as unidades biogeográficas é dado por uma série de fatores de ordem hidrológica e sedimentológica, principalmente pela natureza dos tipos de fundo e pela distribuicão das isotermas $\theta$ isoalinas junto ao fundo. Estes fatores estão em relacão com outros de ordem mais geral: a circulacão das águas oceânicas e a influência da vazão dos rios equatoriais. É possível que uma diferenca importante entre as espécies tropicais disjuntas e as espécies brasileiras estenoalinas esteja na duracão do período larval. Pondo à parte a possibilidade de alguma espécie tropical disjunta ser mais antiga que a barreira amazônica, é de se esperar que uma espécie, originária do Brasil, possa colonizar a Província Antilhana caso suas larvas, pelágicas, possam ultrapassar a barreira amazônica, que é intransponivel para um adulto. Esta colonizacão é possível apenas no sentido Brasil - Antilhas, todo transporte larval em sentido contrário sendo impedido pelo sentido geral da circulacão das águas oceânicas.

HUTCHINS (1947) apresentou um esquema muito interessante sobre as relacões entre a temperatura e a distribuicão das espécies, levando em conta as exigências e tolerâncias das fases menos resistentes e mais resistentes do ciclo de vida. Ampliando o referido esquema para incluir maior quantidade de fatores do ambiente, seria possivel, certamente, melhor compreensão das 
barreiras existentes entre as províncias biogeográficas. No presente estudo, por exemplo, a temperatura, a salinidade, a profundidade e o tipo de fundo mostraram-se importantes para explicar os limites entre as províncias e o mesmo ocorreu na delimitacão das outras províncias existentes no litoral atlântico da América do Sul (COELHO \& RAMOS, 1973a; COELHO \& KOENING, 1973; COELHO, KOENING \& RAMOS, no prelo).

NEYMAN (1971) afirma que as fronteiras biogeográficas coincidem com as fronteiras entre as massas d'água. $E$, por outro lado, as diferencas entre as massas d'água, no que diz respeito à produtividade, conduzem à diferencas na estrutura trófica do bentos. Por este motivo, há também uma coincidência entre os limites das unidades biogeográficas e as estruturas tróficas das comunidades bênticas. Donde se conclui que as comunidades bênticas diferem entre si na importância relativa dos diversos grupos taxonômicos. Por outro lado, como os limites entre as massas d'água são bastante nítidos, as unidades biogeográficas delimitadas na presente pesquisa devem ser consideradas cenotipos abiogênicos de acordo com a nomenclatura de LINDROTH, 1971 (ver também COELHO, KOENING \& RAMOS, no prelo).

\subsubsection{Comunidades Faunisticas}

Foram tentadas classificacão e uma descricão, tão coerentes quanto possivel, dos povoamentos de crustáceos do litoral equatorial brasileiro.

A existência de descontinuidades entre os povoamentos permitiu a utilizacão dos conceitos de comunidade e de fácies, porém tomados num sentido bem largo, esperando poder reestudar posteriormente toda a fauna e toda a flora, empregando então a noção mais precisa de biocenose.

As comunidades faunísticas, definidas pela presenca ou pela ausência de certos grupos de espécies, ultrapassam os limites impostos por um sistema de zonacão, o qual não pode ser aplicado com precisão em virtude do arredondamento decorrente do tamanho dos retângulos.

CERAME-VIVAS \& GRAY (1966) realizaram um estudo muito semelhante ao presente, procurando estabelecer os limites entre 
as unidades biogeográficas existentes no litoral da Carolina do Norte. Este trabalho foi baseado principalmente em coletas com dragas e abrangeu esponjas, celenterados, anelídeos, moluscos, artrópodos e equinodermas. A sua Figura 3, que mostra as áreas biogeográficas, é muito semelhante à Figura 19 do presente trabalho, que mostra as áreas ecológicas. Esta diferenca se prende ao modo de interpretar os resultados. Para CERAME-VIVAS \& GRAY, a comunidade encontrada na «área C» é considerada pertencente à Província Tropical (ou Antilhana), e nāo à Província Caroliniana. Segundo o tipo de análise adotado no presente trabalho, as áreas "B" e "C" de CERAME-VIVAS \& GRAY seriam comunidades bênticas da Província Caroliana. Também DAY, FIELD \& MONTGOMERY (1971) não conseguiram dados suficientes para poder considerar a "área C» como parte da Província Antilhana.

\section{ABSTRACT}

The Brazilian Coast between Amapá and Piauí States is characterized by its hidrology. This results of several factors: the influence of superficial oceanic currents, the discharge of the great equatorial rivers, the upwelling at the edge of continental shelf, etc. There are several bottom types on continental shelf, and their horizontal distribution depends of oceanic and fluvial-terrigenous influences. There are two natural regions, one with sandy and organogenous bottoms, high and stable temperature and salinity, and another with muddy and sandy bottoms, and unstable temperature and salinity. The first natural regions corresponds to the Brazilian Province of the biogeographers, and the second one to Guyanian Province. It is possible to admit 5 faunistic communities of crustaceans inhabiting: 1) muddy and sandy-muddy bottoms; 2) sandy bottoms; 3) coastal organogenous bottoms; 4) organogenous bottoms of transition; 5) deep sandy and organogenous bottoms.

\section{BIBLIOGRAFIA}

AB'SABER, A.N. O relevo brasileiro e seus problemas. In: AZEVEDO, A. dir. Brasil, a terra e o homem. São Paulo, Cia Ed. Nacional, 1964. v.1, cap. 3, p. 135-250.

ALLEE, W.C. \& SCHMIDT, K.P. Ecological animal geography. New York, Willey, 1965. $715 \mathrm{p}$.

BALECH, E. División geográfica del litoral sudamericano. Rev. Biol. Mar., Valparaiso, 4:184-95, 1951.

BALSS, H. Decapoda 7. Geographlsche Verbreitung. Leipzig, Akademische Verlagsgesellschaft Geest \& Portig, 1957. p. 1505-672. (Klassen und Ordnungen des Tierreichs, Bd. 5, Abt. 1, Buch 7, Lief. 12). 
Decapoda 8. Systematik. Leipzig, Akademische Verlagsgesellschaft

Geest \& Portig, 1957. p. 1505-672. (Klassen und Ordnungen des Tierreichs, Bd 5, Abt. 1, Buch 7, Lief. 12).

BEKLENISHEV, C.W. et alii. Le biotope dans le milieu marin. Mar. Biol., Berlin, 15(1):57-73, 1972.

BOTELHO, C.C. Plataforma continental e litoral. in: BRASIL. IBGE. Atlas nacional do Brasil. Rio de Janeiro, 1966. Mapa II-4.

BRASIL. Diretoria de Hidrografia e Navegacão. Atlas de carta plloto. Oceano Attantico de Trinidad ao Rio da Prata. Rio de Janeiro, 1974. (Publ. n. 14.200). «Almirante Saldanha" (14/9 a 16/12/1967). Rio de Janeiro, 1968. 600 p. (DG26-XI).

. XXXV Comissão Oceanográfica. «Operaçăo norte-nordeste I NOC

$\mathrm{CABIOCH}$, L. Contribution a la connaissance des peuplements benthiques de la Manche Occidentale. Trav. Sta. Biol. Roskoff, Nouv. Sér. 18:493-720, 1968-69.

CERAME-VIVAS, J.J. \& GRAY, I.E. The distributional pattern of benthic invertebrates of the continental sheilf off North Carolina. Ecology, Durham, N. Carolina, 47(2):260-70, 1966.

CHACE Jr., F.A. The shrimps of the Smithsonian-Bredin Carlbbean Expeditions with a summary of the West Indian shallow-water species (Crustacea: Decapoda: Natantia). Washington, Smithsonian Institution Press, 1972. 179 p. (Smithsonian Contr. Zool., 98).

COELHO, P.A. A distribuição dos crustáceos decápodos reptantes do Norte do Brasil. Trab. Oceanogr. Univ. Fed. Pernambuco, Recife, 9/11:223-38, 1971.

Nota prévia sobre os Majidae do Norte e Nordeste do Brasil (Crustacea, Decapoda) Arq. Mus. Nac., Rio de Janeiro, 54:137-43, 1971.

\& RAMOS, M.A. A constituicão e distribuicão da fauna de decápodos do litoral leste da América do Sul entre as latitudes de 5\%N e 39\%. Trab. Oceanogr. Univ. Fed. Pernambuco, Recife, 13:133-236, 1973.

COELHO, P.A. et alii. Contribuicão ao conhecimento dos camaróes comerciais do Norte e Nordeste do Brasil. In: BRASIL. Diretoria de Hidrografia e Navegagāo. XXXVIII comissáo oceanogrdifica NOC aAlmirante Seldanhas (5/11 a 20/12/1968). Rio de Janeiro, 1973. Apênd. 3, p. 121-31, 1973. (DG26-XIV). 
et alii. Rémarques sur la biogeographie des crustacés marins du Brésil, de 1'Uruguay et de 1'Argentine (au nord de Mar del Plata). Bul. Mus. Natt. Hist. Nat., Paris. (no prelo).

COOKE, A.H. Molluscs. In: HARMER, S.F. \& SHIPLEY, A.E., ed. The Cembridge natural history. London, Macmillan, $1895.459 \mathrm{p}$.

COSTA, H.R. da. Crustacea, brachyura récoltés par les draguages de la «Calypsow sur les cotes brésilienne (1962). Rec. Trav. Stat. Mar. Endoume, Marseille, 43(59):333-43, 1968.

COUTINHO, P.N. \& MORAIS, J.O. Sediment distribution of the continental plataform of Northern North-Eastern Brazil. FAO Fish. Rep., Roma, (71.1): 121, 1969.

CROSNIER, A \& FOREST, J. Les crevettes profondes de l'Atantique Orientel Tropical. Paris, ORSTOM, 1973. 409 p. (Faune Tropical, 19).

DANA, J.D: On the geographical distribution of crustacea. In: Crustacea. Lochem, Antiquariat Junk, 1972. p. 1451-592. Reimpressão da ed. de 1852.

DAY, J.H. et alii. The use of numerical methods to determine the distribution of benthic fauna across the continental shelf of $\mathrm{N}$. Carolina. J. Anim. Ecol., Oxford, Engl., 40:93-125, 1971.

DEFANT, A. Physical oceanography. London, Pergamon Press, 1961. v. 1.

DIEGUES, F.M.F. Introdução à oceanografia do estuário amazônico. An. Hidrogr. Rio de Janeiro, DH3, 29:129-57, 1972.

ESTADOS UNIDOS. Naval Hydrographic Office. Monthly temperature charts of the South Atantic Ocean. Washington /s.d./ 1 f. (H. O Misc. No. 10.689-1).

Oceanogrephic attas of the North Attantic Ocean. II. Physicel properties, 1967. Washington, 1963. 227 p. (Pub. 700).

. Oceanographic atias of the North Atiantic Ocean. Sec. V. Marine geology. Washington, 1965. 79 p. (Publ. 700).

FOREST, J. \& SAINT LAURENT, D.M. de. Campagne de la Calypso au large des Cotes Atlantique de l'Amérique du Sud (1961-62) Première partie (suite). 6. Crustacés décapodes: pagurides. Ann. Inat. Oceanogr. Resultats Scientifiques des Campagnes de la Calypso. Paris, fasc. 8, Nouv. ser. 45(2):47-169, 1967. 
GARTH, J.S. Eastern Pacific Expedition of the New York Zoological Society. XLIV. Non-intertidal brachygnathous crabs from the west coast of Tropical America. Pt. 1: Brachygnatha Oxyrhyncha. Zoologica, New York, 44(3):105-26, 1959.

GIBBS, R.J. Circulation in the Amazon river estuary and adjacent Atlantic Ocean. J. Mar. Res., New Haven, Conn. 28(2):113-23, 1970.

GUILCHER, A.P. Précls d'hydrologie marine et continentale. Paris, Masson, 1965.

GUILLE, A. Bionomie benthique du plateau continental de la côte catalane francaise. II. Les communautés de la macrofaune. Vie et Milieu, Paris, Ser. B. Oceanogr., Fasc. 1B 21:199-280, 1970.

GUINOT-DUMORTIER, D. Sur une collection de crustacés (Decapoda Reptantia) de Guyane Francaise. I. Brachyura (Oxyrhyncha esclus). Bull. Mus. Natt. Hist. Nat., Paris, 2. ser. 31(5):423-34, 1959.

Bull. Mus. Natt. Hist. Nat., Paris, 31(6): 5-10-15, 1960.

II Brachyura oxyrbyncha et macrura. Bull. Mus. Natt. Hist. Nat., Paris, 32(2): 177-87, 1960.

HAZEL, J.E. Atlantic continental shelf and slope of the United States - ostracode zoogeography in the Southern Nova Scotian and Virginian faunal provinces. In: WOODS HOLE OCEANOGRAPHIC INSTITUTION. Collected reprints, 1970. Woods Hole, 1971. pt. 1. Contribution 2156.

HEDGPETH, J.W. Marine biogeography. In:- Treatise on marine ocology and paleontology. Washington, National Res. Council, 1957. v. 1, cap. 13, p. 359-82. (The Geological Society of America, Memoir, 67).

HENDERSON, J.R. Report on the anomura collected by H.M.S. Challenger during the years 1973-76. In: REPORT on the Scientif ic Results of the Voyage of H.M.S. Chalenger during the years 1873-76. New York, Johnson Repr. Co., 1965. Zoology, v. 27, p. 1-221. Reimpressão da ed. de 1888.

HOLTHUIS, L.B. The crustacea decapoda of Suriname. Zool. Verh., Leiden, 44:1296, 1959.

HUTCHINS, L.W. The bases for temperature zonation in geographical distribution. Ecol. Monogrephs, Oxford, Engl., 17(3):325-35, 1947.

KEMPF, M. et alii. Plataforma continental do Norte e Nordeste do Brasil. Nota preliminar sobre a natureza do fundo. Trab. Oceanogr. Univ. Fed. Pernembuco, Recife, 9/11:9-26, 1970.

KNOX. G.A. Littoral ecology and biogeography of the southern seas. Proc. R. Soc. Ser. B. 152(949):577-624, 1960. 
LABOREL, J. Les peuplements de madrepeporaires des cotes tropicales du Brésil. Marseille, 1967. p. 1-184. Thèse - Faculté des Sciences de l'Université d'Aix Marseille.

LAUBIER, L. Le corralligêne des Albères. Monographie biocénotique. Ann. Inst. Oceanogr., Paris, fasc. 2 et dernier, nouv. ser. 43:137-316, 1966.

LINDROTH, A. On biocenoses: coenotypes and coenoclines. Thelessia Jugost., Proceedings of the Sixth European Symposium on Marine Biology, Zagreb, Yugoslavia, 7(1):185-94, 1971.

MABESOONE, J.M: \& COUTINHO, P.N. Littoral and shallow marine geology of Northern and Northeastern Brazil. Trab. Oceanogr. Univ. Fed. Pernambuco, Recife, 12: 1-214, 1972.

MARTINS, L.R. et alii. Estudo preliminar sobre a distribuicäo faciológica da plataforma continental brasileira. Pesquisas, Porto Alegre, 1:51-6, 1972.

METCALF, W.G. Shallow currents along the Northeastern coast of South America. J. Mar. Res., New Haven, Conn., 26:232-43, 1968.

\& STALCUP, M.C. Origin of the Atlantic Equatorial under current. J. Geophys. Res., Richmond, Virginia, 72(2):4959-75, 1967. (ref. cop.)

MONOD, Th. Hippidea et brachyura ouest-africains. Mem. IFAN, Dakar, 45:1-674, 1956.

NEUMANN, G. Oceanography of the tropical Atlantic. An. Acad. Bras. Ci., Rio de Janeiro, 37:63-86, 1965. Suplemento.

. The equatorial undercurrent in the Atlantic Ocean. In: SYMPOSIUM ON THE OCEANOGRAPHY AND FISHERIES RESOURCES OF THE TROPICAL ATLANTIC., 1:., Abidjan, 1966. Proceedings. Paris, Unesco, 1969. p. 33-44.

. Seasonal salinity variation in the upper strata of the Western Tropical Atiartic Ocean. I. Sea surface salinities. Deep Sea Res., Frederick C. Fuglister, Sixtieth Anniversary volume. London, 16:195-77, 1969. Suppl.

NEYMAN, A.A. Some problems of the division of the shelves of the world's oceans based on bottom fauna. JOINT OCEANOGRAPHIC ASSEMBLY IAPSO IABO CMG SCOR, Tokyo, 1970, Proceedings. /s. 1./ Japan Society for the Promotion of Science, 1971. D2-B-1, p. 451-52.

OTTMANN, F. Estudos das amostras do fundo recolhidas pelo N. Oc. «Almirante Saldanhan na região da embocadura do Rio Amazonas. Treb. Inst. Blol. Mar. Oceanogr. Univ. Recife, 1:77-106, 1959. 
PARKER, R.H. Zoogeography and ecology of macro-invertebrates of Gulf of California and continental slope of Western Mexico. Mem. Amer. Assoc. Petro. Geol., 3:331-76, 1964.

PÉRÈS, J.M. Oceanographie biologique et biologie marine. I. La vie benthique. Paris, Presses Univ. de France, 1961. 541 p.

\section{. La vida en el oceano. Barcelona, Martinez Roca, 1968.}

PERLROTH, I. The distribution of water type struture in the first 300 feet of the equatorial Atlantic. In: SYMPOSIUM ON THE OCEANOGRAPHY AND FISHERIES RESOURCES OF THE TROPICAL ATLANTIC, 1., Abidjan, 1966. Proceedings. Paris, Unesco, 1969. p. 185-91.

PICARD, J. Recherches qualitatives sur les bioceenoses marines des substrats meubles dragables de la région marseillaise. Rec. Trav. Stat. Mar. Endoume, Marseille, 52(36):1-160, 1965.

RATHBUN, M.J. The spider crabs of America. Washington, Government Printing Office, 1925. 613 p. (Smithsonian Institution. U.S. National Museum. Bulletin, 129).

The cancroid crabs of America of the families Euryalidae, Portunidae, Atelecyclidae, Candridae and Xantidae. Washington, Government Printing Office, 1930. 609 p. (Smithsonian Institution. U.S. National Museum, Bulletin, 152).

. The oxystomatous and allied crabs of America. Washington, Gov. Print. Office. 1937. 277 p. (Smithsonian Institution. U.S. National Museum, Bulletin, 166).

RYTHER, J.H. et alii. Influence of the Amazon river outflow on the ecology of the Western Tropical Atlantic. I. Hydrography and nutrient chemistry. J. Mar. Res., New Haven, Conn., 25(1):69-83, 1967.

SILVEIRA, J.D. Morfologia do litoral. In: AZEVEDO, A. ed. Brach, a terra e o homem. São Paulo, Cia. Ed. Nacional, 1964. cap. 4, v. 1, p. 253-305.

SOYER, J. Bionomie benthique du plateau continental de la côte catalane francaise. III. Les peuplements de copépodes harpacticoides (Crustacea). Vie et Milieu, Paris, Sér. B. Oceanogr., Fasc 2 B, 21:337-511, 1970.

THORSON, G. Bottom communities (sublittoral or shallow shelf). In: HEDGPETH, J.W. ed. Treatise on marine ecology and paleoecology. Washington, Natl. Res. Counsil, 1957. v. 1. cap. 17. p. 461-534, 1957. (The Geological Society of America. Memoir, 67). 
TIXIER-DURIVAUT, A. Campagne de la Calypse au large des côtes atlantique de L'Amérique du Sud (1961-62) (Première partie). 24. Octocoralliaires. Ann. Inst. Oceanogr., Paris, 47:145-69, 1970.

TOMMASI, L.R. Faunistic provinces of the Western South Atlantic littoral regions. An. Acad. Bras. Ci., Rio de Janeiro, 37:261-62, 1965. Suplemento.

VALENTINE, J.W. Numerical analysis for marine molluscan ranges on the extratropical Northeastern Pacific shelf. Limnol. Oceanogr., Lawrence, Kansas, 11(2):198-211, 1966.

WELLS, J.W. Coral reefs. In: HEDGPETH, J.W. ed. Treatise on marine ecology and paleoecology. Washington, Natl Res. Council, 1957. v. 1, cap. 20, p. 60931. (The Geological Society of America. Memoir, 67).

WILLIAMS, A.B. Marine decapod crustaceans of the Carolinas. Fish. Bull., Washington, 65(1):1-298, 1965.

ZAKHAROV, L.A. Bottom sediments of the South American shelf between the rivers Amazon and Orinoco. Oceanology, Washington, 14(1): 118-27, 1974. 
A NEXOS 


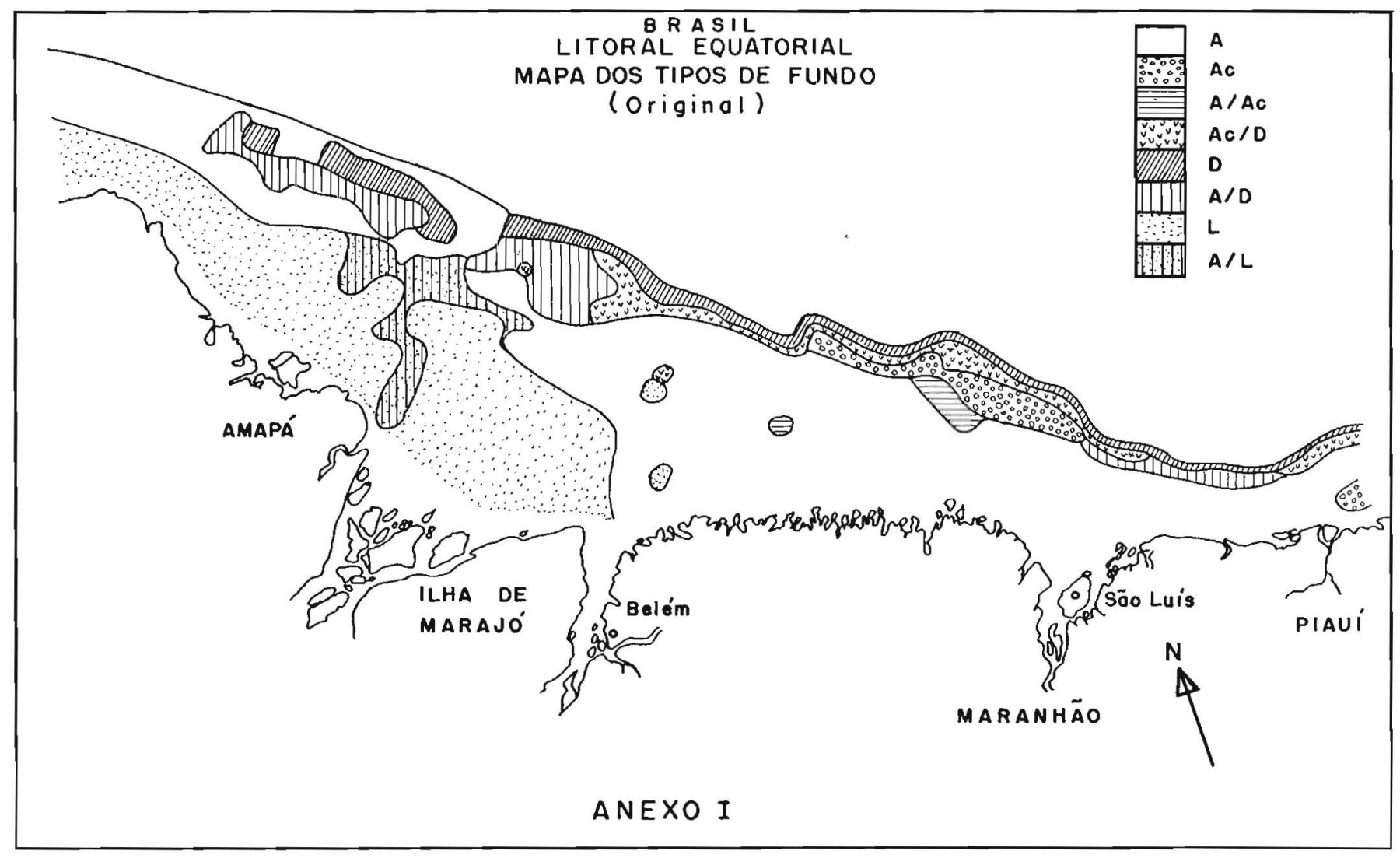




\section{ANEXO II}

\section{LISTA DAS ESPÉCIES}

Os principais dados sobre a distribuição das espécies (biogeografia, ecologia, frequência nos povoamentos), acompanhados de uma indicacão bibliográfica, constituem a lista das espécies. Na coluna intitulada "Ecologia", os símbolos significam, respectivamente: G - espécie guianense, TC - tropical contínua, TD - tropical disjunta, B - brasileira, Bat-anfisubtropical, C - costeira, P - profunda, E - euribata, Va - vasicola, AR - arenicola, CA - cascalhicola, ? - indecisão quanto a classificaçāo da espécie.

Na coluna areferências" os números correspondem aos trabalhos com indicacōes bibliográficas sobre as espécies.

Na coluna efrequência nos povoamentos", os símbolos sảo os mesmos da fig. 20; os números indicam a frequência nos povoamentos e as linhas interrompidas assinalam a frequência das espécies que são caracteristicas de povoamentos ou de fácies.

$\mathrm{Na}$ coluna "Obs." está mencionado que certas espécies foram coletadas manualmente nas proximidades de São Luis (MA), não tendo sido levadas em conta na definição dos povoamentos. 


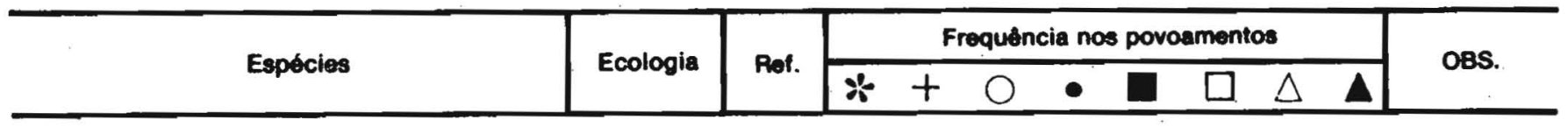

\section{STOMATOPODA}

\section{Família SQUILIDAE}

Meiosquilla schmitti (Lemos de Castro)

Meiosquilla quadridens (Bigelow)

Squilla lijdingi Holthuis

Squilla surinamica Holthuis

Squilla obtusa Holthuis

$\begin{array}{cccccccccccc}\text { TC } & \text { E } & \text { Ar } & 33 & - & - & - & 1 & - & 4 & 7 & 1 \\ \text { TC } & \text { C } & \text { Ca } & 33 & - & - & - & - & 3 & - & - & - \\ \text { G } & \text { C } & \text { Va } & 33 & 1 & 2 & - & - & - & - & 2 & 1 \\ \text { G } & \text { C } & \text { Va } & 33 & 3 & 3 & - & - & - & - & - & 1 \\ \text { TC } & \text { C } & \text { Va } & 33 & - & 1 & - & - & - & - & - & -\end{array}$

\section{Familia GONODACTYLIDAE}

Pseudosquilla ciliata (Fabricius)

Odontodactylus brevirostris (Miers)

Gonodactylus lacunatus Manning

Gonodactylus torus Manning

TD E Ar

TD E Ca

TD C Ar

Bat $\mathrm{P}^{\circ} \mathrm{Ca}$

\begin{tabular}{|c|c|c|c|c|c|c|}
\hline 33 & - & - & - & 1 & 7 & \\
\hline 33 & - & - & - & - & - & \\
\hline 33 & - & - & - & - & 10 & \\
\hline 33 & - & - & - & - & 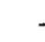 & \\
\hline
\end{tabular}

\section{ISOPODA}

Familia ANTHURIDAE

Anthuridae n. det.

Cyathura sp.

Anthelura sp.

$\begin{array}{llllll}\mathrm{B} & \mathrm{C} & \mathrm{Ar} & - & - & - \\ \mathrm{B} & \mathrm{E} & \mathrm{Ar} & - & - & - \\ ? & \mathrm{C} & \mathrm{Ar} & - & - & -\end{array}$

\section{Família PARANTHURIDAE}

Paranthuridae $\mathrm{n}$. det.

Accalathura crenulata (Richardson)

$\begin{array}{cccccccccccc}\text { Bat } & \mathrm{P} & \mathrm{Va} & - & - & - & - & - & - & - & 2 & - \\ \mathrm{TC} & \mathrm{E} & \mathrm{Ar} & 32 & - & 1 & - & - & 3 & 4 & 5 & 1\end{array}$




\section{Espocies}

Ecologia

Ret.

\begin{tabular}{|c|}
\hline \multicolumn{3}{|c|}{ Frequência nos povoamentos } \\
\hline$+\quad \square \triangle \square$
\end{tabular}

OBS.

\section{Família CIROLANIDAE}

Cirolanidade $\mathbf{n}$. det.

Cirolana parva Hansen

Cirolana minuta Hansen

Cirolana gracilis Hansen

Excorallana costata Lemos de Castro

Excorallana sp.

Excorallana oculata (Hansen)

Excorallana richardsonae Lemos de Castro

Alcirona krebsi Hansen

Rocinela signata Schioedte \& Meinert

\begin{tabular}{|c|c|c|c|c|c|c|c|c|c|c|c|}
\hline Bat & $\mathbf{P}$ & ? & - & - & - & - & - & - & - & - & 1 \\
\hline TD & C & $\mathrm{Ca}$ & 31 & - & - & - & - & 3 & 1 & 1 & - \\
\hline Bat & $\mathbf{P}$ & $?$ & 44 & - & - & - & - & - & - & - & 1 \\
\hline TC & $E$ & $\mathrm{Ca}$ & 31 & 1 & 1 & - & - & - & 3 & 8 & 3 \\
\hline B & $E$ & $\mathrm{Ar}$ & 5 & - & 1 & 4 & 1 & - & 3 & 3 & 4 \\
\hline B & $E$ & $\mathrm{Ar}$ & - & - & 1 & - & 1 & 7 & - & 3 & 1 \\
\hline TC & $\mathbf{E}$ & $\mathrm{Ar}$ & 31 & - & 1 & 2 & 1 & 3 & 2 & - & 1 \\
\hline B & $E$ & Ar & 5 & - & 2 & 4 & 1 & - & 3 & 7 & 2 \\
\hline TC & C & Ar & 44 & - & - & - & 1 & 3 & 1 & - & 1 \\
\hline TC & $E$ & Ar & 36 & 1 & - & 6 & 1 & 3 & 3 & 2 & 3 \\
\hline
\end{tabular}

Família SPHAEROMATIDAE

Sphaeromatidae $\mathbf{n}$. det.

Discerceis linguicauda Fichardson

Discerceis sp.

Discerceis sp. A

Discerceis sp. B

Ancinus depressus (Say)

Cerceis sp.

Cymodoce australis Richardson

\begin{tabular}{|c|c|c|c|c|c|c|c|c|c|}
\hline Bat & $\mathrm{Ca}$ & - & - & - & - & - & - & 1 & - \\
\hline TC & Ar & 44 & - & - & - & - & - & 2 & - \\
\hline Bat & $\mathrm{Ar}$ & - & - & - & - & - & - & - & 2 \\
\hline$?$ & E Ar & - & - & - & - & - & - & - & 3 \\
\hline G & Ar & - & - & - & - & - & - & - & 2 \\
\hline TC & $E$ & 47 & 1 & - & - & - & 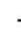 & - & - \\
\hline Bat & $P$ ? & - & - & 1 & - & - & - & - & - \\
\hline B & $\mathrm{E} \quad \mathrm{Ar}$ & 43 & - & - & 2 & 1 & 3 & - & - \\
\hline
\end{tabular}




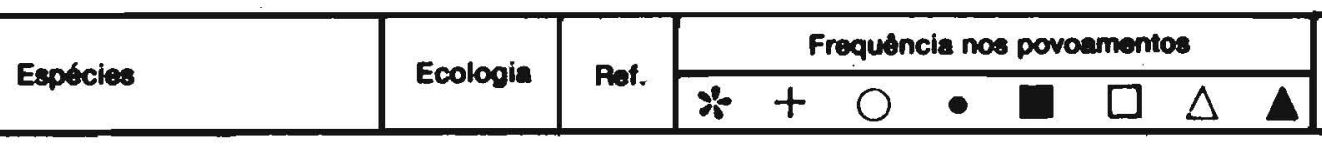

OBs.

Familia SEROLIDAE

Serolis $\mathbf{s p}$.

TC E ? -

Familia ARCTURIDAE

Arcturidae $\mathrm{n}$. det.

Astacilla sp. A

Astacilla sp. B

$\begin{array}{lll}? & \mathrm{C} & ? \\ \text { Bat } & \mathrm{P} & \mathrm{Ar} \\ ? & \mathrm{C} & \mathrm{Ar}\end{array}$

Familia IDOTHEIDAE

Chaetilinae n. det. .

Cleantis planicauda Benedict

B C ? - 1

Família STENETRIIDAE

Stenetrium occidentale Hansen

TC $\mathrm{C} \quad \mathrm{Ca}$

31

\section{Família BOPYRIDAE}

Munidion sp.

Guge sp. (?) ou lone sp. (?)

Grapsicepon sp.

$\begin{array}{llll}? & \mathrm{C} & ? & - \\ ? & \mathrm{C} & ? & - \\ ? & \mathrm{C} & ? & -\end{array}$

\section{DECAPODA}

Família PENAEIDAE

Solenocera geijskesi Holthuis

Trachypenaeus constrictus (Stimpson)

Trachypenaeus similis (Smith)

$\begin{array}{cccccccccccc}G & E & V a & 18 & 2 & 2 & 6 & - & - & - & 2 & 1 \\ \text { TC } & C & V a & 18 & 1 & 1 & 2 & - & - & - & - & - \\ G & C & V a & 18 & 1 & 2 & - & - & - & - & 2 & 1\end{array}$




\begin{tabular}{|c|c|c|c|c|c|c|c|c|c|c|c|c|c|}
\hline \multirow{2}{*}{ Espbcies } & \multirow{2}{*}{\multicolumn{3}{|c|}{ Ecologia }} & \multirow{2}{*}{ Ref. } & \multicolumn{8}{|c|}{ Frequôncia nos povoamentos } & \multirow{2}{*}{ OBs. } \\
\hline & & & & & $*$ & + & & $\bullet$ & & & $\triangle$ & $\Delta$ & \\
\hline Xiphopenaeus kroyeri (Heller) & TC & $E$ & $\mathrm{Va}$ & 18 & 7 & 4 & - & - & - & - & - & 1 & \\
\hline Metapenaeopsis martinella Perez Farfante & $\mathrm{TC}$ & $\mathrm{C}$ & $\mathrm{Ca}$ & 18 & - & - & - & - & 3 & 2 & 2 & - & \\
\hline Metapenaeopsis goodei (Smith) & TC & $\mathrm{C}$ & Ar & 18 & - & - & 4 & - & - & 1 & - & - & \\
\hline Sicyonia burkenroadi Cobb & G & $\mathbf{E}$ & $?$ & 18 & - & - & - & - & - & - & - & 1 & \\
\hline Sicyonia parri (Burkenroad) & TD & C & $\mathrm{Ar}$ & 18 & - & - & - & - & 7 & 1 & - & - & \\
\hline Sicyonia dorsalis Kingsley & TC & C & Va & 18 & 2 & 2 & 4 & - & - & - & - & 2 & \\
\hline Sicyonia laevigata Stimpson & $\mathrm{TC}$ & C & $\mathrm{Va}$ & 18 & - & 1 & 4 & - & 7 & 1 & 2 & 1 & \\
\hline \multicolumn{14}{|l|}{ Família SERGESTIDAE } \\
\hline Acetes americanus Ortmann & TC & $\mathrm{C}$ & Ar & 18 & 1 & - & - & 1 & - & - & - & - & \\
\hline \multicolumn{14}{|l|}{ Família PASIPHAEIDAE } \\
\hline Leptochela bermudensis Gurney & $\mathrm{G}$ & C & Ar & 4 & - & - & - & 1 & - & - & 2 & - & \\
\hline Lepetochela serratorbita Bate & $\mathrm{TC}$ & $\mathrm{C}$ & $\mathrm{Va}$ & 18 & 2 & 1 & 4 & 2 & 3 & 2 & - & - & \\
\hline Leptochela carinata Ortmann & $\mathrm{TC}$ & $E$ & Ar & 18 & - & - & 10 & 3 & 3 & 4 & 3 & 1 & \\
\hline \multicolumn{14}{|l|}{ Família PALAEMONIDAE } \\
\hline Palaemon schmitti Holthuis & B & C & Va & 18 & 7 & 1 & - & - & - & - & - & 1 & \\
\hline Lipkebe holthuisi Chace & Bat & $\mathbf{P}$ & $\mathrm{Ca}$ & 18 & - & - & - & - & - & 1 & - & 1 & \\
\hline Pontonia margarita Smith & $\mathrm{TD}$ & $\mathrm{C}$ & Ar & 29 & - & - & - & - & - & 1 & - & - & \\
\hline Periclimenaeus ascidiarum Holthuis & TD & $\mathrm{C}$ & Ar & 18 & - & - & - & 1 & - & - & - & - & \\
\hline Periclimenaeus pearsei (Schmitt) & TD & C & $\mathrm{Ca}$ & 29 & - & - & - & - & - & 1 & - & - & \\
\hline Periclimenaeus bermudensis (Armstrong) & TD & C & $\mathrm{Ca}$ & 18 & - & - & - & - & - & 1 & - & - & \\
\hline Periclimenes americanus (Kingsley) & TD & $E$ & Ar & 18 & - & - & 2 & - & - & 3 & 2 & 1 & \\
\hline Periclimenes longicaudatus (Stimpson) & TD & $\mathrm{C}$ & Ar & 18 & 1 & - & - & 1 & - & - & - & - & \\
\hline Anchystioides antiguensis (Schmitt) & TD & $E$ & $\mathrm{Ca}$ & 18 & - & - & - & $\div$ & - & 1 & - & .- & \\
\hline
\end{tabular}




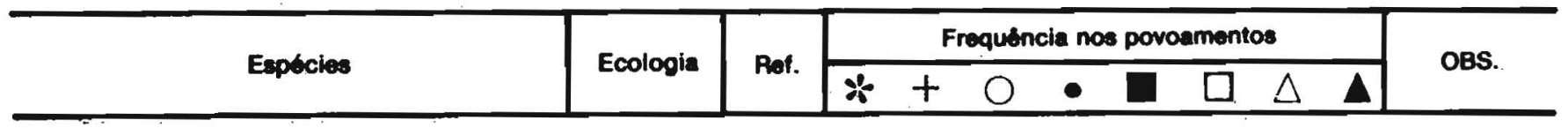

Família ALPHEIDAE

Alpheus macrocheles (Hailstone)

Alpheus intrinsecus Bate

Alpheus floridanus. Kingsley

Alpheus cylindricus Kingsley

Automate sp.

$\begin{array}{llllllllllll}\text { TD } & \mathrm{E} & \mathrm{Ca} & 18 & - & - & - & - & 3 & 4 & 3 & - \\ \mathrm{TC} & \mathrm{C} & \mathrm{Va} & 18 & 1 & - & - & - & - & - & - & - \\ \mathrm{TC} & \mathrm{C} & \mathrm{Ar} & 6 & - & 2 & 2 & 1 & 3 & - & 2 & - \\ \mathrm{TD} & \mathrm{C} & \mathrm{Ca} & 18 & - & - & - & - & - & 1 & - & - \\ & & \mathrm{Va} & & 1 & 2 & - & - & - & 2 & - & \end{array}$

\section{Familia OGYRIDIDAE}

Ogyrides sp.

Va

3

\section{Familia HIPPOLYTIDAE}

Exhippolysmata oplophoroides (Holthuis)

Trachycaris restricta (A. Milne Edwards)

TC C Va 6

Bat $P$ ? 18

\section{Família CALLIANASSIDAE}

Ctenocheles sp.

Callianasse guara Rodrigues

Callianassa latispina Dawson

Callianassa marginata Rathbun

Callianassidae $\mathrm{n}$. det.

Upogebia (Upogebia) brasiliensis Holthuis

Upogebia (Upogebia) marina Coelho

Upogebia (Upogebia) omissa Gomes Corrêa

Upogebia (Calliadne) acanthura Coelho

$\begin{array}{cccc}\text { Bat } & \mathrm{P} & ? & - \\ \mathrm{B} & \mathrm{C} & \mathrm{Va} & 18 \\ \mathrm{G} & \mathrm{E} & \mathrm{Ar} & 2 \\ \mathrm{TC} & \mathrm{E} & \mathrm{Ar} & 18 \\ \text { Bat } & \mathrm{P} & \mathrm{Ar} & - \\ \mathrm{B} & \mathrm{C} & ? & 18 \\ \mathrm{~B} & \mathrm{C} & \mathrm{Ca} & 17 \\ \mathrm{~B} & \mathrm{C} & \mathrm{Ar} & 18 \\ \mathrm{~B} & \mathrm{C} & \mathrm{Ar} & 18\end{array}$




\section{Família AXIIDAE}

Meticonaxius lemoscastroi (Rodrigues \& Carvalho)

Meticonaxius minutus Coelho

Axiopsis spinulicauda?

Calastacus angulatus Coelho

Calastacus spinosus Coelho

Bat P ?
G E V

\section{Familia SCYLLARIDAE}

Scylarus chacei Holthuis

TC $C$ Va 18

$-$

\section{Família PAGURIDAE}

Pagurus longimanus Wass

Pylopagurus holthuisi Provenzano

Pylopagurus discoidalis (A. Milne Edwards)

Iridopagurus iris (A. Milne Edwards)

Iridopagurus violaceus de Saint Laurent

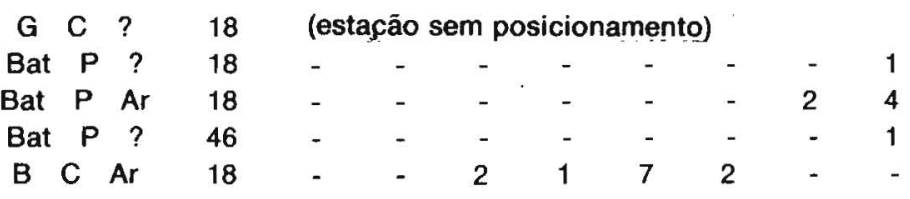

\section{Família DIOGENIDAE}

Paguristes erythrops Holthuis

Dardanus venosus (Milne Edwards)

Dardanus fucosus Biffar \& Provenzano

Petrochirus diogenes (Linnaeus)

Clibanarius foresti Holthuis

Clibanarius vittatus (Bosc)

$\begin{array}{llll}\text { B } & \text { C } & \text { Ar } & 18 \\ \text { TD } & \text { E } & \text { Ar } & 18 \\ \text { G } & \text { E } & \text { Ar } & 3 \\ \text { TC } & \text { C } & \text { Ar } & 18 \\ \text { G } & \text { C } & \text { Va } & 18 \\ \text { TC } & \text { C } & ? & 18\end{array}$

Col. manual 


\section{Espécies}

Família PYLOCHELIDAE

Pylochelis'ae n. det.

Bat $P$

$-$

\section{Família CHIROSTYLIDAE}

Uroptychus minutus Benedict

Bat $P$

18

\section{Familia GALATHEIDAE}

Munida simplex Benedict

Munida irrasa A. Milne Edwards

Munida brasiliae Coelho

Munidopsis barbarae (Boone)

\begin{tabular}{|c|c|c|c|c|c|c|c|c|}
\hline Bat $\mathrm{P} \quad \mathrm{Ca}$ & 1 & - & - & - & - & - & 3 & 2 \\
\hline Bat $P$ ? & 18 & - & - & - & - & - & 1 & - \\
\hline $\mathrm{B} \quad \mathrm{C} \quad \mathrm{Ca}$ & 14 & - & - & - & - & - & 4 & 2 \\
\hline Bat $P$ ? & 37 & 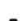 & & & & - & & - \\
\hline
\end{tabular}

\section{Familia PORCELLANIDAE}

Pachycheles rugimanus A. Milne Edwards Pachycheles ackleianus A. Milne Edwards Petrolisthes armatus Gibbes

Petrolisthes galathinus (Bosc)

Minyocerus angustus Dana

Porcellana sigsbeiana A. Milne Edwards

Porcellana sayana (Leach)

Pisidia sp. A

Pisidia sp. B

Pisidia sp. C

Megalobrachium mortenseni Haig

\begin{tabular}{|c|c|c|c|c|c|c|c|c|c|c|c|c|}
\hline Bat & $P$ & $?$ & 17 & - & - & - & - & - & - & - & 1 & \\
\hline TD & $\mathrm{C}$ & $\mathrm{Ca}$ & 18 & - & - & - & - & - & 2 & 3 & - & \\
\hline TC & C & $?$ & 18 & & & & & & & & & Col. manual \\
\hline TC & $\mathrm{C}$ & Ar & 18 & - & - & 6 & - & - & - & - & - & \\
\hline TC & $\mathrm{C}$ & $\mathrm{Ar}$ & 18 & - & - & 1 & - & - & 1 & - & & \\
\hline G & $\mathrm{C}$ & Va & 37 & 1 & 1 & - & - & - & - & - & - & \\
\hline TC & C & $\mathrm{Va}$ & 18 & 1 & 1 & - & - & - & - & - & - & \\
\hline B & $\mathrm{C}$ & $\mathrm{Ar}$ & - & 2 & - & 2 & 1 & - & - & - & - & \\
\hline B & $\mathrm{C}$ & $?$ & - & & & & & & & & & Col. manual \\
\hline$?$ & C & $?$ & - & & & & & & & & & Col. manual \\
\hline TD & $\mathrm{C}$ & $\mathrm{Ar}$ & 18 & - & - & 2 & - & 3 & - & - & - & \\
\hline
\end{tabular}




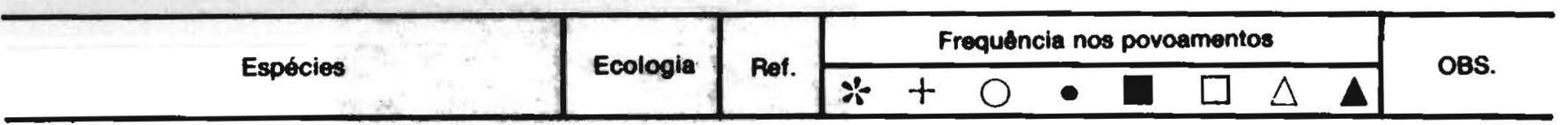

\section{Familia ALBUNEIDAE}

Albunea paretii Guerin

$\begin{array}{llllllllllll}\text { TC } & \mathrm{C} & \mathrm{Ar} & 18 & - & 2 & 8 & 2 & 3 & - & 3 & -\end{array}$

\section{Familia RANINIDAE}

Ranilia constricta (A. Milne Edwards)

Raninoides loevis (Latreille)

Symethis variolosa (Fabricius)

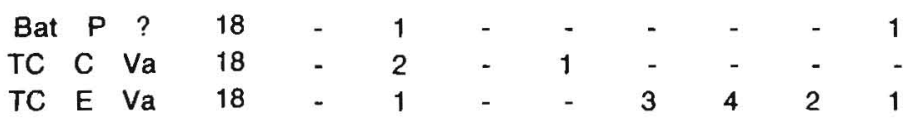

\section{Família DROMIIDAE}

Hypoconcha sabulosa (Herbst)

Hypoconcha arcuata Stimpson

TD $\mathrm{C}$ Ar 18

TC C Ar 18

\section{Família DORIPPIDAE}

Ethusa mascarone americana (A. Milne Edwards)

Clythrocerus carinatus Coelho

Clythrocerus stimpsoni Rathbun

Chythrocerus granulatus Rathbun

Clythrocerus analogus Coelho

Clythrocerus perpusillus Rathbun

Cymonomus quadratus (A. Milne Edwards)

$\begin{array}{ccccccccccc}\text { TD C } & \text { Ar } & 18 & - & - & - & - & 10 & - & - & - \\ \text { B C } & \text { Ar } & 9 & - & - & 6 & 1 & 3 & - & - & - \\ \text { Bat P ? } & 41 & - & - & - & - & - & - & - & 1 \\ \text { Bat P ? } & 50 & - & - & - & - & - & - & - & 1 \\ \text { B C Ca } & 8 & - & - & - & - & - & 1 & - & - \\ \text { B P ? } & 50 & - & - & - & - & - & - & - & 1 \\ \text { Bat P ? } & 41 & - & - & - & - & - & - & - & 1\end{array}$

\section{Família CALAPPIDAE}

Calappa nitida Holthuis

Calappa sulcata Rathbun

C E ?

TC C Va

20

Calappa ocellata Holthuis

TC C Va 18




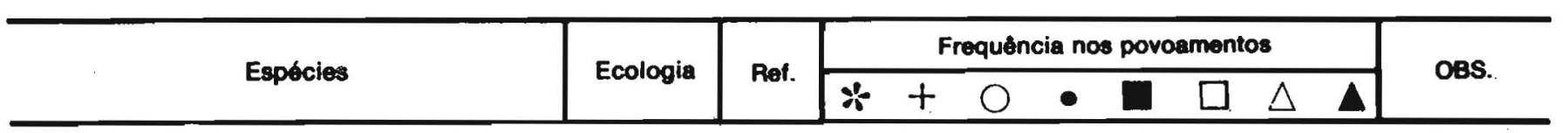

Cycloes bairdii Stimpson

Hepatus gronovii Holthuis

Hepatus scaber Holthuis

Hepatus pudibundus (Herbst)

Osachila antillensis Rathbun

$\begin{array}{cccccccccccc}\text { TC } & \text { E } & \text { Ar } & 18 & - & 1 & 4 & 1 & 7 & 5 & 10 & 4 \\ \text { G } & \text { C } & \text { Va } & 18 & 2 & 3 & 2 & - & - & - & - & - \\ \text { G } & \text { C } & \text { Va } & 18 & 3 & - & 6 & - & - & - & 2 & 2 \\ \text { TC } & \mathrm{C} & \mathrm{Va} & 18 & - & - & - & 1 & - & - & - & - \\ \text { TD } & \mathrm{E} & \mathrm{Ar} & 18 & - & - & - & 1 & - & 1 & - & 1\end{array}$

Família LEUCOSIIDAE

Ebalia cariosa Stimpson

Ebalia conica Coelho

Ebalia obliqua Coelho

Ebalia stimpsoni A. Milne Edwards

Ebalia vertiginosa Coelho

Speloeophorus elevatus Rathbun

Persephona punctata (Linnaeus)

Persephona finneganae Rathbun

Persephona lichtensteinii Leach

Callidactylus asper Stimpson

Iliacantha sparsa Stimpson

Iliacantha intermedia Miers

lliacantha subglobosa Stimpson

$\begin{array}{cccccccccccc}\mathrm{TD} & \mathrm{C} & \mathrm{Va} & 49 & 1 & - & 4 & - & - & - & - & - \\ \mathrm{B} & \mathrm{E} & \mathrm{Ar} & 10 & - & 1 & - & - & 3 & - & 3 & 3 \\ \mathrm{~B} & \mathrm{C} & \mathrm{Ar} & 11 & - & - & 4 & - & - & - & - & - \\ \mathrm{TC} & \mathrm{C} & \mathrm{Ar} & 18 & - & 2 & 2 & 2 & 7 & - & 3 & 1 \\ \mathrm{~B} & \mathrm{E} & \mathrm{Ca} & 12 & - & - & - & - & - & 2 & 2 & 1 \\ \mathrm{TD} & \mathrm{C} & \mathrm{Ar} & 18 & - & - & - & - & 3 & 1 & - & - \\ \mathrm{TC} & \mathrm{C} & \mathrm{Va} & 18 & 2 & - & - & - & - & - & - & - \\ \mathrm{TC} & \mathrm{C} & \mathrm{Va} & 18 & 2 & 5 & 2 & - & - & - & - & 1 \\ \mathrm{~B} & \mathrm{C} & \mathrm{Va} & 18 & 2 & 1 & - & - & - & - & - & - \\ \mathrm{TD} & \mathrm{C} & \mathrm{Ca} & 18 & - & - & - & - & 3 & - & - & - \\ \mathrm{TD} & \mathrm{C} & \mathrm{Ca} & 18 & - & - & - & - & 3 & - & - & - \\ \mathrm{TD} & \mathrm{C} & \mathrm{Ar} & 18 & - & - & - & 1 & - & - & - & - \\ \mathrm{TC} & \mathrm{E} & \mathrm{Ar} & 18 & - & - & - & 1 & - & - & - & 5\end{array}$


Familia PORTUNIDAE

Portunus nufiremus Holthuis

Portunus anceps (Saussure)

Portunus ordwayi Stimpson

Portunus spinicarpus (Stimpson)

Callinectes ornatus Ordway

Callinectes bocourti A. Milne Edwards

Cronius ruber (Lamarck)

Cronius tumidulus (Stimpson)

$\begin{array}{llllllllllll}\text { G } & \text { C } & \text { Va } & 18 & 1 & 4 & 2 & - & - & - & - & - \\ \text { TC } & \text { E } & \text { Ar } & 18 & - & 1 & 4 & 2 & - & 2 & 2 & 1 \\ \text { TD } & \text { C } & \text { Ar } & 18 & - & - & 2 & 1 & 3 & - & - & - \\ \text { TC } & \text { E } & \text { Ar } & 18 & - & 1 & - & - & - & - & - & 2 \\ \text { TC } & \text { C } & \text { Va } & 18 & 3 & 2 & - & 1 & - & - & - & - \\ \text { TC } & \text { C } & \text { Va } & 18 & 1 & - & - & - & - & - & - & - \\ \text { TC } & \text { E } & \mathrm{Ca} & 18 & - & - & - & - & - & 2 & 5 & 2 \\ \text { TD } & \mathrm{C} & \mathrm{Ca} & 18 & - & - & - & 1 & - & - & - & -\end{array}$

\section{Família XANTHIDAE}

Euryozius bouvieri (A. Milne Edwards)

Nanoplax xanthiformis (A. Milne Edwards)

Coralliope spinipes (A. Milne Edwards)

Micropanope pusilla A. Milne Edwards

Micropanope nuttingi (Rathbun)

Micropanope urinator (A. Milne Edwards)

Micropanope sculptipes Stimpson

Paractaea rufopuctata forma nodosa (Stimpson)

Actaea acantha (Milne Edwards)

Banareia palmeri (Rathbun)

Lophopanopeus $\mathrm{sp}$.

Paropeus hartii Smith

Hexapanopeus paulensis Rathbun

Hexapanopeus caribbaeus (Stimpson)

\begin{tabular}{|c|c|c|c|c|c|c|c|c|c|c|c|}
\hline B & $E$ & $\mathrm{Ca}$ & $22 \quad 28$ & - & - & - & - & 3 & 2 & 2 & - \\
\hline Bat & $P$ & $?$ & 18 & - & - & - & - & - & . & - & 3 \\
\hline TD & C & Ar & 18 & - & - & - & - & - & 1 & 2 & - \\
\hline TD & C & Ar & 40 & - & - & - & 1 & 10 & 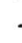 & - & - \\
\hline TC & $E$ & Ar & 18 & - & - & 2 & - & 10 & 2 & 2 & 3 \\
\hline TD & $\mathrm{C}$ & $\mathrm{Ca}$ & 50 & - & - & - & - & - & 3 & - & - \\
\hline Bat & $P$ & ? & 22 & - & - & - & - & - & . & - & 1 \\
\hline TC & $E$ & Ar & 18 & - & - & - & - & 3 & 3 & 7 & 3 \\
\hline Bat & $\mathrm{P}$ & $\mathrm{Ca}$ & 18 & - & - & - & - & - & 3 & - & 3 \\
\hline TD & $E$ & $\mathrm{Ca}$ & $22 \quad 28$ & - & - & - & - & - & 2 & 2 & - \\
\hline$B$ & $E$ & $\mathrm{Ca}$ & - & - & - & - & - & 3 & 3 & 5 & 2 \\
\hline TD & C & Ar & 18 & - & - & - & - & 7 & - & - & - \\
\hline TC & C & $\mathrm{Va}$ & 18 & 1 & - & 4 & 1 & - & 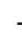 & - & - \\
\hline TD & C & $\mathrm{Ar}$ & 18 & 1 & - & - & - & 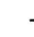 & 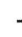 & - & - \\
\hline
\end{tabular}




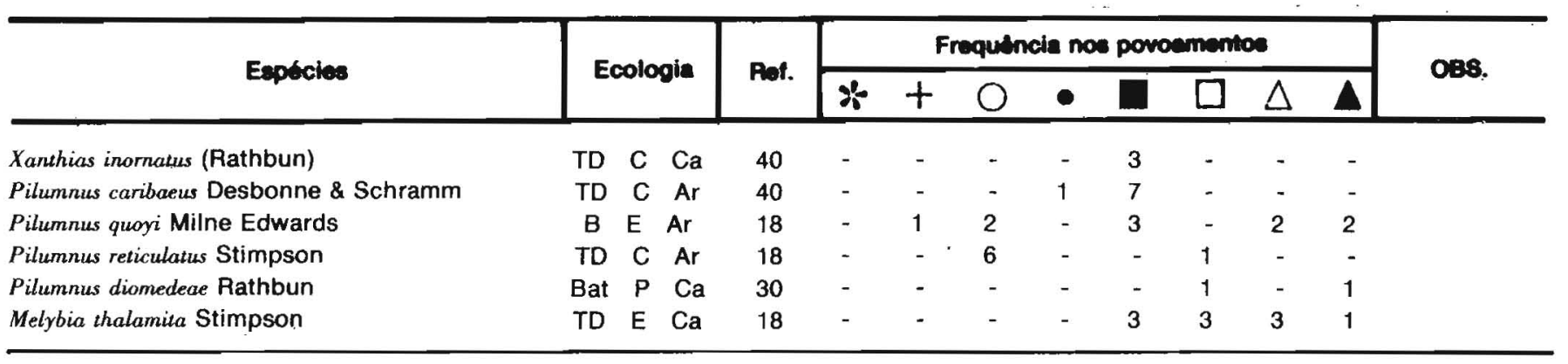

\section{Família GONEPLACIDAE}

Cycloplax pinnotheroides Guinot

Panoplax depressa Stimpson

Euryplax nitida Stimpson

Frevilea hirsuta (Borradaile)

Chasmocarcinus sp. B

Chasmocarcinus sp. C

Chasmocarcinus sp. D

Speocarcinus sp. C

\begin{tabular}{|c|c|c|c|}
\hline G & C & $\mathrm{Va}$ & $\begin{array}{ll}22 & 28\end{array}$ \\
\hline TC & $\mathrm{C}$ & $\mathrm{Ar}$ & 22 \\
\hline TD & C & Ar & 19 \\
\hline Bat & $P$ & $?$ & 18 \\
\hline B & $E$ & $\mathrm{Ar}$ & - \\
\hline $\mathrm{G}$ & C & $\mathrm{Va}$ & - \\
\hline G & C & $\mathrm{Va}$ & - \\
\hline G & C & $\mathrm{Va}$ & - \\
\hline
\end{tabular}

\section{Família PINNOTHERIDAE}

Pinnotheres sp.

Dissodactylus crinitichelis Moreira

Pinnixa cristata Rathbun

Pinnixa sayana Stimpson

Pinnixa sp. A

Pinnixa sp. B

Pinnixa sp. D

$\begin{array}{cccc}? & \mathrm{C} & \mathrm{Ar} & \\ \mathrm{TC} & \mathrm{C} & \mathrm{Va} & 18 \\ \mathrm{G} & \mathrm{C} & \mathrm{Va} & 18 \\ \mathrm{TC} & \mathrm{C} & \mathrm{Va} & 18 \\ ? & \mathrm{C} & \mathrm{Va} & 18 \\ ? & \mathrm{C} & \mathrm{Ar} & 18 \\ \mathrm{~B} & \mathrm{C} & \mathrm{Va} & 18\end{array}$

8
8
8
8
8




\begin{tabular}{|c|c|c|c|c|c|c|c|c|c|c|c|}
\hline \multirow{2}{*}{ Espécies } & \multirow{2}{*}{ Ecologia } & \multirow{2}{*}{ Rot. } & \multicolumn{8}{|c|}{ Frequência nos povoamentos } & \multirow{2}{*}{ OBS. } \\
\hline & & & $x$ & $t$ & 0 & $\bullet$ & & $\square$ & $\triangle$ & $\Delta$ & \\
\hline $\begin{array}{l}\text { Pinnixa sp. G. } \\
\text { Parapinnixa bouvieri Rathbun } \\
\text { Parapinnixa hendersoni Rathbun }\end{array}$ & 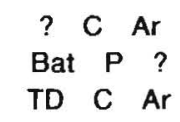 & $\begin{array}{l}- \\
39 \\
18\end{array}$ & $\begin{array}{l}1 \\
- \\
-\end{array}$ & $\begin{array}{l}- \\
-\end{array}$ & $\begin{array}{l}- \\
-\end{array}$ & $\begin{array}{l}- \\
- \\
1\end{array}$ & $\begin{array}{l}- \\
- \\
-\end{array}$ & $\begin{array}{l}- \\
-\end{array}$ & $\begin{array}{l}- \\
- \\
-\end{array}$ & $\begin{array}{l}- \\
1 \\
-\end{array}$ & \\
\hline $\begin{array}{l}\text { Familia PALICIDAE } \\
\text { Palicus sicus (A. Milne Edwards) } \\
\text { Palicus dentatus (A. Milne Edwards) } \\
\text { Palicus sp. B. } \\
\text { Palicus affinis A. Milne Edwards \& Bouvier }\end{array}$ & $\begin{array}{lll}\text { Bat } & P & ? \\
\text { Bat } & P & ? \\
\text { Bat } & P & ? \\
\text { TD } & E & \text { Ar }\end{array}$ & $\begin{array}{l}38 \\
38 \\
- \\
18\end{array}$ & $\begin{array}{l}- \\
- \\
- \\
-\end{array}$ & i & $\begin{array}{l}- \\
- \\
-\end{array}$ & $\begin{array}{l}- \\
- \\
-\end{array}$ & $\begin{array}{l}- \\
- \\
3\end{array}$ & $\begin{array}{l}- \\
- \\
-\end{array}$ & $\begin{array}{l}- \\
- \\
- \\
3\end{array}$ & $\begin{array}{l}1 \\
3 \\
2 \\
-\end{array}$ & \\
\hline $\begin{array}{l}\text { Família GRAPSIDAE } \\
\text { Euchirograpsus sp } \\
\text { Pachygrapsus gracilis (Saussure) }\end{array}$ & $\begin{array}{l}? \text { C } \\
\text { TC } C \text { C }\end{array}$ & $\overline{18}$ & - & - & - & - & - & 1 & - & - & Col. manual \\
\hline $\begin{array}{l}\text { Família OCYPODIDAE } \\
\text { Ocypode quadrata (Fabricius) } \\
\text { Uca (Uca) maracoani (Latreille) } \\
\text { Uca (Minuca) mordax (Smith) } \\
\text { Uca (Minuca) rapax (Smith) } \\
\text { Uca (Minuca) leptodactyla Rathbun }\end{array}$ & $\begin{array}{ccc}\text { TC } & \mathrm{C} & ? \\
\text { TC } & \mathrm{C} & ? \\
\mathrm{G} & \mathrm{C} & ? \\
\text { TC } & \mathrm{C} & ? \\
\text { TC } & \mathrm{C} & ?\end{array}$ & $\begin{array}{c}18 \\
18 \\
15 ; \quad 30 \\
18 \\
18\end{array}$ & & & & & & & & & $\begin{array}{l}\text { Col. manual } \\
\text { Col. manual } \\
\text { Col. manual } \\
\text { Col. manual } \\
\text { Col. manual }\end{array}$ \\
\hline $\begin{array}{l}\text { Família HAPALOCARCINIDAE } \\
\text { Troglocarcinus corallicola Verrill }\end{array}$ & TD $\mathrm{C} \quad \mathrm{Ca}$ & 18 & - & - & - & - & - & 1 & - & - & \\
\hline
\end{tabular}




\section{Espocies}

\section{Familia PARTHENOPIDAE}

Parthenope (Parthenope) agona (Stimpson)

Parthenope (Platylambrus) serrata (Milne Edwards)

Parthenope (Platylambrus) pourtalesii (Stimpson)

Parthenope (Platylambrus) fratercula (Stimpson)

Thyrolambrus astroides Rathbun

Leiolambrus nilidus Rathbun

Mesorthoea sexpinosa Stimpson

Cryplopodia concava Stimpson

Heterocrypta lapidea Rathbun

$\begin{array}{cccccccccccc}\text { Bat } & \mathrm{P} & ? & 37 & - & - & - & - & - & - & 2 & 2 \\ \mathrm{TC} & \mathrm{C} & \mathrm{Ar} & 18 & - & - & - & 1 & 7 & 1 & - & - \\ \mathrm{Bat} & \mathrm{P} & \mathrm{Ca} & & - & - & - & - & - & - & - & 3 \\ \mathrm{Bat} & \mathrm{P} & \mathrm{Ar} & 18 & - & 2 & - & - & - & 1 & 2 & 4 \\ \mathrm{TD} & \mathrm{C} & \mathrm{Ca} & 42 & - & - & - & - & 3 & 2 & - & - \\ \mathrm{G} & \mathrm{C} & ? & 42 ; 30 & - & 2 & - & - & - & - & - & - \\ \mathrm{TC} & \mathrm{C} & \mathrm{Va} & 50 & - & - & - & 1 & - & - & 2 & - \\ \mathrm{TD} & \mathrm{C} & \mathrm{Ar} & 18 & - & - & - & 1 & 7 & - & - & - \\ \mathrm{TD} & \mathrm{C} & \mathrm{Ar} & 18 & - & 1 & - & 1 & - & 1 & - & -\end{array}$

\section{Familia MAJIDAE}

Aruchnopsis filipes Stımpson

Aepinus septemspinosus (A. Milne Edwards)

Euprognatha acuta A. Milne Edwards

Euprognatha gracilipes A. Milne Edwards

Batrachonotus brasiliensis Rathbun

Collodes inermis A. Milne Edwards

Collodes trispinosus Stimpson

Collodes armatus Rathbun

Podochela gracilipes Stimpson

Podochela algicola (Stebbing)

Stenorhynchus seticornis (Herbst)

Paradrasygyus tuberculatus (Lemos de Castro)

Anasimus latus Rathbun

\begin{tabular}{|c|c|c|c|c|c|c|c|c|c|c|}
\hline \multirow{2}{*}{$\begin{array}{l}\text { Bat } \\
\text { TD }\end{array}$} & \multirow{2}{*}{${ }_{C}^{P}$} & \multirow{2}{*}{$\begin{array}{c}? \\
\text { Va }\end{array}$} & 18 & - & \multirow{2}{*}{ - } & - & - & - & 1 & - \\
\hline & & & 18 & 1 & & - & - & - & 1 & 2 \\
\hline Bat & $P$ & $\mathrm{Ca}$ & $\begin{array}{ll}35 & 18\end{array}$ & - & - & - & - & - & - & - \\
\hline $\mathrm{TC}$ & $E$ & Ar & 18 & - & - & - & - & 3 & - & 3 \\
\hline$B$ & C & $\mathrm{Ar}$ & 18 & - & - & - & 1 & - & 2 & 2 \\
\hline $\mathrm{TC}$ & $E$ & $\mathrm{Va}$ & 18 & 2 & 2 & - & - & 7 & - & - \\
\hline Bat & $P$ & $\mathrm{Ca}$ & 49 & - & - & - & - & - & - & - \\
\hline Bat & $P$ & $\mathrm{Ca}$ & 41 & - & - & - & - & - & 1 & - \\
\hline TC & $E$ & Ar & 18 & - & - & - & - & - & - & 2 \\
\hline$B$ & C & $\operatorname{Ar}$ & 18 & - & - & - & - & 3 & - & - \\
\hline TC & $E$ & Ar & ¡8 & - & 1 & 2 & 1 & 7 & 1 & 3 \\
\hline $\mathrm{B}$ & C 1 & $\mathrm{Va}$ & 18 & 3 & 1 & - & - & - & - & - \\
\hline $\mathrm{G}$ & $\mathrm{C}$ & $\mathrm{Ar}$ & 18 & 1 & 1 & - & - & - & - & - \\
\hline
\end{tabular}




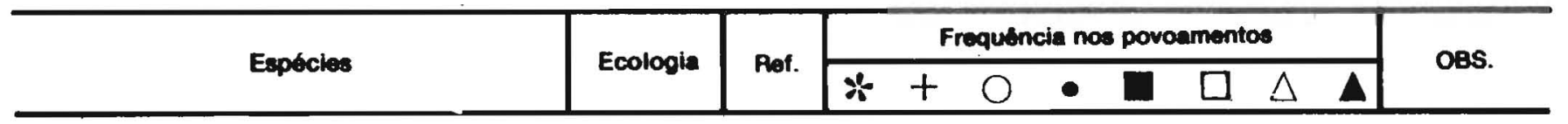

Anasimus fugax A. Milne Edwards Inachoides forceps A. Milne Edwards Pitho therminieri (Schramm)

Picroceroides tubularis Miers Espialloides rostratus Coelho Mocosoa crebripunctata Stimpson Notolopas brasiliensis Miers Pelia rotunda A. Milne Edwards Libinia Jerreirae Brito Capelio Hemus cristulipes A. Milne Edwards Mithrax (Mithrax) acuticomis (Stimpson) Michrax (Mithrax) caribbaeus Rathbun Mithrax (Mihhrax) hispidus (Herbst) Mithrax (Mithraculus) forceps (A. M. Edwards) Microphrys interruptus Rathbun Macrocoeloma trispinosum (Latreille) Macrocoeloma laevigatum (Stimpson) Macrocoeloma eutheca (Stimpson)

Macrocoelorna concavum Miers

Leptopisa setirostris (Stimpson)

$\begin{array}{cccccccccccc}\text { Bat } & \text { P } & ? & 18 & - & - & - & - & - & - & - & 1 \\ \mathrm{TC} & \mathrm{C} & \mathrm{Ar} & 18 & - & - & 2 & 1 & 3 & - & - & 1 \\ \mathrm{TD} & \mathrm{C} & \mathrm{Ar} & 18 & - & - & 6 & 1 & 7 & - & - & - \\ \mathrm{TD} & \mathrm{C} & \mathrm{Ar} & 18 & - & - & - & - & - & 2 & 3 & - \\ \mathrm{B} & \mathrm{C} & \mathrm{Ar} & 18 & - & - & - & - & 7 & - & - & - \\ \mathrm{TD} & \mathrm{C} & \mathrm{Ar} & 18 & - & - & - & - & 3 & - & - & - \\ \mathrm{B} & \mathrm{C} & \mathrm{Va} & 18 & - & 1 & 2 & 1 & 3 & - & - & - \\ \mathrm{B} & \mathrm{C} & \mathrm{Ar} & 18 & - & 1 & 4 & - & 3 & 2 & 2 & - \\ \mathrm{B} & \mathrm{C} & \mathrm{Va} & 18 & 1 & - & 2 & - & - & - & - & - \\ \mathrm{TD} & \mathrm{C} & \mathrm{Ca} & 18 & - & - & - & - & 3 & - & - & - \\ \mathrm{TC} & \mathrm{E} & \mathrm{Ar} & 18 & - & - & - & - & 7 & 3 & 4 & 4 \\ \mathrm{G} & \mathrm{C} & \mathrm{Ar} & 18 & - & 1 & 2 & - & - & - & - & - \\ \mathrm{TD} & \mathrm{C} & \mathrm{Ar} & 18 & - & - & 2 & 1 & - & 1 & - & - \\ \mathrm{TD} & \mathrm{C} & \mathrm{Ar} & 18 & - & - & - & 1 & 7 & - & - & - \\ \mathrm{TD} & \mathrm{C} & \mathrm{Ca} & 18 & - & - & - & - & 3 & - & - & - \\ \mathrm{TD} & \mathrm{C} & \mathrm{Ar} & 18 & - & - & - & - & 3 & - & - & - \\ \mathrm{TD} & \mathrm{C} & \mathrm{Ca} & 18 & - & - & - & - & 3 & 1 & - & - \\ \mathrm{FD} & \mathrm{C} & \mathrm{Ar} & 18 & - & - & - & - & 7 & 3 & - & - \\ \mathrm{TD} & \mathrm{C} & \mathrm{Ca} & 18 & - & - & - & - & 3 & 1 & - & - \\ \mathrm{TD} & \mathrm{C} & \mathrm{Ar} & 18 & - & - & - & - & 7 & 2 & - & -\end{array}$


1. BENEDICT, J. E. Descriptions of a new genus and forty-six now specles of crustaceans of the family galatheidae, with a list of the known marine species. Washington, Government Printing Office, 1903. p. 243-344. (Smithsonian Institution. Proceedings of the United States National Museum, v. 26, n. 1311).

2. BIfFAR, T. A. The genus Callianassa (Crustacea, Decapoda, Thalassinidea) in South Florida, with key to the Western Atlantic species. Bull. Mar. Sci., Coral Gables, Flo. 21(3): 637-715, 1971.

3. - - — \& PROVENZANO Jr., A. J. A reexamination of Dardanus venosus (H. Milne Edwards) and $D$. imperator (Miers), with a description of a new species of Dardanus from the Western Atlantic (Crustacea, Decapota, Diogenidae). Bull. Mar. Sci., Coral Gables, Flo., 22(4): 777-805, 1972.

4. CARVALHO, H. A. de \& RODRIGUES, S. de A. Marcusiaxius lemoscastroi, g. n., sp. n., nova ocorrência da familia Axiidae (Crustacea, Decapoda, Thalassi-

5. CASTRO, A. Lemos de. Quatro espécies novas, brasileiras, de Excorallana Stebbing, 1904. Arq. Mus. Nac., Rio de Janeiro, 50: 61-78, 1960.

6. CHACE Jr., F. A. The shrimps of the Smithsonian-Bredin Carbbean Expeditions with a summary of the West Indan shallow-water species (Crustacea: Decapoda: Natantia. Washington, Smithsonian Institution Press, 1972. 179 p. (Smithsonian Contribution to Zoology, 98).

7. COÊLHO, P. A. Descricão preliminar de Calastacus angulatus, n. sp. e de $C$. spinosus n. sp., do Norte do Brasil (Crustacea, Decapoda, Axiidae). C. e Cult. Resumos da Reunião Anual da Sociedade Brasileira para o Progresso da Ciência, 25., liha do Fundão, Guanabara, 1973. Sāo Paulo, 25(6): 344-5, 1973. Suplemento.

8. - - - - Descricão preliminar de Clythrocerus analogus, n. sp., do litoral brasileiro (Crustacea, Decapoda, Dorippidae). C. e Cult. Resumos da Reunião Anual da Sociedade Brasileira para o Progresso da Ciência. 25., Ilha do Fundão, Guanabara, 1973. São Paulo, 25(6): 343-4, 1973. Suplemento.

9. - - - Descriçāo preliminar de Clythrocerus carinatus, n. sp., do Norte e Nordeste do Braśil (Crustácea, Decapoda, Dorippidae). Ci. e Cult. Resumos da Reunião Anual da Sociedade Brasileira para o Progresso da Ciência, 25., IIha do Fundão, Guanabara, 1973. São Paulo, 25(6): 343, 1973. Suplemento. 
10.

- Descrição preliminar de Ebalia conica n. sp., do Norte e Nordeste do Brasil (Crustacea, Decapoda, Leucosiidae). Ci. e Cult. Resumos da Reuniāo Anual da Sociedade Brasileira para o Progresso da Ciência, 25. Ilha do Fundāo, Guanabara, 1973. Sāo Paulo, 25(6): 342, 1973. Suplemento.

11. - - - Descrição preliminar de Ebalia obliqua, n. sp., do Norte e Nordeste do Brasil (Crustacea, 'Decapoda, Leucosiidae). Ci. e Cult. Resumos da Reunião Anual da Sociedade Brasileira para o Progresso da Ciência, 25. IIha do Fundāo, Guanabara, 1973. São Paulo, 25(6): 342-3, 1973. Suplemento.

12. - - - . Descrição preliminar de Ebalia vertiginosa, n. sp., do Norte e Nordeste do Brasil (Crustacea, Decapoda, Leucosiidae). Ci. e Cult. Resumos da Reuniáo Anual da Sociedade Brasileira para o Progresso da Ciência, 25., Ilha do Fundão, Guanabara, 1973. São Paulo, 25(6): 343, 1973. Suplemento.

13. - - - Descriçāo preliminar de Meticonaxius minutus, n. sp., do Norte e Nordeste do Brasil (Crustacea, Decapoda, Axiidae). Ci. e Cult. Resumos da Reunião Anual da Sociedade Brasileira para o Progresso da Ciência, 25., Ilha do Fundão, Guanabara, 1973. São Paulo, 25(6): 34், 1973. Suplemento.

14. - Descricão preliminar de Munida brasiliae, n. sp., do Norte e Nordeste do Brasil (Crustacea, Decapoda, Galatheidae). Ci e Cult. Resumos da Reunião Anual da Sociedade Brasileira para o Progresso da Ciência, 25., Ilha do Fundāo, Guanabara, 1973. São Paulo, 25(6): 344, 1973. Suplemento.

15. Descricão preliminar de uma espécie de $U_{c a}$ de Pernambuco e Paraiba. In: CONGRESSO BRASILEIRO DE ZOOLOGIA, 5., São Paulo, 1972. p. 42.

16.

Descricāo preliminar de Upogebia (Calliadne) acanthura, n. sp., do Brasil (Crustacea, Decapoda, Callianassidae). Ci e Cult. Resumos da Reuniāo Anual da Sociedade Brasileira para o Progresso da Ciência, 25., llha do Fundão, Guanabara, 1973. São Paulo, 25(6): 342-3, 1973. Suplemento.

17. —— Descrição preliminar de Upogebia (Upogebia) marina, n. sp., do Nordeste do Brasil (Crustacea, Decapoda, Callianassidae). Ci e Cult. Resumos da Reunião Anual da Sociedade Brasileira para o Progresso da Ciência, 25. Ilha do Fundão, Guanabara, 1973. São Paulo, 25(6): 345, 1973. Suplemento.

18.

\& RAMOS, M. A. A constituição e a distribuição da fauna de decápodos do litoral leste da América do Sul entre as latitutdes de $5^{\circ} \mathrm{N}$ e $39^{\circ} \mathrm{S}$. Trab. Oceanogr. Univ. Fed. Pe., Recife, 13: 133-236, 1973. 
19. CORRÊA, M. M. G. Contribuição ao conhecimento da fauna do Arquipélago de Abrolhos, Bahia, Brasil. 2-Lista preliminar dos crustáceos decápodos. Separata do B. Mus. Hist. Nat. Univ. Fed. Minas Gerais, Zoologia, Belo Horizonte (15): 1-19, 1972.

20. FAUSTO Filho, J. Sôbre os calapídeos do Norte e Nordeste do Brasil. Arq. Est. Biol. Mar. Univ. Fed. Ceara, Fortaleza, 7(1): 41-62, 1967.

21. GUINOT, D. Sur divers Xanthidae, notamment sur Actaea de Haan et Paractaea gen. nov. (Crustacea, Decapoda, Brachyura). Cah. Pacif., 13: 233-67, 1969.

22.

. Recherchés préliminaires sur les groupements naturels chez les crustacés décapodes brachyoures. I. Les affiniés des genres Aethra, Osachila, Hepatus, Hepatella et Actaeomorpha. Bull. Mus. Nat. Hist. Nat., Paris, 2. ser. 38(5): 744-62, 1966.

23. - - (suite et $\mathrm{fin}$ ). Bull. Mus. Natd. Hist. Nat., Paris, 2. ser. 38 (6): 828-54, 1966.

24. - - Les anciens genres Micropanope Stimpsom et Medaeus Dana. Bull. Mus. Natt. Hist. Nat., Paris, 2. ser. 39(2): 345-74, 1967.

25. - _ - _ - VI. Les Carpilinae. Bull. Mus. Natt. Hist. Nat., Paris, 2. ser. 40(2): 320-34, 1968.

26. - _-_ - _-_ VII. Les Goneplacidae. Bull. Mus. Natt. Hist. Nat., Paris, 2. ser. 41(1): 241-65, 1969.

27. - _ - _ - _- (suite). Bull. Mus. Nat. Hist. Nat., Paris, 2. ser. 41(2): $507-28,1969$

28. - - - - - (suite et fin). Bull. Mus. Natt. Hist. Nat., Paris, 2. ser. 41(3): 688-724, 1969.

29. HOLTHUIS, L. B. A general revision of the Palaemonidae (Crustacea, Decapoda, Natantia) of the Americas. I. The subfamilies Euryrhynchinae and Pontoninae. Los Angeles, The Univ. of Southern Calif. Press, 1951. $332 \mathrm{p}$. (Allan Hancock Found. Pub. Occasional paper, 11).

30. - - The crustacea decapoda of Suriname (Dutch Guiana). Leiden, E. J. Brill, 1959. 296 p. (Rijksmuseum van Natuurlijke Historie to Leiden. Zoologische Verhandelingen, 44).

31. KOENING, M. L. Nota sôbre a ocorrência de alguns isópodos do Norte e Nordeste do Brasil. Trab. Oceanogr. Univ. Fed. Pe., Recife, 13: 237-44, 1972. 
32. Ocorrência de Accalathura crenulata (Richardson, 1901) no Brasil (Isopoda-Paranthuridae). Trab. Oceanogr. Univ. Fed. Pe., Recife, 13: 26170, 1972.

33. MANNING, R. B. Stomatopod crustacea of the Westem Atantic. Coral Gables, Flo., Univ. of Miami Press, 1969. 380 p. (Studies in Tropical Oceanography, 8).

34. MENZIES, R. J. \& FRANKENBERG, D. Handbook on the common marine lsopod crustacea of Georgia. Athens, Univ. Georgia Press, 1966, 93 p.

35. MILNE-EDWARDS, A. \& BOUVIER, E. L. Les porcellanides et des brachyures. In: reports on the results of dredging. Under the supervision of Alexander Agassiz, in the Gulf of Mexico (1877-78), in the Caribbean sea (1878-79), and along the Atlantic Coast of the United States (1880), by the U. S. Coast Survey steamer "Blake»). Cambridge, USA, Printed for the Museum, 1923. p. 283-395. (Memoirs of the Museum of Comparative Zoology at Harvard College, v. 47. n. 4). Fotocópia.

36. MOREIRA, P. S. Species of marine Isopoda (Crustacea, Peracarida) from Southern BrazH. B. Inst. Oceanogr., Sāo Paulo, 21: 163-79, 1972.

37. PEQUEGNAT, L. H. \& PEQUEGNAT, W. E. Deep-sea anomurans of superfamily Galatheoidea with description of two new species. Separata de \& CHAGE Jr., F. A. ed. Contributions on the biology of the Gulf of Mexico. Houston, Gulf, Publ. Co., 1970. 5, p. 125-70. (Texas A. \& M. Univ. Oceanographic Studies, 1).

38. PEQUEGNAT, W. E. Deep-water brachyuran crabs. Separata de - - - - \& CHACE Jr., F. A. Contribution on the biology of the Gulf of Mexico. Houston, Gulf Publ. Co., 1970. 6, p. 171-204. (Texas A. \& M. Univ. Oceanographic Studies, 1).

39. RATHBUN, M. J. Brachyuran crabs of Porto Rico and the Virgin Islands. In: NEW YORK ACADEMY OF SCIENCE. Sclentifique survey of Porto Rico and the Virgin Islands. New York, 1933. v. 15, pt. 1, p. 1-121.

40. - - . The cancroid crabs of America of the families Eunylidae, Portunidee, Atelecyclide, Cancridae and Xanthidae. Washington, Government Printing Office, 1930: 609 p. (Smithsonian Institution. U. S. National Museum. Bulletin, 152).

41.

The oxystomatous and allied crabs of America. Washington, Government Printing Office, 1937. 277 p. (Smithsonian Institution. U. S. National Museum. Bulletin, 166). 
42. The spider crabs of America. Washington, Government Printing Office, 1925. 613 p. (Smithsonian Institution. U. S. National Museum. Bulletin, 129).

43. RICHARDSON, H. Description of new isopod crustaceans of the family Sphaeromidae. Washington, Government Printing Office, 1960. 22 p. (Smithsonian Institution. Proceedings U. S. National Museum, v. 31, n. 1479).

44. - _ - A monograph of the isopods of North America. Washington, Government Printing Office, 1905. 727 p. (Smithsonian Institution. U. S. National Museum. Bulletin, 54).

45. RODRIGUES, S. A. \& CARVALHO, H. A. Marcusiaxius lemoscástroi, g. n., sp. n., primeira ocorrência da familia Axiidoe (Crustacea, Decapoda Thalassinidea) no Brasil. Ci e Cult. Resumos da Reunião Anual da Sociedade Brasileira para o Progresso da Ciência, 24., São Paulo, 1972. São Paulo, 24(6): $357,1972$.

46. SAINT LAURENTSDÉCHANCÉ, M. de. Iridopagurus, genre nouveau de Paguridae (Crustacés Décapodes) des mers tropicales américaines. Bull. Mus. Natt. Hist. Nat., Paris, 2. ser., 38(2): 151-73, 1966.

47. SILVA, J. Loyola. Sôbre os gêneros Ancinus Milne Edwards, 1940 e Bathycopes Tattersal, 1909, da coleção do U. S. Natl. Mus. (Isopoda-Crustacea). Arq. Mus. Nac., Rio de Janeiro, 54: 209-23, 1971.

48. THISTLE, D. A toxonomic comparison of the American Upogebia (Decapoda, Thalassinidea), including two new species from the Caribbean. Breviora, Mus. Comp. Zool., Cambridge, 408: 1-23, 1973.

49. WILLIAMS, A. B. Marine decapod crustaceans of the Carolinas. Fishery Bull., Washington, 65(1): 1-298, 1965.

50. - - New records of brachyuran decapod crustaceans from the continental shelf off North Carolina, U.S.A. Crustaceana, Leiden, 15(1): 4166, 1968. 